\title{
Investigation into nonlinear phenomena for various railway vehicles in transition curves at velocities close to critical one
}

\author{
Krzysztof Zboinski • Milena Golofit-Stawinska $\mathbb{D}$
}

Received: 17 January 2019 / Accepted: 30 May 2019 / Published online: 25 October 2019

(C) The Author(s) 2019

\begin{abstract}
In this paper recent simulation results aimed at studying nonlinear phenomena that accompany motion of railway vehicle in transition curve at velocities around the vehicle critical velocity are presented by the authors. Such results concern six different objects representing railway vehicles. These are: three 2-axle railway bogies, two 2-axle railway cars, and 4-axle railway car. The paper attention is devoted to presenting as many different nonlinear behaviours of the studied objects as possible. This is done first of all to give an idea to the readers of great number of the nonlinear behaviour types that can appear for railway vehicles in transition curves at velocities lower and bigger than vehicle critical velocity. The differences arising from specificity of particular objects are highlighted while systematic variation of the system parameters in order to study influence of such variation on differences in the behaviour is less represented. The paper ends with the comprehensive comments by the authors to the results obtained.
\end{abstract}

Keywords Nonlinear phenomena - Railway vehicle dynamics - Transition curve - Critical velocity . Numerical simulation · Vehicle lateral stability

K. Zboinski $(\varangle) \cdot$ M. Golofit-Stawinska Faculty of Transport, Warsaw University of Technology, Koszykowa 75, 00-662 Warsaw, Poland e-mail: kzb@wt.pw.edu.pl

\section{Introduction}

This paper presents current results on nonlinear phenomena appearing during railway vehicle transition curve (TC) negotiation at velocities around nonlinear critical velocity of the vehicle. Both, the velocities higher and lower than the critical velocity are studied. On the other hand, results for the higher velocities are of primary interest while those for the lower ones make the reference to them most often. The authors focus on motion of the vehicle, i.e. corresponding lateral dynamics co-ordinates of railway vehicle model are of primary interest. Despite motion in TC is of major importance, the vehicle motion in straight track (ST) and circular curve (CC) track sections are also presented. They make reference for the vehicle behaviour in TCs. The observations of the phenomena of interest are based on the results of numerical simulations of the vehicle-track system dynamical models.

In this paper six different objects representing railway vehicles are studied. These objects are: three 2axle bogies of railway cars, two 2-axle freight cars, and 4-axle passenger car. Their names and features are as follows: $25 \mathrm{TN}$ bogie of the freight car, the bogie of average parameters, bogie of passenger MKIII car, 2axle freight car of average parameters in an unloaded state, hsfv1 freight car in a laden state, and 4-axle passenger car MKIII of two bogies.

The aim of this paper is first of all to enlighten the readers on great number of the nonlinear behaviour types that can appear for railway vehicles in TCs at 
velocities lower and bigger than vehicle critical velocity. The knowledge on that and number of the corresponding publications are both very low. The differences arising from specificity of six studied objects are highlighted. This is helpful for the second major aim of this paper. It is visualisation to the readers that nonlinear phenomena of interest do not refer to particular object or particular vehicle class but are general and could happen in any class of rail vehicles. In this paper results focused on systematic variation of the system parameters in order to study influence of such variation on differences in the vehicle behaviour is less represented. This is because direct studying the reason of particular nonlinear behaviour is not of primary importance at this stage, although some remarks of such a nature are included. Those are a matter of the author's next paper while here the most intriguing and even unexpected results are gathered. Most of them have not been published, yet. Both just mentioned aspects are equally important and present in the authors publications so far [1-8]. Division of the results into two parts serves effective dissemination of the knowledge collected and is caused by the great number of the results obtained.

Without any doubt the problem being studied in this paper is connected with lateral stability studies of rail vehicles. Such connection is first of all through the critical velocity notion, the key parameter in stability studies, and simulation software that is used often in the stability analysis. The authors mean here bifurcation approach to nonlinear stability analysis. The bifurcation plot for motion of railway vehicle of typical subcritical properties in ST is shown in Fig. 1. Similar figures can be found, e.g. in [9-12] while analogous figures for vehicle motion in CC can be found in $[13,14]$. In this approach linear $v_{c}$ and nonlinear $v_{n}$ critical velocities are recognised as generally different quantities. They are related to Hopf and saddle-node bifurcations, respectively (Fig.1). Figure 1 reveals that typical subcritical system has got three different ranges of velocity $v$. First is the range from 0 to $v_{n}$ where only stable periodic solutions can appear. The second one is placed between $v_{n}$ and $v_{c}$. Here two stable solutions coexist, namely stationary and periodic ones. Which of them is adopted by the system depends on perturbation value (in simulation it can be initial conditions values). In the theory and in real conditions the systems move away from unstable solutions (here either stationary or periodic) and are attracted to positions defined by the stable solutions. Third is the rage for $v>v_{c}$ where only stable periodic solutions can exist since as just said the coexisting unstable stationary solutions cannot be adopted by the system both in the theory and practice. This range ends with velocity $v_{s}$, representing stop of the calculations. This stop can be caused by unbounded growth of the solution (called sometimes numerical derailment, but not physical one) or arbitrarily by the software operator, e.g. due to unnaturally big velocity values $[11,14,15]$. As shown, e.g. in [12], some railway vehicle systems has got supercritical properties. Then, plot in Fig. 1 transforms so that point of saddle-node bifurcation moves down to the horizontal axis and overlaps point of Hopf bifurcation (so $v_{n}=v_{c}$ ) while unstable periodic solutions line degenerates and vanishes. Note that for mechanical systems of many degrees of freedom (DOFs) as railway vehicle (or vehicle-track) systems are no analytical methods exist to find value of nonlinear critical velocity $v_{n}$. Therefore numerical calculation (simulation) methods are in use. In case of linear critical velocity $v_{c}$ simulation methods can be used, too. Besides, analytical methods exist for multidimensional systems provided linear model of the system is applied (solution of the eigenvalue problem). On the other hand, use of linear models in modern railway vehicle dynamics is hardly acceptable. Note also that critical velocity $v_{n}$ can be much lower than critical velocity $v_{c}$. This causes that information about moment (velocity) periodic solution (hunting motion in real vehicle) appears based on $v_{c}$ is misleading and can even be dangerous, especially one usually does not know either the real system is super- or subcritical. That is why nowadays use of easier determinable linear critical velocity $v_{c}$ is very often contested (e.g. [11,16,17]) while simulation methods for $v_{n}$ determination are used commonly and still developed.

One can see in Fig. 1 that velocity $v_{c}$ corresponds with the moment stable stationary solution loses its stability and bifurcates into unstable periodic and unstable stationary solutions in case of subcritical system. Nonlinear critical velocity $v_{n}$ corresponds in Fig. 1 to the moment stable stationary solution loses its stability and bifurcates into stable periodic solution provided perturbation (initial conditions) are high enough. Otherwise, stationary solution still lasts. In case of supercritical systems $v_{c}=v_{n}$ which corresponds to the moment stable stationary solution loses its stability and bifurcates into stable periodic and unstable stationary solution. 
Fig. 1 Bifurcation plot for typical railway vehicle of subcritical properties in ST

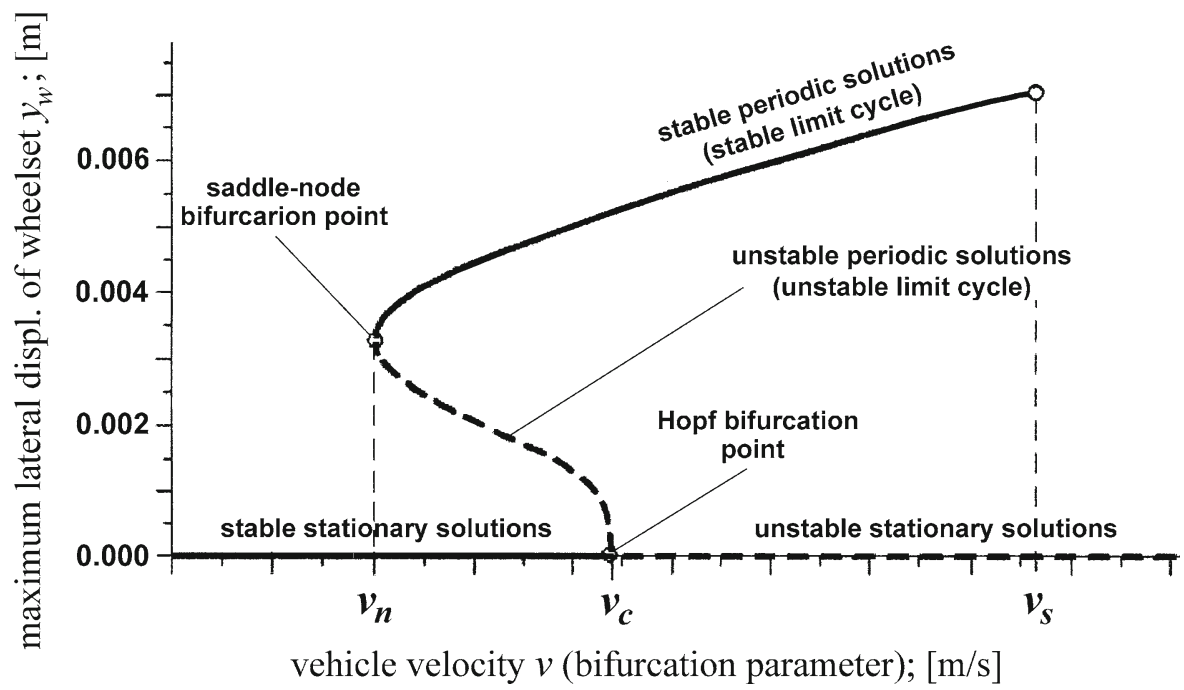

Taking account of possible case $v_{n}<v_{c}$ and its conditional character for subcritical systems (perturbation big enough), nonlinear critical velocity $v_{n}$ is the smallest velocity at which stable periodic solutions can appear in the mechanical system represented by the railway vehicle dynamical model, no matter the system is super- or subcritical. Besides, the authors distinguish between values of critical velocity in ST and CCs of different radii. Authors of this paper always mean nonlinear critical velocity when shortened term critical velocity is used by them.

Note that stable periodic solutions can appear for ST and CC as such sections of the route represent constant conditions of motion. This is not the case in TC, where curvature and superelevation of 3-dimensional track change continuously. Consequently, in TC neither stable periodic nor stable stationary solutions can be expected and searched for, what makes the essence of the stability analysis. Going further, critical velocity in TC cannot be determined, too. On the other hand, any solution, even the nonstationary or nonperiodic, can be checked for its stability. So also in TC, one could introduce series of some small perturbations into the system, and check if the newly obtained solutions are close enough to the solution taken as the model solution. If yes, the solution in TC would be stable. Authors of this paper do not perform such formal checks for stability of solutions in TC, however. They limit their activities to analysis of the solutions (simulation results) so that earlier mentioned aims of this paper can be satisfied. Example works connected with stability anal- ysis as meant here are works by other researchers $[9,10,16,18-24]$ and the lead author $[11,13,14]$.

The main motive of considering nonlinear phenomena of railway vehicles in this paper is limited knowledge on the vehicles behaviour in TC and its vicinity at velocities around critical one and low cognisance of highly nonlinear features of railway vehicles in such conditions. It is especially motivating as knowledge on the vehicle behaviour and features in ST and CC at velocities around critical one, including problem of stability, is incomparably bigger. Apart from the purely cognitive aspects, the new knowledge gathered in this area can finally bring practical benefits concerning improvement in railway vehicle construction and safety of motion, which issues are expanded at the end of Sect. 3.

It is really hard task to find some serious number of the literature items by other researchers that treat the matter being studied in this paper directly [25-28]. One should realise of unquestionably smaller number of the results on dynamics of rail vehicles in TC even in publications generally referring to this problem as compared to similar results for ST and CC sections of railway track. Small number of works by other authors and thus originality of the problem do not mean that considered subject arouses no considerable interest in the railway vehicle dynamics society. In case of present authors the proof for it are: acceptance of the corresponding papers for presentation at the IAVSD Symposia [1-3], lively discussions at these conferences, other conference publications [4-6,8] and journal papers [7], as 
well as financial support for the authors' studies, i.e. scientific grant as mentioned in the "Acknowledgements" section.

Apart from joint works by these authors, the publications close to the results in this paper mostly are [25-29]. They include examples of courses for lateral dynamics co-ordinates (lateral displacements alone and/or yaw angles) of vehicle elements (wheelsets, bogie frames, and car body) at velocities higher than critical one. The routes include at least ST, entrance $\mathrm{TC}$, and $\mathrm{CC}$ or even more, i.e. the ST, entrance TC, CC, exit TC, and ST sections. Generally, results for TCs in publications [25-29] were obtained as a result of the stability studies where either stationary or periodic solutions in ST and CC were looked for. Some of the first results by the lead author shown in [29] were not a major subject for the studies but obtained by incident or on the occasion of the studies of different aims. In $[25,26] 2$-axle freight car was studied in TC. In [27] heavy-haul 4-axle vehicle of 2 bogies is considered. In [28] four-axle passenger car of two bogies is studied. In [29] two bogies and two 2-axle freight cars were of interest. In $[25,26]$ behaviour in TC is to some extent logical passage of the behaviours in ST to those in $\mathrm{CC}$ section where vibrations exist. The regular limit cycle in ST is shown. Nevertheless, due to dry friction and nonsmoothness in the suspension explicit perturbation in the regular behaviour in TC and CC can be observed. In [27] interesting is the absence of the vibrations in ST and their appearance in the middle of TC length and continuation in $\mathrm{CC}$ in a form of the limit cycle. In [28] existence of the result for TC is forced by capability of the used software. It does not permit to start simulation in CC. In order to get result for CC the simulation has to start in ST and then entrance into CC through TC happens. Vibrations appear immediately at the $\mathrm{TC}$ beginning and are continued in $\mathrm{CC}$ in a form of the limit cycle. In [29] results for TC being logical passage from ST to $\mathrm{CC}$, where limit cycles exist, are shown. Besides, three intriguing results are shown. So, complete disappearance of vibrations in TC with simultaneous existence of limit cycles in ST and CC is one of them. The second is disappearance of vibrations existing in ST and TC after the entrance into CC but for the leading wheelset only. The third is switch of the vibrations from one type of limit cycle solution to the other one (of different amplitude and frequency) approximately in the middle of TC. The results in [29] are the oldest ones and became the major motivation for these authors studies in [1-8] and in the present paper. The common feature of the results in [25-29] is just single result for each of the objects. No intentional variation of the system parameters or conditions of motion are performed in these works. The exception is $[25,26]$ where results for two different velocities are shown. The difference between both results is in fact limited to vibration amplitudes, however.

The group of works of the certain importance for this paper are those where the results of interest, i.e. coordinates representing and arising from vehicle dynamics in TC above critical velocity, were in fact generated but not published or could be potentially generated. The main reasons for not showing these results are other than lateral dynamics co-ordinates dynamical quantities particular authors are interested in or velocities below the critical one. Example publications of such type are [30-38]. The interesting subgroup within such publications are those based on vehicle-track models simulation, which use dynamical approach, but not the traditional engineering one, to search for proper, best or even optimum shape of TCs. Here, as a rule lateral dynamics co-ordinates are of interest but velocities are below vehicle critical velocity. Example works here are [39-42].

Finally, the group of works concerning nonlinear systems design and control can be mentioned with [43, 44] as the representative examples.

\section{Modelling approach, objects' models, and software applied in the study}

\subsection{Approach to modelling in the authors' studies}

Authors of this paper use modelling approach as proposed and used by the lead author for many years. The most up-to-date information about this approach is given in [41,45]. First of these publications [45] is entirely focused on the modelling issues and gives very detailed information while in the second one [41] modelling is just one of the parts and is presented in more concise form.

Discussed way of modelling rail vehicle system dynamics is in several aspects the generalised one. The most important aspect of the generalisation is single model that serves any conditions of motion, i.e. it is valid for any type of TC, CC, and ST sections of track. Vehicle dynamics is dynamics of relative motion, 
i.e. relative to track based moving (noninertial) coordinate systems. Inertia terms arising from motion of the co-ordinate system(s), called imaginary or correction forces, are explicitly recorded in the equations of motion. These terms are the only ones in the equations which depend on the track shape, which is 3dimensional (3-D) in the method in general. Thus 3-D curve representing any $\mathrm{TC}$ with superelevation ramp can be considered, providing this curve is described with parametric equations. CC and ST cases are treated as 2-D and 1-D special cases of 3-D curve. In practice, information about track shape is introduced into the equations through the linear and angular velocities and accelerations of transportation that is of motion of the co-ordinate system(s) relative to the absolute system. This way generalisation of the model in conditions of motion (track shape) is achieved. Another element of the generalisation of the modelling approach is its validity for any formalism of the equations building (any type of the dynamical equations of motion). What is more this statement comprises both the equations derived traditionally (on paper) and numerically with use of the software for automatic generation of equations of motion (AGEM).

Authors of this paper make use of both these major elements of the approach generalisation. Indeed, each model of the studied objects serves description of its motion in ST, TC, and CC. Besides, two different formalisms of equations building adapted to relative motion description were used, namely Lagrange equations of type II and Kane's equations. Both the equations derived traditionally and numerically, with the AGEM software, were utilised. This is analogous to use of the same approach in [41], where it is discussed in detail. General equations of relative motion for the Lagrange type II and Kane's formalisms are shown there, for example. These explain why modelling issues in this paper are limited to the general information given in current subsection.

General form of the dynamical equations of relative motion for discrete mechanical systems, no matter which formalism is used, can be recorded as follows:

$$
f d \mathbf{B}^{\prime}=f d \mathbf{Z}+f p \mathbf{P}(v, w) \Rightarrow\left\{x^{\prime}=x^{\prime}(t), \dot{x}^{\prime}=\dot{x}^{\prime}(t)\right\}
$$

where $f d$ operator that represents any formalism adapted to description of relative motion (here, motion relative to track based moving (noninertial) co-ordinate systems); $f p$ operator of imaginary forces, matching the selected formalism; $\mathbf{B}^{\prime}$ forces of inertia in motion relative to moving co-ordinate systems; $\mathbf{Z}$ external forces; $\mathbf{P}$ imaginary forces (inertia forces dependent on the transportation); $u(t), \quad v(t), \quad w(t)$ functions of time defining displacements, velocities, and accelerations of the transportation, and $x^{\prime}, \dot{x}^{\prime}$ system co-ordinates and velocities in relative motion, respectively.

The terms in (1) including $\mathbf{B}^{\prime}$ and $\mathbf{Z}$ forces are generated in typical way, i.e. identically with inertia and external forces determination in absolute systems. For example, operator $f d$ in case of the formalisms that utilise kinetic energy to derive equations of motion means that first such energy has to be determined and then differentiated properly, with respect to generalised co-ordinates, velocities and time most often. If equations of motion concern railway vehicle, equations are expressed in generalised co-ordinates and generalised or quasi-velocities, and co-ordinates are adopted typically then the general universal form of the imaginary forces can be recorded [41]. It is as follows:

$$
\begin{aligned}
P_{\rho}= & \sum_{j=1}^{n}\left[-m_{j} \boldsymbol{a}_{o 1 j}-m_{j} \boldsymbol{\varepsilon}_{j} \times \boldsymbol{r}_{j}^{\prime}-m_{j} \boldsymbol{\omega}_{j}\right. \\
& \left.\times\left(\boldsymbol{\omega}_{j} \times \boldsymbol{r}_{j}^{\prime}\right)-2 m_{j} \boldsymbol{\omega}_{j} \times \boldsymbol{v}_{j}^{\prime}\right] \cdot \frac{\partial \boldsymbol{r}_{j}^{\prime}}{\partial q_{j}} \\
& +\sum_{j=1}^{n}\left[-\mathbf{J}_{j} \cdot \boldsymbol{\varepsilon}_{j}-\boldsymbol{\omega}_{j} \times \mathbf{J}_{j} \cdot \boldsymbol{\omega}_{j}-2 \boldsymbol{\omega}_{j}^{\prime}\right. \\
& \left.\times\left(\mathbf{J}_{j}-0,5 \vartheta_{j} s \mathbf{E}\right) \cdot \boldsymbol{\omega}_{j}\right] \cdot \frac{\partial \boldsymbol{\omega}_{j}^{\prime}}{\partial \dot{q}_{\dot{p}}}
\end{aligned}
$$

where $j$ indicator of rigid body; $n$ number of rigid bodies; $\rho$ generalised co-ordinate indicator; $\boldsymbol{r}^{\prime}$ radius vector of body in moving co-ordinate system; $\boldsymbol{v}^{\prime}$ linear velocity of body in moving co-ordinate system; $\omega^{\prime}$ angular velocity of body relative to moving co-ordinate system; $m$ body mass; $\mathbf{J}$ inertia tensor; $\mathbf{E}$ unit tensor; $\vartheta$ trace of tensor $\mathbf{J}$, i.e. $\vartheta=J_{11}+J_{22}+J_{33} ; q, \dot{q}$ generalised coordinate and velocity, respectively; $\boldsymbol{a}_{o 1}, \boldsymbol{\omega}, \boldsymbol{\varepsilon}$ vectors of linear acceleration and angular velocity and acceleration of transportation, i.e. of track based moving co-ordinate system relative to absolute system. Note that components of vectors $\omega, \varepsilon$ depend on track centre line shape. Their components in the moving system $\boldsymbol{\omega}=\boldsymbol{\omega}\left(\omega_{x}, \omega_{y}, \omega_{z}\right)$ and $\boldsymbol{\varepsilon}=\boldsymbol{\varepsilon}\left(\varepsilon_{x}, \varepsilon_{y}, \varepsilon_{z}\right)$ introduce track shape into equations of motion. 
(a)
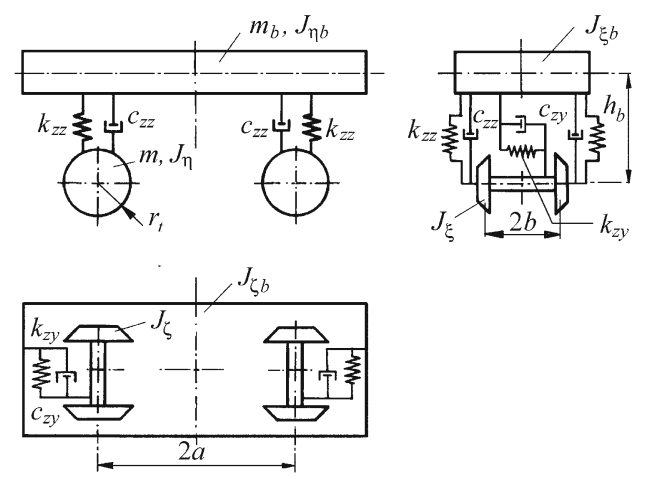

(b)
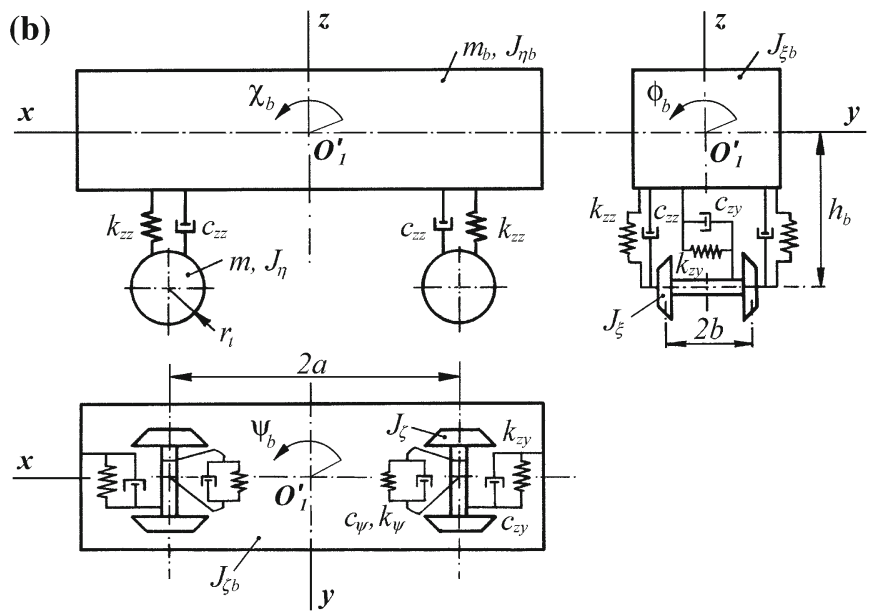

Fig. 2 Nominal models of 2-axle objects: a bogies [8], b freight cars [29,42]

Terms of the generalised imaginary forces can be named according to [46]. So, after scalar multiplication of all the addends in square brackets in (2) these terms are called as follows: the first term-inertia forces of translation, the second and fifth terms-inertia forces of rotation, the third and sixth terms-centrifugal forces of inertia, and the fourth and seventh terms-gyroscopic forces.

Formally Eq. (2) is valid for the equations of motion expressed in generalised co-ordinates $q$ and generalised velocities $\dot{q}$. It can be extended to the equations expressed in generalised co-ordinates $q$ and quasivelocities $u$ adopting some assumptions. First, let us assume that generalised co-ordinates are adopted in the most typical in railway vehicle dynamics way. So, they are: linear longitudinal $x$, lateral $y$ and vertical $z$ coordinates and angular roll $\phi$, pitch $\chi$ and yaw $\psi$ rotation co-ordinates. Taking account of nonoccurrence of nonholonomic constraints in railway vehicle dynamics let us assume that quasi-velocities are adopted specifically as equal directly to generalised co-ordinates time derivatives, i.e. $\dot{q} \equiv u$. In such circumstances one can write down:

$$
\frac{\partial \boldsymbol{r}_{j}^{\prime}}{\partial q_{j \rho}} \equiv \frac{\partial \boldsymbol{v}_{j}^{\prime}}{\partial \dot{q}_{j \rho}} \equiv \frac{\partial \boldsymbol{v}_{j}^{\prime}}{\partial u_{j} \rho} ; \quad \frac{\partial \boldsymbol{\omega}_{j}^{\prime}}{\partial \dot{q}_{j \rho}} \equiv \frac{\partial \boldsymbol{\omega}_{j}^{\prime}}{\partial u_{j \rho}}
$$

One can see now that after introduction of (3) into Eq. (2) this last can also be used for the systems expressed in generalised co-ordinates and quasi-velocities providing they are adopted as assumed before.
These assumptions do not lead to loss of generality in terms of practice. And so it was utilised in the authors models. Equation (2) was used directly in case of models based on the Lagrange equations of type II while form of (2) extended with (3) was used in case of the Kane's equations.

\subsection{Nominal models of the studied objects}

To begin with it is worth saying that objects studied in this paper are treated by the authors as generic ones. They are intentionally relatively simple examples representing railway vehicles. Their more or less direct connection with the real vehicles is needed to avoid objections of their unreality. The authors' studies are not intended to learn more or improve any particular real railway vehicle but to learn more on whole diversity of railway vehicles and eventually formulate recommendations for all of them in future.

In fact the authors study vehicle-track discrete systems. Each of the six models of studied objects, represented by rigid bodies, is supplemented with the same discrete models of track flexible laterally and vertically.

Structures of the 2-axle objects studied by the authors are shown in Fig. 2a for the bogies and Fig. 2b for the cars. In fact structures of bogie of MKIII car, bogie of average parameters and both 2-axle cars are the same. This means the same number of degrees of freedom (DOFs), which including track is equal to 18 . The exception is $25 \mathrm{TN}$ bogie-track model that possesses 16 DOFs. Two constraints that reduce 18 to 16 
Table 1 Parameters of models for the adopted 2-axle objects

\begin{tabular}{|c|c|c|c|c|c|c|c|}
\hline \multirow[t]{2}{*}{ Notation } & \multirow[t]{2}{*}{ Description } & \multirow[t]{2}{*}{ Unit } & \multicolumn{5}{|c|}{ Parameter value } \\
\hline & & & $25 \mathrm{TN}$ bogie & $\begin{array}{l}\text { Bogie } \\
\text { aver. } \\
\text { param. }\end{array}$ & $\begin{array}{l}\text { Bogie } \\
\text { MKIII car }\end{array}$ & $\begin{array}{l}\text { Freight car av. } \\
\text { param. }\end{array}$ & $\begin{array}{l}\text { Hsfv1 } \\
\text { freight car }\end{array}$ \\
\hline$m_{b}$ & $\begin{array}{l}\text { Vehicle body/bogie } \\
\text { frame mass }\end{array}$ & $\mathrm{kg}$ & 1600 & 1600 & 2707 & 10,000 & 30,000 \\
\hline$m$ & Wheelset mass & $\mathrm{kg}$ & 1400 & 1400 & 1375 & 2400 & 2392 \\
\hline$I_{\zeta b}$ & $\begin{array}{l}\text { Vehicle body/bogie } \\
\text { frame moment of } \\
\text { inertia; longitudinal } \\
\text { axis }\end{array}$ & $\mathrm{kg} \mathrm{m}^{2}$ & 790 & 790 & 1800 & 5830 & 51,000 \\
\hline$I_{\eta b}$ & $\begin{array}{l}\text { Vehicle body/bogie } \\
\text { frame moment of } \\
\text { inertia; lateral axis }\end{array}$ & $\mathrm{kg} \mathrm{m}^{2}$ & 1000 & 1000 & 3500 & 61,700 & 240,000 \\
\hline$I_{\zeta b}$ & $\begin{array}{l}\text { Vehicle body/bogie } \\
\text { frame moment of } \\
\text { inertia; vertical axis }\end{array}$ & $\mathrm{kg} \mathrm{m}^{2}$ & 1090 & 1090 & 3500 & 61,700 & 222,000 \\
\hline$I_{\xi}$ & $\begin{array}{l}\text { Wheelset moment of } \\
\text { inertia; longitudinal } \\
\text { axis }\end{array}$ & $\mathrm{kg} \mathrm{m}^{2}$ & 747 & 747 & 790 & 1700 & 1662 \\
\hline$I_{\eta}$ & $\begin{array}{l}\text { Wheelset moment of } \\
\text { inertia; lateral axis }\end{array}$ & $\mathrm{kg} \mathrm{m}^{2}$ & 131 & 131 & 100 & 200 & 50 \\
\hline$I_{\zeta}$ & $\begin{array}{l}\text { Wheelset moment of } \\
\text { inertia; vertical axis }\end{array}$ & $\mathrm{kg} \mathrm{m}^{2}$ & 747 & 747 & 790 & 1700 & 1662 \\
\hline$k_{z x}$ & $\begin{array}{l}\text { Longitudinal stiffness of } \\
\text { primary suspension }\end{array}$ & $\mathrm{fkN} / \mathrm{m}$ & - & 2615 & 880 & 800 & 2067 \\
\hline$k_{z y}$ & $\begin{array}{l}\text { Lateral stiffness of } \\
\text { primary suspension }\end{array}$ & $\mathrm{kN} / \mathrm{m}$ & 3890 & 890 & 3925 & 800 & 431 \\
\hline$k_{z z}$ & $\begin{array}{l}\text { Vertical stiffness of } \\
\text { primary suspension }\end{array}$ & $\mathrm{kN} / \mathrm{m}$ & 1017 & 1017 & 2667 & 1000 & 4100 \\
\hline$c_{z x}$ & $\begin{array}{l}\text { Longitudinal damping } \\
\text { of primary suspension }\end{array}$ & $\mathrm{kN} \mathrm{s} / \mathrm{m}$ & - & 52.2 & 0 & 42 & 0 \\
\hline$c_{z y}$ & $\begin{array}{l}\text { Lateral damping of } \\
\text { primary suspension }\end{array}$ & $\mathrm{kN} \mathrm{s} / \mathrm{m}$ & 42 & 42 & 0 & 47 & 56 \\
\hline$c_{z z}$ & $\begin{array}{l}\text { Vertical damping of } \\
\text { primary suspension }\end{array}$ & $\mathrm{kN} \mathrm{s} / \mathrm{m}$ & 7 & 7 & 170 & 60 & 28 \\
\hline$a$ & Semi-wheel base & $\mathrm{m}$ & 0.9 & 0.9 & 1.3 & 3.16 & 3.15 \\
\hline$h_{b}$ & $\begin{array}{l}\text { Vertical distance } \\
\text { between wheelset and } \\
\text { vehicle body/bogie } \\
\text { frame mass centres }\end{array}$ & $\mathrm{m}$ & 0.25 & 0.25 & 0.303 & 1.04 & 1.175 \\
\hline$r_{t}$ & Wheelset rolling radius & $\mathrm{m}$ & 0.46 & 0.46 & 0.457 & 0.46 & 0.375 \\
\hline
\end{tabular}

DOFs are those making relative yaw rotations between both wheelsets and bogie frame impossible. That is why parameters $k_{z x}$ and $c_{z x}$ for this bogie in Table 1 are undefined. Structure of the 4-axle passenger car is shown in Fig. 3a. Together with the track it has got 38 DOFs. Structure of model of laterally flexible track is shown in Fig. 3b. Structure of model of vertically flexible track is shown in Fig. 3c. Laterally flexible track model extends number of system DOFs by 1 on each of the wheelsets when compared to rigid track model. Vertically flexible track extends number of system DOFs by 2 on each of the wheelsets and reduces it by 2 due 


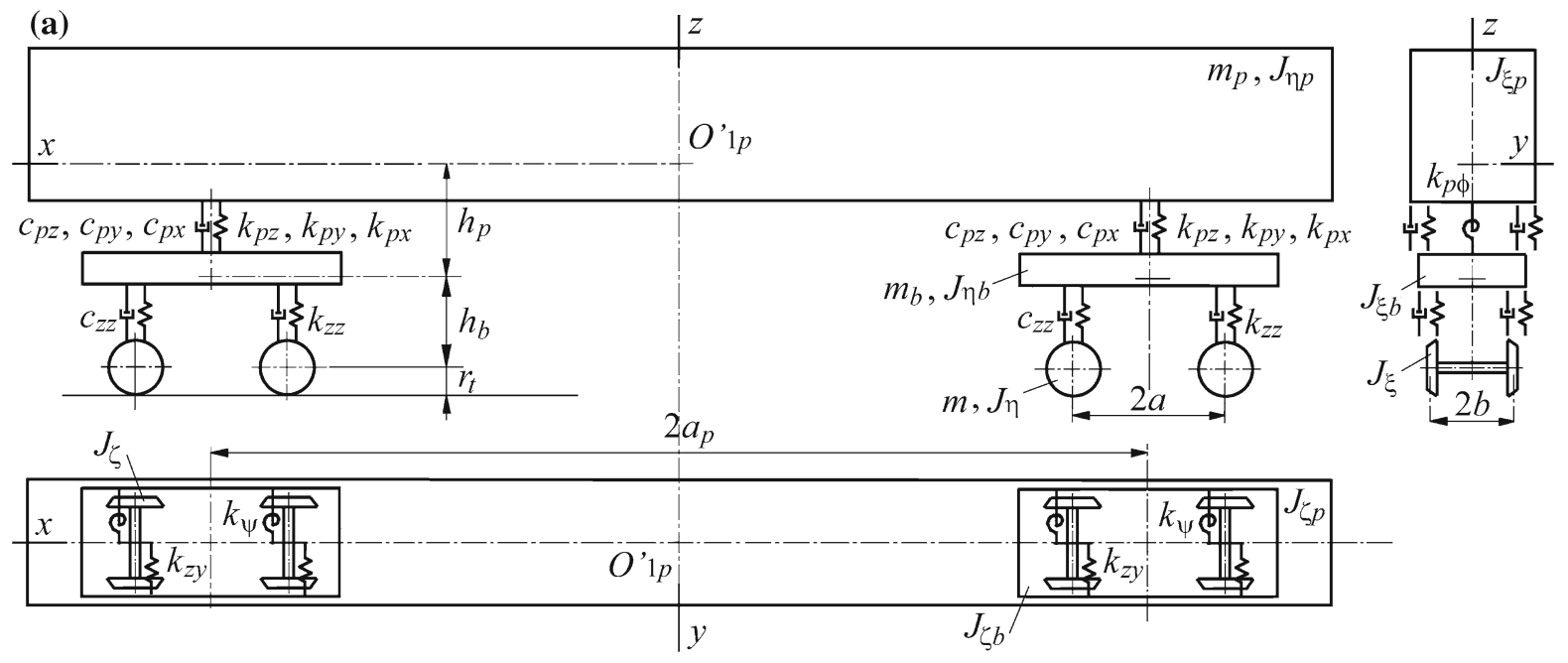

(b)

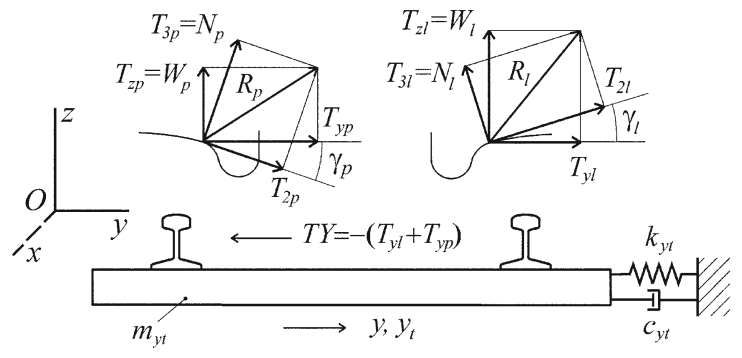

(c)
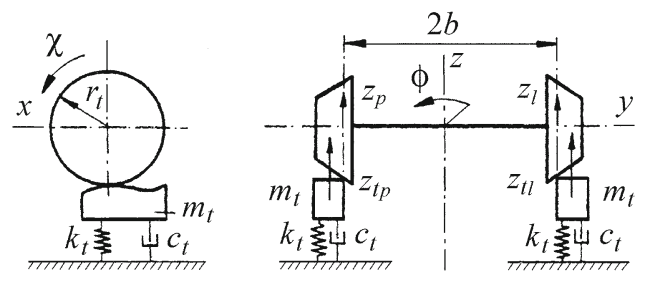

Fig. 3 Nominal models [15] of: a 4-axle passenger car, b laterally flexible track, c vertically flexible track

to constraints [15]. Finally, both track models extend system DOFs number by 1 on each of the wheelsets when compared to rigid track models.

Parameters for 2-axle objects are collected in Table 1 while for 4-axle object and track in Table 2. Primary source for parameters of $25 \mathrm{TN}$ bogie of freight car, bogie of MKIII passenger car, freight car of average parameters and hsfvl freight car is [29]. Such source for bogie of average parameters is [42] while for MKIII passenger car is [15]. Parameters of the track were published first in $[29,42]$. The bogies $25 \mathrm{TN}$ and of average parameters are loaded vertically by half of the 4-axle vehicle body mass equal $12,300 \mathrm{~kg}$. The corresponding value for bogie of MKIII car is given in Table 2 .

\subsection{The simulation software}

Based on the modelling principles discussed in Sect. 2.1 the simulation software was built for the objects described in Sect. 2.2. In fact three different simula- tion programs built and co-built by the lead author were used for all six objects studied in the present paper.

The first simulation software to be mentioned is that for $25 \mathrm{TN}$ bogie of the freight car. It is the software build individually for that particular object. The second simulation software is of the same nature, i.e. it was also build individually for the particular object being the bogie of average parameters. It was not possible to use the same software as for $25 \mathrm{TN}$ bogie due to the different structure (DOFs number) for the bogie of average parameters. On the other hand, thanks to identical structure of bogie of average parameters, bogie of MKIII passenger car, 2-axle freight car of average parameters, and 2-axle hsfv1 freight car the same software for all four objects was used. The differences for them arise from their parameters shown in Table 1, only. In the first and second simulation, software Lagrange formalism of type II was applied. The equations of motion were derived traditionally at first. References to the literature for the parameters of particular objects in Sect. 2.2. 
Table 2 Parameters of the model of 4-axle passenger car except its bogie and models of track

\begin{tabular}{|c|c|c|c|}
\hline Notation & Description & Unit & Param. value \\
\hline$m p$ & Vehicle body mass & $\mathrm{kg}$ & 28,658 \\
\hline$I_{\xi p}$ & Body moment of inertia; longitudinal axis & $\mathrm{kg} \mathrm{m}^{2}$ & 35,986 \\
\hline$I_{\eta p}$ & Body moment of inertia; lateral axis & $\mathrm{kg} \mathrm{m}^{2}$ & $1,089,000$ \\
\hline$I_{\zeta p}$ & Body moment of inertia; vertical axis & $\mathrm{kg} \mathrm{m}^{2}$ & $1,089,000$ \\
\hline$k p x$ & Longitudinal stiffness of secondary suspension & $\mathrm{kN} / \mathrm{m}$ & 20 \\
\hline kpy & Lateral stiffness of secondary suspension & $\mathrm{kN} / \mathrm{m}$ & 476 \\
\hline$k p z$ & Vertical stiffness of secondary suspension & $\mathrm{kN} / \mathrm{m}$ & 828 \\
\hline$k p \phi$ & Bogie frame-car body secondary roll stiffness & $\mathrm{kN} \mathrm{m} / \mathrm{rad}$ & 1822 \\
\hline$c p x$ & Longitudinal damping of secondary suspension & $\mathrm{kN} \mathrm{s} / \mathrm{m}$ & 0.5 \\
\hline cpy & Lateral damping of secondary suspension & $\mathrm{kN} \mathrm{s} / \mathrm{m}$ & 80 \\
\hline $\operatorname{cpz}$ & Vertical damping of secondary suspension & $\mathrm{kN} \mathrm{s} / \mathrm{m}$ & 53 \\
\hline ap & Half of bogies pivot distance & $\mathrm{m}$ & 8 \\
\hline$h p$ & Vertical distance between bogie frame and car body mass centres & $\mathrm{m}$ & 1.343 \\
\hline$m_{t}$ & Vertical mass of the rail & $\mathrm{kg}$ & 200 \\
\hline$k_{t}$ & Vertical stiffness of the rail & $\mathrm{kN} / \mathrm{m}$ & 70,000 \\
\hline$c_{t}$ & Vertical damping of the rail & $\mathrm{kN} \mathrm{s} / \mathrm{m}$ & 200 \\
\hline$m_{t y}$ & Lateral mass of the track & $\mathrm{kg}$ & 500 \\
\hline$k_{t y}$ & Lateral stiffness of the track & $\mathrm{kN} / \mathrm{m}$ & 25,000 \\
\hline$c_{t y}$ & Lateral damping of the track & $\mathrm{kN} \mathrm{s} / \mathrm{m}$ & 500 \\
\hline
\end{tabular}

match the corresponding software and represent first use of the software, too.

The third simulation software is the AGEM software where Kane's formalism was applied. This software was co-built [47] by the lead author and is called ULYSSES. Detailed information on the software building can be found in $[15,45,47,48]$. Publications $[47,48]$ can be treated as the first use of this software for relatively simple cases. Results of this software use for the MKIII passenger car were published in [15] firstly.

The wheel-rail contact was modelled in the identical way in all three software items. Tangential contact forces are nonlinear there. They are generated with use of the FASTSIM program [49], based on the so-called simplified theory of rolling contact. Coefficient of friction between wheel and rail in the contact forces calculation was equal to 0.3 . Wheel-rail contact geometry is nonlinear in the sense real wheel and rail profiles are taken into account. They are introduced into the software through the contact parameters in form of table generated with use of the RSGEO software [50]. Values of these parameters between discrete points included in the table are interpolated. If not stated otherwise the nominal (i.e. unworn) profiles S1002 and UIC60 were used for wheel and rail, respectively. Track gauge in the studies was equal $1435 \mathrm{~mm}$ while track inclination $1: 40$.

The integration is done with the Gear's method capable of solving stiff ordinary differential equations [51,52]. The used integration procedure is capable of automatic correction of its relative error $E$ during calculations.

It is worth noting that described modelling approach, models of considered objects, and corresponding simulation programs are really well verified. They were tested, corrected and applied with success many times and for many years. Limited selection of scientific problems solved with their use might be represented with publications [1-7,11,13-15,29,41,42,47]. Total number of the software applications runs into tens. Except the numerous applications of the models some actions focused directly on models verification were undertaken. Thus, apart from building models of 2-axle freight cars individually, models of the same objects were also built with use of the ULYSSES program. Then results from both types of software were com- 
pared and the software corrected till the same results from them were obtained. Another verification was qualitative comparison of the results for MKIII passenger car obtained with the ULYSSES software with the results for similar passenger object from the commercial VI-Rail (ADAMS Rail formerly) code. Those comparisons are discussed in [14].

\section{Principles of the results calculation and presentation: method of the analysis}

Results of dynamical simulations were obtained most often for the objects' models moving along the compound route built from three consecutive sections: ST, TC, and CC. These sections are indicated on the figures by the vertical lines that split them up. Detailed data about the routes are given in the subsections where particular results are discussed. TC used in the studies was always the parabolic curve of 3rd degree. Superelevation values $h$ in CC were as a rule selected in the way ensuring exact balance between components of gravity and centrifugal forces in the track plane. Nevertheless, if $h$ value defined in such a way exceeded maximum value permitted in Poland, i.e. $h=150 \mathrm{~mm}$ then this maximum value was adopted.

Results presented in the figures are time history plots representing vehicle lateral dynamics co-ordinates most often. These are lateral displacements $y$ and yaw angles $\psi$. The other co-ordinates being shown rarely are vertical displacements $z$ and roll angle $\phi$. The general indices accompany mentioned co-ordinates as follows. In case of 2-axle objects these are: $b, l$, and $t$ that indicate vehicle body or bogie frame, leading wheelset, and trailing wheelset, respectively. In case of 4-axle vehicle these are: $p, b 1, b 2,1,2,3$, and 4 . They indicate vehicle body, leading bogie frame, trailing bogie frame, leading wheelset in the $b 1$ frame, trailing wheelset in the $b 1$ frame, leading wheelset in the $b 2$ frame, and trailing wheelset in the $b 2$ frame, respectively. In some studied cases intensive variations over system parameters were performed. Then supplementary information is necessary which is given with the indices extensions. They are introduced further on at the beginning of the corresponding subsections.

In case nonzero initial conditions were applied at the simulation beginning the nonzero values always concern lateral displacements of all rigid bodies that make the object model. This values are always the same for all the bodies. The corresponding value adopted most often for 2-axle objects is $y_{i}(0)=0.0045 \mathrm{~m}$, while in case of 4-axle car $y_{j}(0)=0.004 \mathrm{~m}$. Here and further on, the subscripts $i$ and $j$ are joint representations of subscripts $b, l$, and $t$ and $p, b 1, b 2,1,2,3$, and 4 , respectively.

Method of the analysis in the present paper matches its aims. It is relatively straightforward. It consists in searching for and finding interesting results of vehicle (object) nonlinear behaviour with simulation, presenting these results on the plots, commenting or alternatively explaining shown results, and concluding whole of the results at the end. Despite such straightforward methodology, it is expected by the authors that some people, especially practitioners, will say presented study is too theoretical because application of the results obtained can hardly be seen. It does not greatly upset the authors, because such opinions have been typical for many research problems being just started. As realities show the cognitive findings and knowledge gathered thanks to research become common property and start to be applied very soon.

Despite issue of solutions stability and values of critical velocity are not point of interest themselves in this paper, they are, however, important indirectly. They are useful at the results concluding stage, namely they contribute to the deeper going conclusions. The issues in view are treated with simulation technique, this time, however, it is more complicated and less straight forward than it was described in the paragraph above. In case of the stability issue the solutions, either stationary or periodic, were checked for their stability every time initial conditions were varied. Every time simulations brought the same fixed solution in spite of different values of the initial condition the solution was proved to be stable. Such a feature is the fundamental one for stable limit cycles (periodic solutions). Corresponding results do not make mathematical proof of the stability but the proof in practical sense, accepted and utilised by very many other authors studying railway vehicle stability with simulation. The authors performed variations of initial conditions they studied influence of the initial conditions on the results directly. Such variations accompanied also each process of the critical velocity value determination (described below). Very many results from such actions, especially connected with critical velocity determination, have to be omitted as not making main message in this paper. In other cases the authors just anticipated that properties shown in Fig. 1 hold and no formal check for stability of solu- 
Fig. 4 Co-ordinates of wheelsets and bogie frame of $25 \mathrm{TN}$ bogie of freight car; $R=300 \mathrm{~m}$; $h=0.15 \mathrm{~m} ; v=29.5 \mathrm{~m} / \mathrm{s}$; $y_{i}(0)=0.0045 \mathrm{~m}$
Fig. 5 Co-ordinates of wheelsets and bogie frame of $25 \mathrm{TN}$ bogie of freight car; $R=400 \mathrm{~m}$; $h=0.15 \mathrm{~m} ; v=29.5 \mathrm{~m} / \mathrm{s}$; $y_{i}(0)=0.0045 \mathrm{~m}$
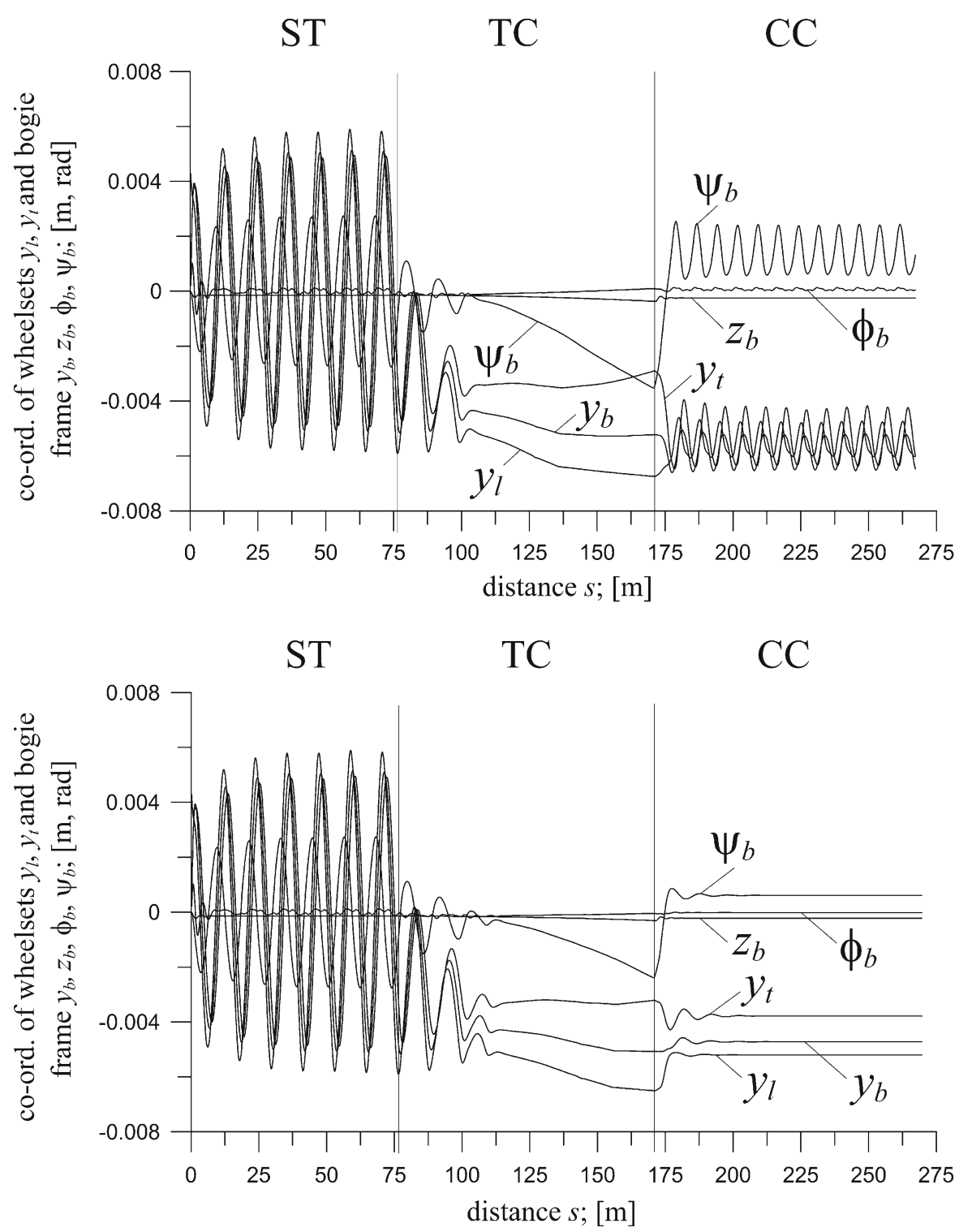

tions was performed. In case of need one can find more details of these authors approach to stability of solutions in $[11,13,14]$ where lateral stability of railway vehicles is the main matter.

There are four methods known in the literature [15] for determination of critical velocity $v_{n}$ value with simulation approach. The first one is based on direct use of the simulation software used in railway vehicle dynamics. So it is also for the second method. Both methods are based on the same principle; however, their use differs in the procedure accuracy. Generally, the method consists in systematic, simulations for consecutively increasing or decreasing velocities, however, with initial conditions consecutively varied for each of the adopted velocities. The aim is to find the smallest velocity value at which stable stationary solution bifurcates and stable periodic solution appears. The first method is called approximate one, the second extended one [13]. In the first method velocity interval is higher and sweeping over initial conditions is with higher intervals and can even be limited to higher values of initial conditions only. In extreme case one set of the initial conditions of high values is used. In the extended method velocity interval is small, while dense sweeping over whole ini- 
Fig. 6 Co-ordinates of wheelsets and bogie frame of $25 \mathrm{TN}$ bogie of freight car; $R=900 \mathrm{~m}$;

$h=0.142 \mathrm{~m} ; v=29.5 \mathrm{~m} / \mathrm{s}$; $y_{i}(0)=0.0045 \mathrm{~m}$
Fig. 7 Co-ordinates of wheelsets and bogie frame of $25 \mathrm{TN}$ bogie of freight car; $R=6000 \mathrm{~m}$; $h=0.021 \mathrm{~m} ; v=29.5 \mathrm{~m} / \mathrm{s}$; $y_{i}(0)=0.0045 \mathrm{~m}$
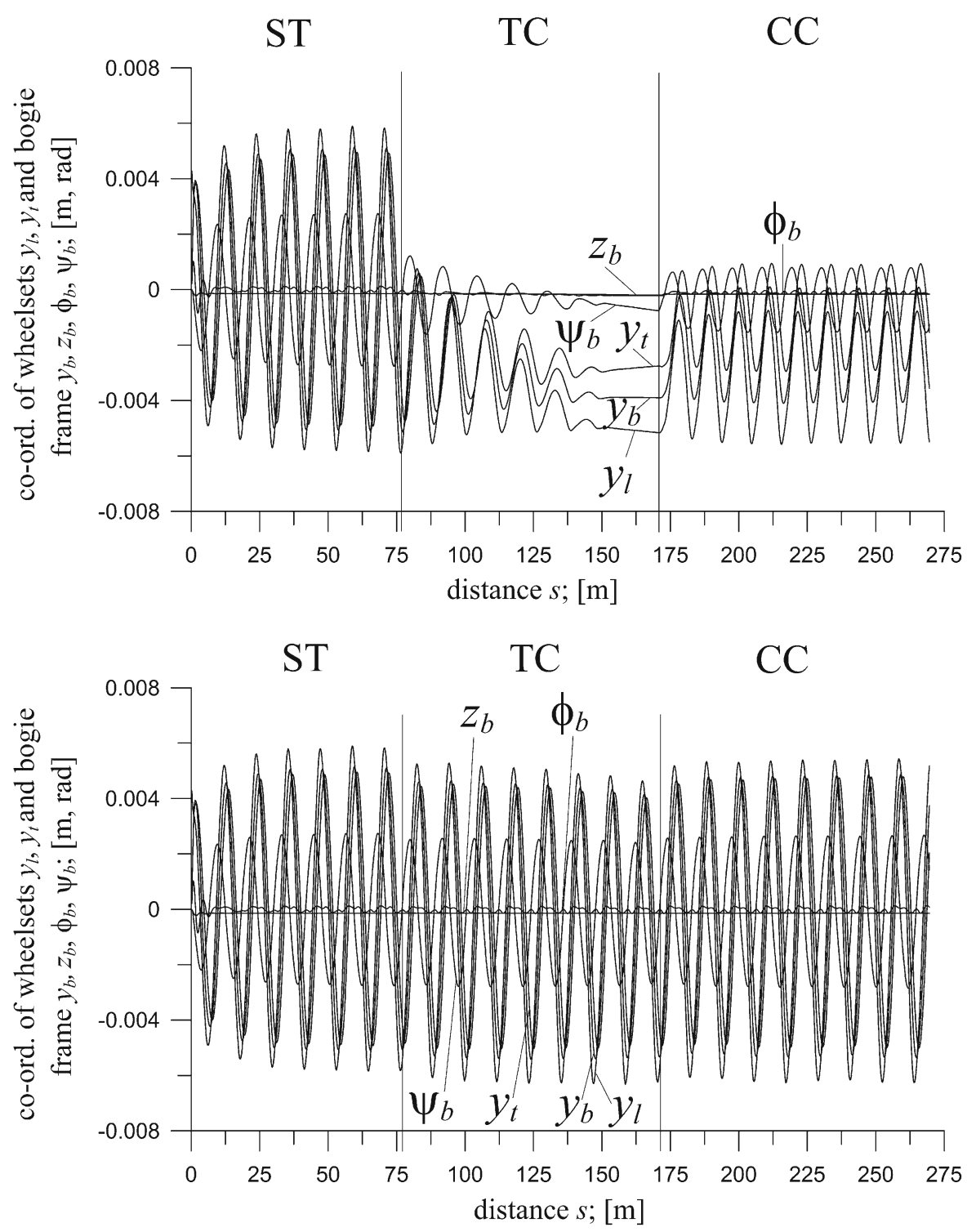

tial conditions rage is a must. The approximate method brings the results fast but value of velocity $v_{n}$ is approximate. Besides, the danger of omitting multiple solutions exists, what can sometimes mean that real critical velocity $v_{n}$ is even lower than earlier found. That is why some experience in use of this method is desirable. The extended method brings precise critical velocity values and no danger of multiple solutions omission exists. Nevertheless, this method is very laborious when used rigorously, so it is time-consuming. Example use of the approximate method by the lead author can be seen in [11], where 2-axle objects were studied. Results of the extended method use for the same objects can be found in [13]. Comparison of the results from the approximate and extended methods can be found in [13]. No inacceptable differences were found there. Combined use of the approximate and extended methods for two 4-axle passenger cars can be found in [14]. The third method of velocity $v_{n}$ determination is called the ramping method. Examples of its use can be found $[9,16,25]$. The simulation software, usually capable of constant speed simulations, has to be modified to enable simulation with variable velocity. The method consists in single simulation with decreasing velocity and looking for the moment (velocity) vibrations start to decay unambiguously. The method seems to be very attractive 
Fig. 8 Co-ordinates of wheelset and bogie frame of $25 \mathrm{TN}$ bogie of freight car; $R=300 \mathrm{~m} ; h=0.15 \mathrm{~m}$; $v=29.5 \mathrm{~m} / \mathrm{s}$

$y_{i}(0)=0.0045 \mathrm{~m}$;

$k_{t y}=2500(0.1 \times)$,

$25,000(1 \times)$,

$250,000(10 \times), 2,500,000$

$(100 \times) \mathrm{kN} / \mathrm{m}$; density of discrete points in contact parameter table- 15 points
Fig. 9 Co-ordinates of wheelset and bogie frame of $25 \mathrm{TN}$ bogie of freight car; $R=300 \mathrm{~m} ; h=0.15 \mathrm{~m}$; $v=29.5 \mathrm{~m} / \mathrm{s}$; $y_{i}(0)=0.0045 \mathrm{~m}$; $k_{t y}=2500(0.1 \times)$, $25,000(1 \times)$, $250,000(10 \times)$ $2,500,000(100 \times) \mathrm{kN} / \mathrm{m}$; density of discrete points in contact parameter table-39 points
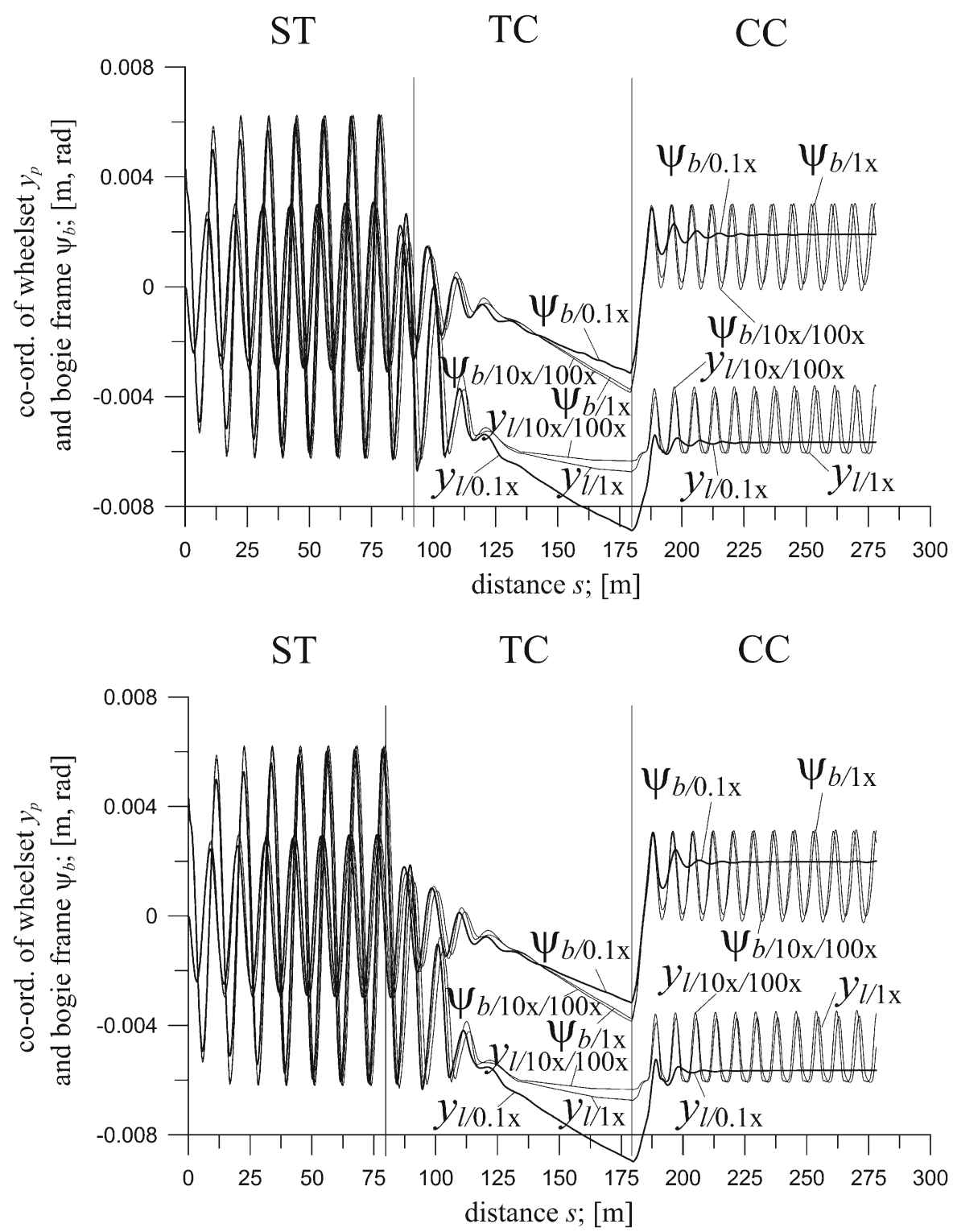

and is used by others but its use by the lead author disclosed several practical problems $[15,53]$. First, indicating the moment vibrations start to decay is troublesome and too much subjective. Second, quite different results are obtained for different decelerations (speeds of velocity decrease). Third, the problem exists to perform simulation in $\mathrm{CC}$ for decreasing velocity when velocity of unbounded solutions growth (of numerical derailment $v_{s}$ ) is close to $v_{n}$, due to some initial distance necessary for the transient phenomena to vanish. The fourth approach are continuation methods where final results of simulation make initial conditions for the next simulation. Example use of such method can be found in $[16,22]$. This method needs consecutive simulations for decreasing velocities. The method consists in looking for the smallest velocity for which stable periodic solutions exist. Accuracy of the method depends on the velocity interval. Its accuracy is the same as the second (extended) method. The consecutive simulations can be done individually by the software operator or, after the software modification, the process can potentially be automated. The method can be time-consuming but 
Fig. 10 Co-ordinates of bogie frame of $25 \mathrm{TN}$ bogie of freight car; $R=300 \mathrm{~m}$; $h=0.15 \mathrm{~m} ; v=29.5 \mathrm{~m} / \mathrm{s}$; $y_{i}(0)=0.0045 \mathrm{~m}$; $k_{z y}=3890(1 \times)$, $7780(2 \times), 15,560(4 \times)$, $23,340(6 \times), 31,120(8 \times)$, $38,900(10 \times)$, $77,800(20 \times)$, $155,600(40 \times)$ $233,400(60 \times)$, $311,200(80 \times)$, $389,000(100 \times) \mathrm{kN} / \mathrm{m}$

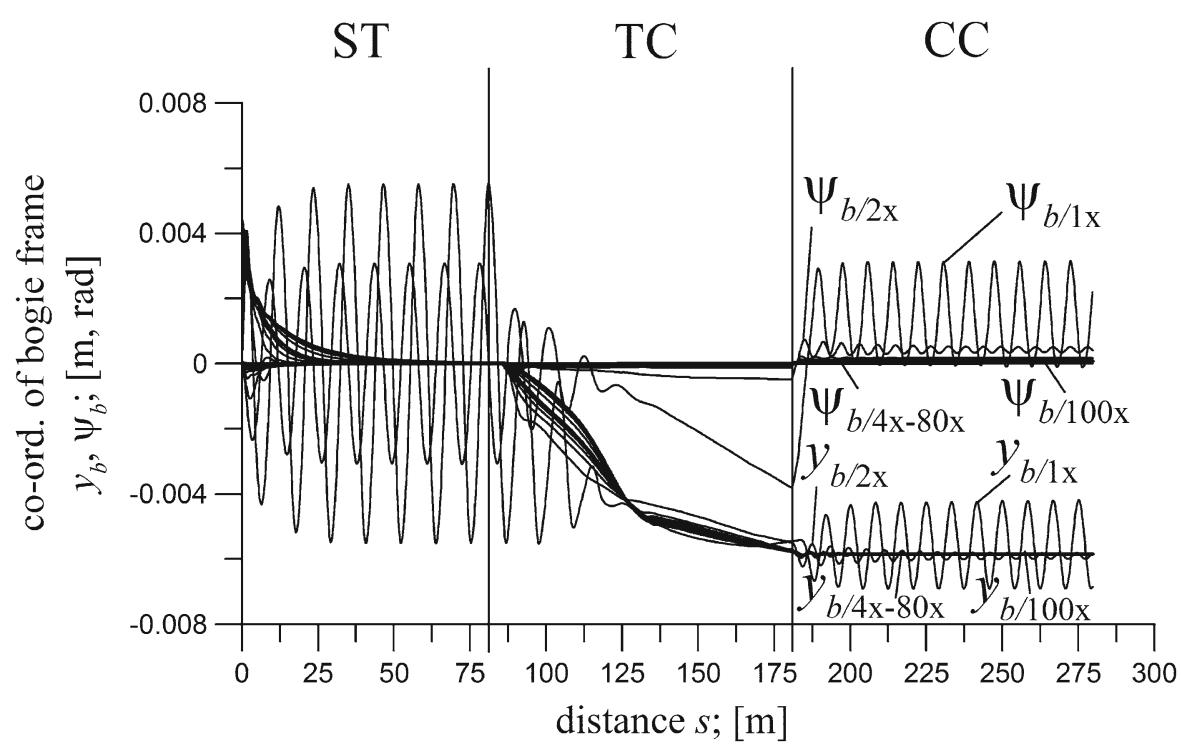

Fig. 11 Co-ordinates of wheelset and bogie frame of bogie of average parameters; $R=600 \mathrm{~m}$; $h=0.15 \mathrm{~m} ; v=54 \mathrm{~m} / \mathrm{s}$; $y_{i}(0)=0.0045 \mathrm{~m}$; $E=0.01 ; 0.1 ; 0.4$

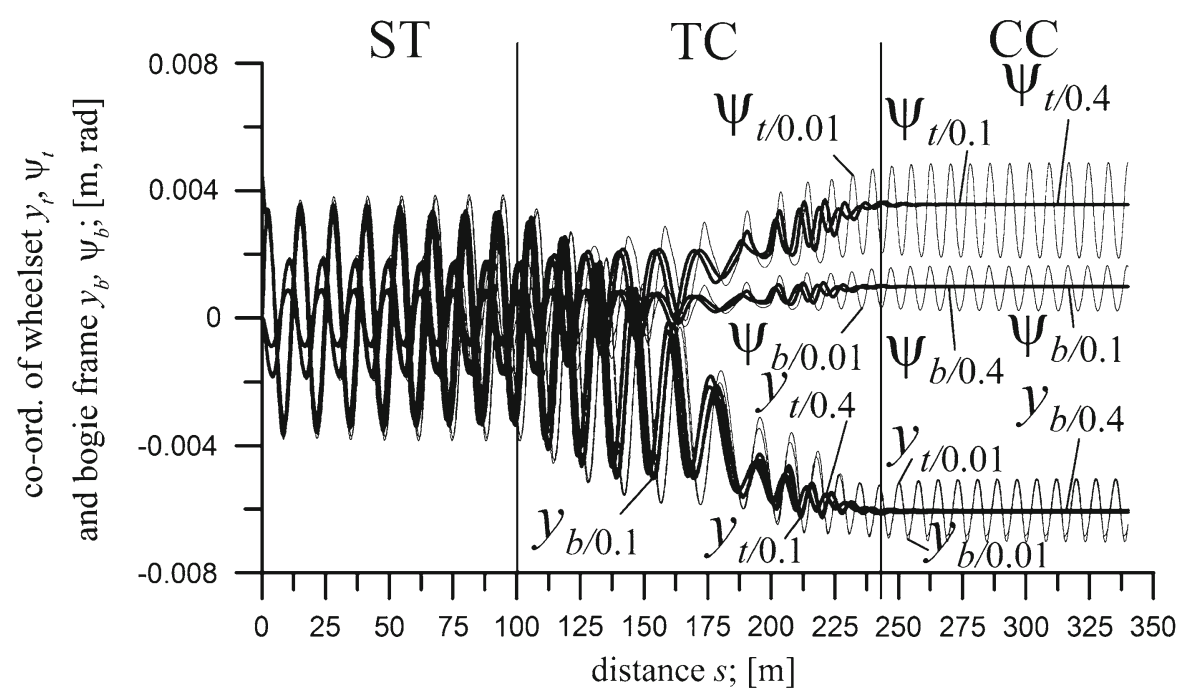

still less than it is for the second method. Despite potential attractiveness of this method it seems that its practical usefulness in case of looking for $v_{n}$ in CCs was nowhere checked. Taking account of this paper needs, experience of the lead author in use of the first, second, and third methods as well as of the combined use of first and second methods, and possibility to shorten the calculations in the first method while ensuring high accuracy in the second method the combined use of the approximate (first) and extended (second) methods was applied in this paper.

In the authors opinion studies on rail vehicle dynamics in TC above critical velocity, both for individual vehicles and generally, can bring benefits in searching for construction of vehicles of properties equally good in ST and in tight CC. It is known for years that these two properties are opposite and hard to combine. This issue is still an open problem in the rail vehicle dynamics. Thanks to close connection between rail vehicle lateral stability studies and issue studied in this paper, as explained in the Introduction, it is possible to transfer some benefits from the stability studies on the current and future results. For example these are the findings expressing connection between stability and safety. In particular the authors mean higher critical velocities and better connection between veloc- 
Fig. 12 Co-ordinates of wheelsets and bogie frame of bogie of average $h=0.15 \mathrm{~m} ; v=54 \mathrm{~m} / \mathrm{s}$ $y_{i}(0)=0.0045 \mathrm{~m}$ parameters; $R=600 \mathrm{~m}$;

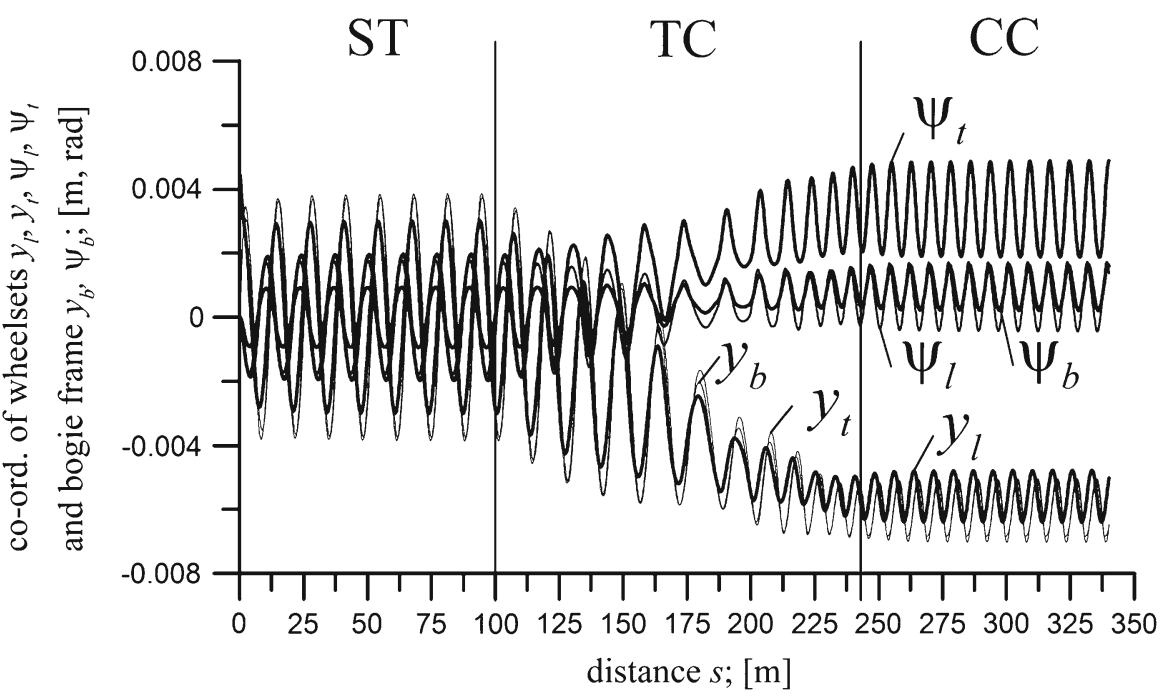

Fig. 13 Co-ordinates of wheelsets and bogie frame of bogie of average parameters; $R=2000 \mathrm{~m}$; $h=0.045 \mathrm{~m} ; v=54 \mathrm{~m} / \mathrm{s}$; $y_{i}(0)=0.0045 \mathrm{~m}$

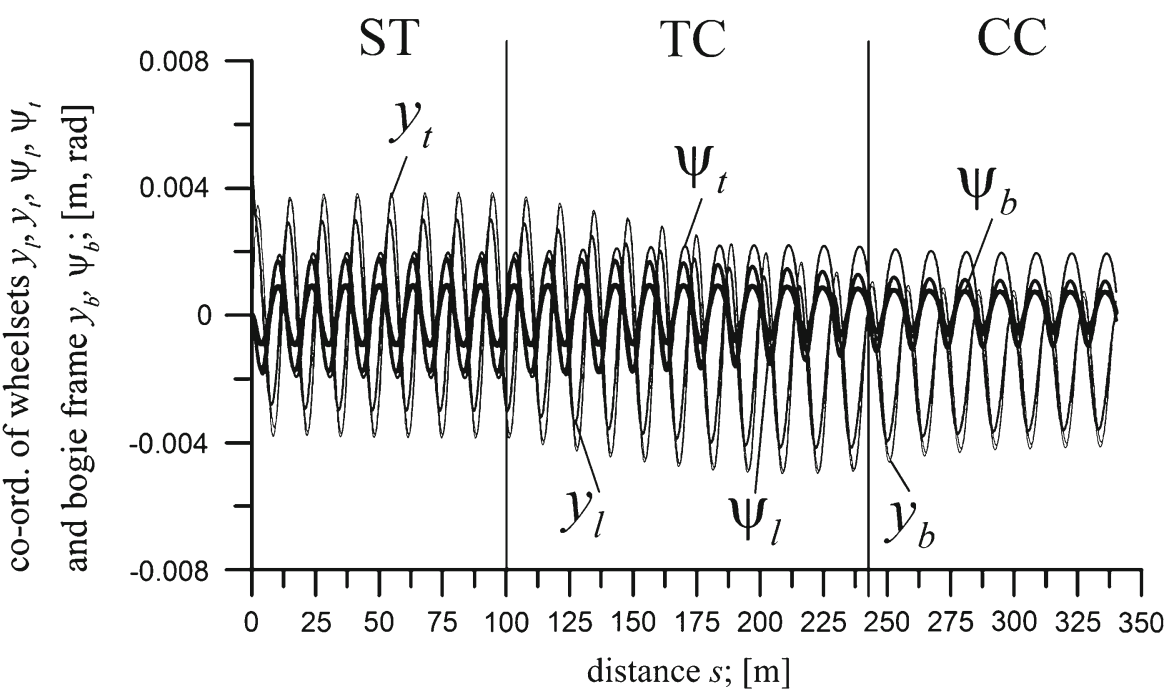

ity of vehicle physical derailment and velocity of socalled numerical derailment, corresponding to stop of the numerical calculations. Besides, the valuable information would be explanation in which circumstances vibration amplitudes in TC are higher than in ST and CCs as well as when vibrations in TC disappear completely despite motion above critical velocity. Understanding of such different behaviour types can result in undertaking measures (including constructional ones) that tend to eliminate first of the features (undesired state) and bring on the second one (the most desired state).

\section{Results of simulations for 2 -axle bogies}

\subsection{Results for 25TN bogie of freight cars}

Results obtained for $25 \mathrm{TN}$ bogie of freight car are presented in Figs. 4, 5, 6, 7, 8, 9 and 10. The common parameters for routes in Figs. 4, 5, 6 and 7 are lengths of ST $(l=76.6 \mathrm{~m})$, TC $(l=95 \mathrm{~m})$, and CC $(l=98 \mathrm{~m})$. Common are also nonzero initial conditions $y_{i}(0)=0.0045 \mathrm{~m}$. The main difference is in CC radius $R$ variation, i.e. $R=300 \mathrm{~m}$ in Fig. 4 , $R=400 \mathrm{~m}$ in Fig. 5, $R=900 \mathrm{~m}$ in Fig. 6, and $R=6000 \mathrm{~m}$ in Fig. 7. The superelevations $h$ are equal to $0.15,0.15,0.142$, and $0.021 \mathrm{~m}$, respectively. Different are lengths of ST $(l=85.0 \mathrm{~m})$ in Figs. 8 
Fig. 14 Co-ordinate of wheelset of bogie of average parameters; $R=2000 \mathrm{~m} ; h=0.045 \mathrm{~m}$; $v=30,35,40$ and $42 \mathrm{~m} / \mathrm{s}$; $y_{i}(0)=0.0045 \mathrm{~m} ; k_{z x}=$ $1,046,000 \mathrm{~N} / \mathrm{m}(0.4 \times)$

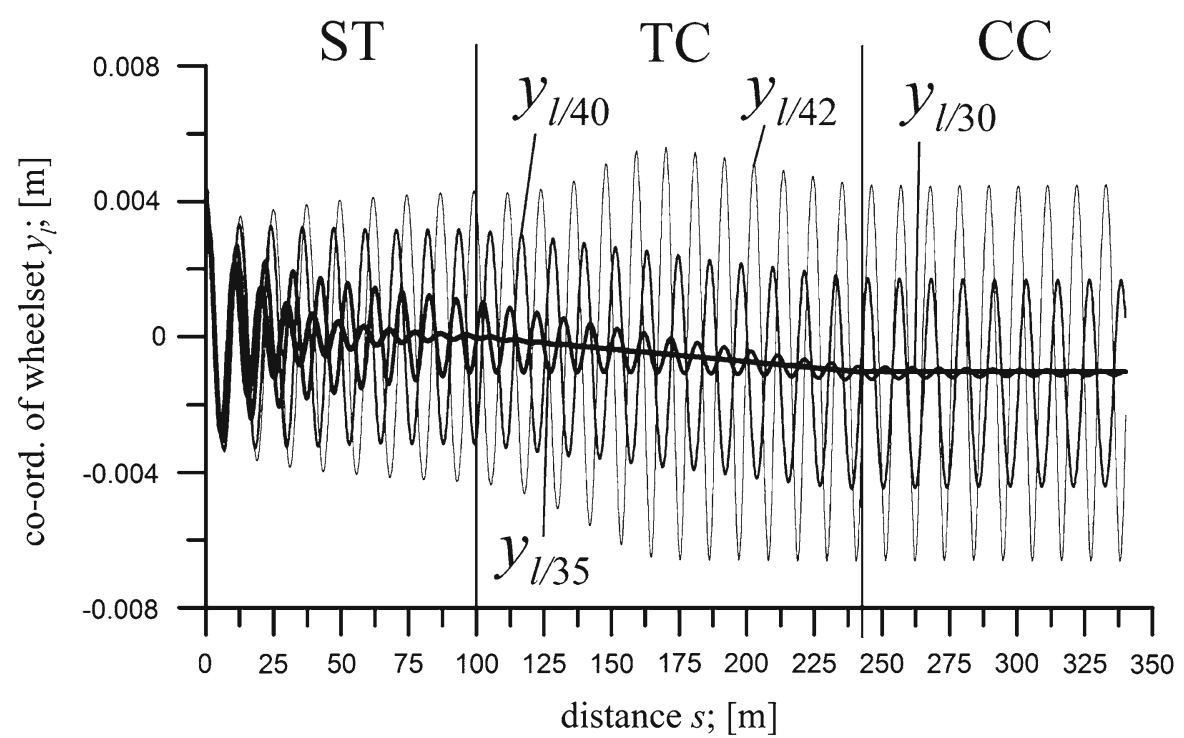

and 9 as well as ST $(l=86.5 \mathrm{~m})$ in Fig. 10. In these three figures $R=300 \mathrm{~m}$ and $h=0.15 \mathrm{~m}$. In Figs. 8 and 9 , results of variation of discrete points number in contact parameter table are represented. The variants adopted in the study are: 15 (Fig. 8), 23 (result not shown), 31 (result not shown) and 39 (Fig. 9) points. Besides, the lateral track stiffness $k_{t y}$ is varied in Figs. 8 and 9 . The variants adopted in the study are values ten times smaller than nominal one $(2500 \mathrm{kN} / \mathrm{m}-0.1 \times)$, nominal one $(25,000 \mathrm{kN} / \mathrm{m}-1 \times)$, ten times $(250,000$ $\mathrm{kN} / \mathrm{m}-10 \times)$ and one hundred times $(2,500,000 \mathrm{kN} / \mathrm{m}$ $-100 \times)$ bigger than nominal one. The supplementary indices in the figures used to indicate above variants of $k_{t y}$ are: $/ 0.1 \times, / 1 \times, / 10 \times$ and $/ 100 \times$, respectively. Besides, in Fig. 10, the lateral stiffness $k_{z y}$ in bogie suspension is varied. The variants adopted are the following values: nominal one $(3890 \mathrm{kN} / \mathrm{m}$ $-1 \times)$, twice $(7780 \mathrm{kN} / \mathrm{m}-2 \times)$, four times $(15560$ $\mathrm{kN} / \mathrm{m}-4 \times)$, six times $(23,340 \mathrm{kN} / \mathrm{m}-6 \times)$, eight times $(31,120 \mathrm{kN} / \mathrm{m}-8 \times)$, ten times $(38,900 \mathrm{kN} / \mathrm{m}$ $-10 \times)$, twenty times $(77,800 \mathrm{kN} / \mathrm{m}-20 \times)$, forty times $(155,600 \mathrm{kN} / \mathrm{m}-40 \times)$, sixty times $(233,400$ $\mathrm{kN} / \mathrm{m}-60 \times)$, eighty times $(311,200 \mathrm{kN} / \mathrm{m}-80 \times)$ and one hundred times $(389,000 \mathrm{kN} / \mathrm{m}-100 \times)$ bigger than nominal one. The supplementary indices in the figures used to indicate above variants of $k_{z y}$ are: $/ 1 \times$, $/ 2 \times, / 4 \times, / 6 \times, / 8 \times, / 10 \times, / 20 \times, / 40 \times, / 60 \times, / 80 \times$ and $/ 100 \times$, respectively. Furthermore, the calculations were done also for the other cases of stiffness $k_{z y}$, namely $(3 \times, 5 \times, 7 \times, 9 \times, 12 \times, 14 \times, 16 \times, 17 \times, 18 \times$ and $1000 \times$ ). The tries to vary $k_{z y}$ values below the nominal value failed, i.e. they finished with numerical derailments.

It should be also stated that Figs. 4, 5, 6 and 7 are obtained for formally different contact parameters table than Figs. 8, 9 and 10. First of the tables is original one, while the second one was obtained with the newer software as a verification of the first table. The authors have not got the software that generated quite old original table. Therefore, they decided to verify their older simulation results using new table obtained with the RSGEO programme [50] being much newer software version and at the authors disposal at the same time. More reasons and results of this verification are discussed broadly in [2]. Generally, results of 25TN bogie for both tables are quite close to each other both qualitatively and quantitatively.

The most intriguing results for the $25 \mathrm{TN}$ bogie are presented in Figs. 4, 5, 6 and 7, where wheelsets' lateral displacements $y_{l}$ and $y_{t}$ as well as bogie frame co-ordinates $y_{b}, z_{b}, \phi_{b}$ and $\psi_{b}$ are represented. The motivation to study these results deeper is Fig. 4 that was presented in [29] at first. Result shown in this figure represents intriguing case where limit cycles in ST and CC exist, while vibrations disappear completely and quite quickly in TC. The next intriguing result is Fig. 5. Results in ST and TC are qualitatively the same and quantitatively similar to those in Fig. 4. In CC results in Fig. 5 are stationary ones, opposite to Fig. 4 where results in form of limit cycle in $\mathrm{CC}$ exist. One could 
Fig. 15 Co-ordinates of wheelsets and bogie frame of bogie of MKIII passenger car; $R=300 m ; h=0.15$ $\mathrm{m} ; v=38 \mathrm{~m} / \mathrm{s}$; $y_{i}(0)=0.0045 \mathrm{~m}$
Fig. 16 Co-ordinates of wheelsets and bogie frame of bogie of MKIII passenger car; $R=300 \mathrm{~m} ; h=0.15$ $\mathrm{m} ; v=52 \mathrm{~m} / \mathrm{s}$; $y_{i}(0)=0.0045 \mathrm{~m}$
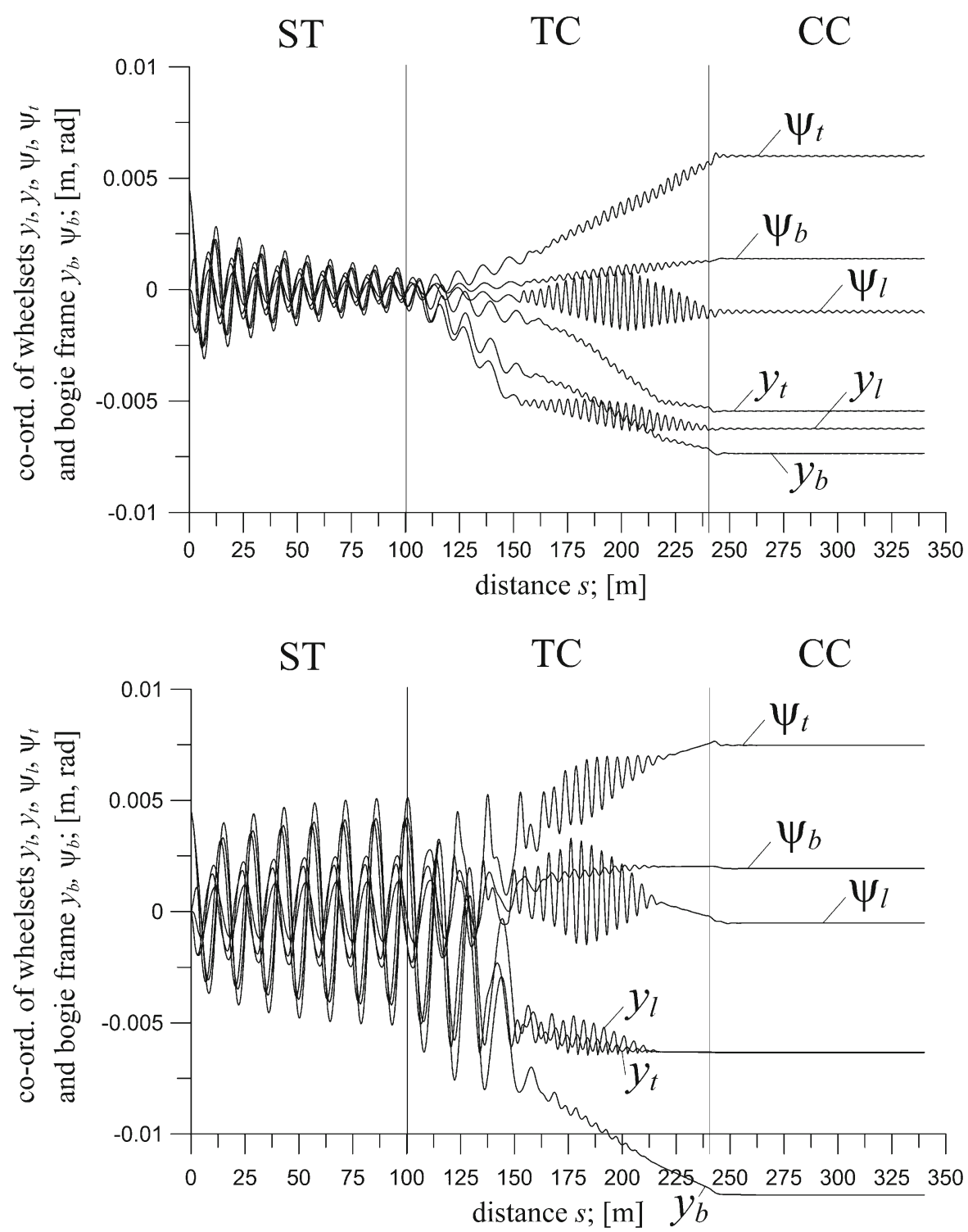

be surprised, especially because curve radius for Fig. 5 is bigger $(R=400 \mathrm{~m})$ than it is in Fig. $4(R=300$ $\mathrm{m})$. It is in contradiction with often expressed opinion that limit cycles in CC, if appear at all, can happen for larger radii only while for smaller ones definitely only stationary (quasi-static) solutions exist. The exceptionality of the results intensifies with results in Fig. 6 obtained for $R=900 \mathrm{~m}$ where periodic solutions (limit cycles) revive, however, of amplitude bigger and frequency smaller than for $R=300 \mathrm{~m}$. The revive of the oscillations in CC can be observed even earlier, i.e. for $R=600 \mathrm{~m}$ (result not shown here) but amplitudes are much smaller than for $R=900$ $\mathrm{m}$. Figure 7 for $R=6000 \mathrm{~m}$ and not shown results for $R=1200,2000,3000,4000,9000$ and $10,000 \mathrm{~m}$ make fluent passage from the case of $R=900 \mathrm{~m}$ to ST case, where $R=\infty$. This passage means that section with vibrations in TC elongates, while section with no vibrations shortens with increase in radius $R$ value until second section disappears completely. The amplitudes of vibrations increase with the increase in $R$ value at the same time.

The results shown in Figs. 8 and 9 represent leading wheelset lateral displacement $y_{l}$ and bogie frame yaw angle $\psi_{b}$ for 15 and 39 discrete points in the contact parameter table, respectively. They and results not 
Fig. 17 Co-ordinates of wheelsets and bogie frame of bogie of MKIII passenger car; $R=600 \mathrm{~m} ; h=0.15$ $\mathrm{m} ; v=38 \mathrm{~m} / \mathrm{s}$; $y_{i}(0)=0.0045 \mathrm{~m}$
Fig. 18 Co-ordinates of wheelsets and bogie frame of bogie of MKIII passenger car; $R=600 \mathrm{~m} ; h=0.15$ $\mathrm{m} ; v=52 \mathrm{~m} / \mathrm{s}$; $y_{i}(0)=0.0045 \mathrm{~m}$
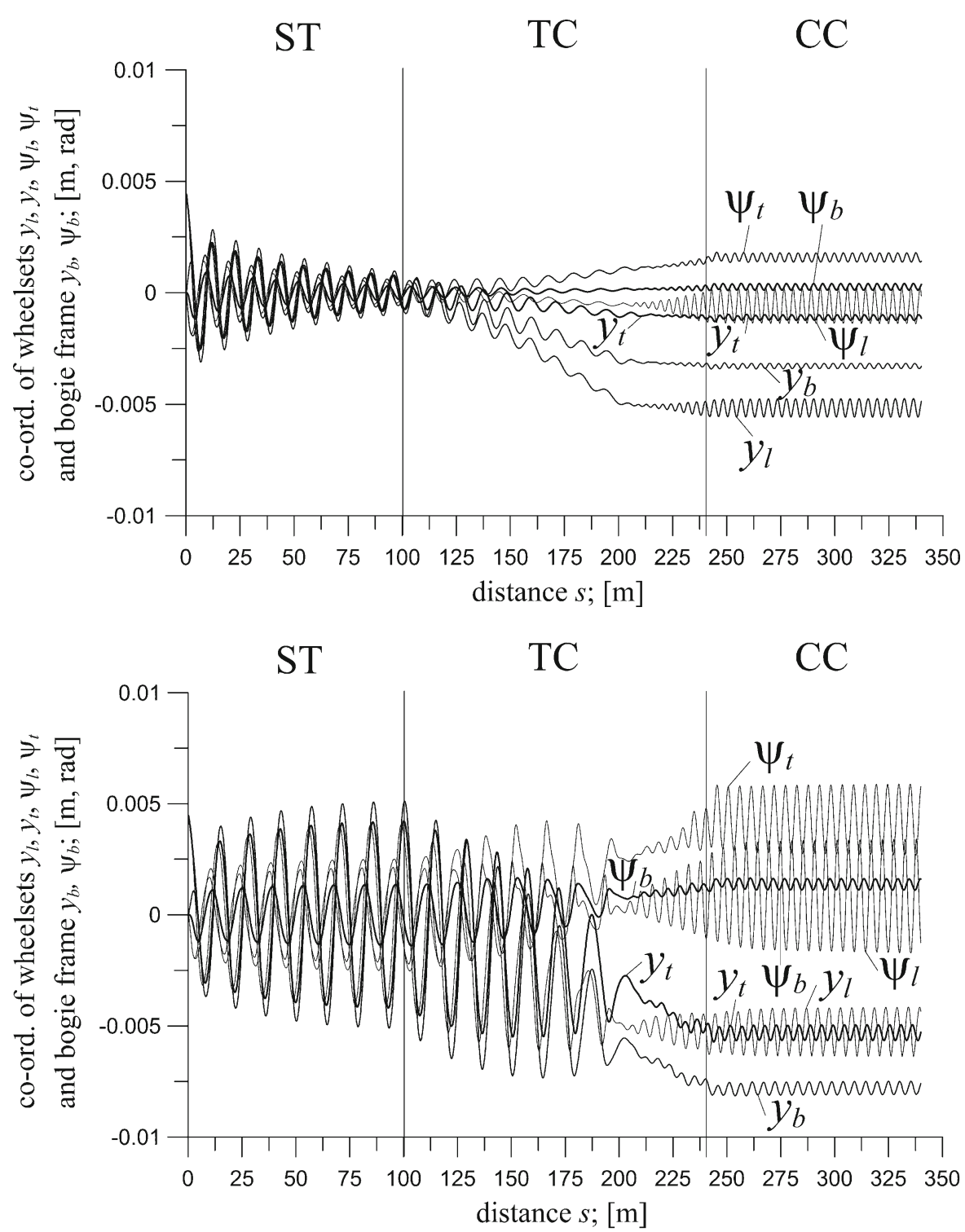

shown here for 23 and 31 points indicate negligible influence of the points number on the results. Results in Figs. 8 and 9 are almost identical. It could be surprising from the one hand, but on the other hand it is a positive information because preferred by the authors smaller number of points results in shortened times of simulation calculations. It is one of the authors activities aimed at the software verification.

Conclusions in the above paragraph concern also variation of the track lateral stiffness $k_{t y}$ represented in Figs. 8 and 9. This means that influence of $k_{t y}$ variation in both figures is the same. Generally, variation of $k_{t y}$ stiffness has got significant influence on the results in TC and CC, while in ST this influence is negligible. Solutions in TC and CC for nominal $(1 \times)$ value of $k_{t y}$ as well as ten times $(10 \times)$ and one hundred times $(100 \times)$ bigger than nominal value, are almost the same, especially in CC. The result for stiffness $k_{t y}$ ten times smaller $(0.1 \times)$ than nominal value differs from them mostly. In TC one can observe significant quantitative differences, while in CC periodic solution is replaced with the stationary solution. Subjectively, one could expect that the system of stiffer track could have bigger tendency to stationary solutions. Here it is opposite, the most flexible track generates stationary solutions and the stiffer ones periodic solutions. Results 
Fig. 19 Co-ordinates of wheelsets and bogie frame of bogie of MKIII passenger car; $R=600 \mathrm{~m} ; h=0.15$ $\mathrm{m} ; v=54 \mathrm{~m} / \mathrm{s}$; $y_{i}(0)=0.0045 \mathrm{~m}$
Fig. 20 Co-ordinates of wheelsets and bogie frame of bogie of MKIII passenger car; $R=900 \mathrm{~m} ; h=0.10$ $\mathrm{m} ; v=30 \mathrm{~m} / \mathrm{s}$; $y_{i}(0)=0.0045 \mathrm{~m}$
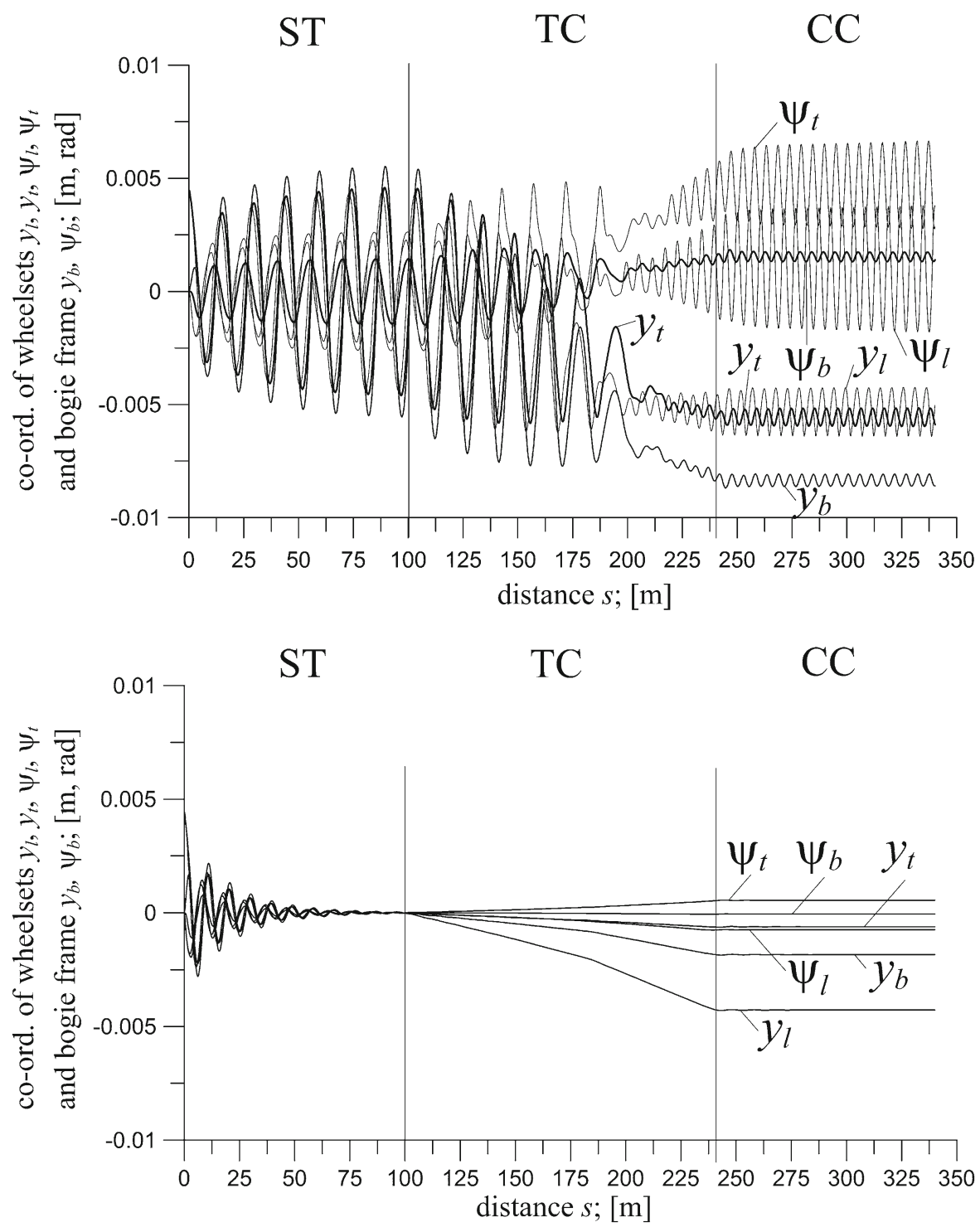

just discussed indicate that underestimated values of the model physical parameter $k_{t y}$ could lead to solutions misaligned with real system behaviour. They also reflect further authors activities in the range of their models and software verification.

Some contradiction to $k_{t y}$ variation described in the previous paragraph are results shown in Fig. 10, which represent lateral displacements $y_{b}$ and yaw angle $\psi_{b}$ of bogie frame. These results concern variation of lateral stiffness $k_{z y}$ in $25 \mathrm{TN}$ bogie suspension. The variation of this parameter has got significant influence on the results in ST, TC and CC. The solutions within the stiffness range from twice $(2 \times)$ to one hundred times
$(100 \times)$ bigger than nominal value $(1 \times)$ are quantitatively similar and just slightly different qualitatively, especially in CC. The solutions for stiffness raised above the nominal value are stationary in ST and CC. No vibrations occur in TC. The solution for the nominal value of $k_{z y}$ stiffness differs from them mostly. Here, the solutions have got a character of limit cycle in ST and CC, while one can observe vibrations in TC's initial part. Contrary to $k_{t y}$ variation it is inversely here, the most laterally flexible suspension generates periodic solutions while the stiffer ones stationary solutions. 
Fig. 21 Co-ordinates of wheelsets and bogie frame of bogie of MKIII passenger car; $R=900 \mathrm{~m} ; h=0.10$ $\mathrm{m} ; v=46 \mathrm{~m} / \mathrm{s}$; $y_{i}(0)=0.0045 \mathrm{~m}$
Fig. 22 Co-ordinates of wheelsets and bogie frame of bogie of MKIII passenger car; $R=900 \mathrm{~m} ; h=0.10$ $\mathrm{m} ; v=52 \mathrm{~m} / \mathrm{s}$; $y_{i}(0)=0.0045 \mathrm{~m}$
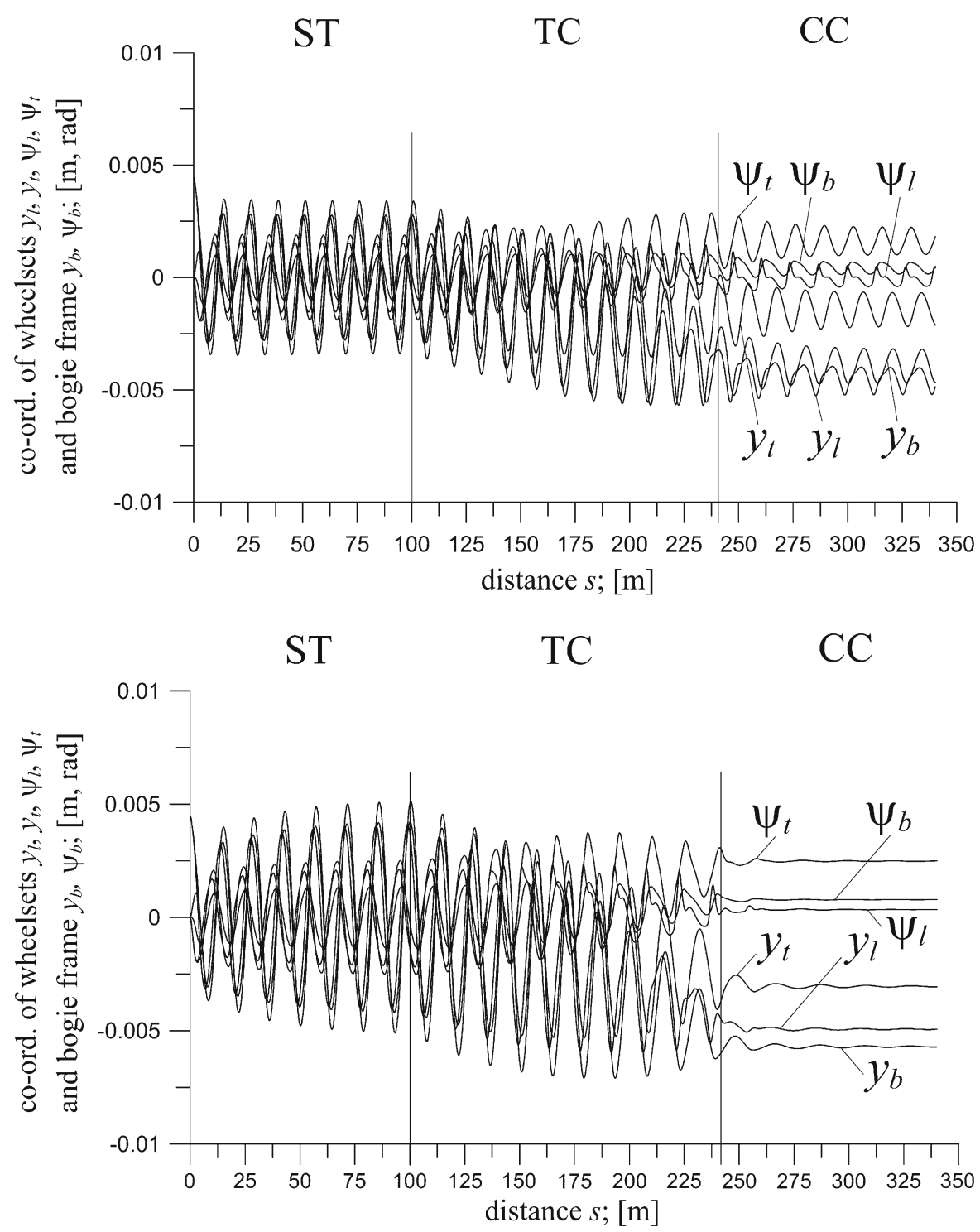

4.2 Results for bogie of average parameters

Selected results obtained for boogie of average parameters are presented in Figs. 11, 12, 13 and 14. The routes concerning these figures have got the following common parameters, namely length of ST $(l=100 \mathrm{~m})$, TC $(l=140 \mathrm{~m})$ and $\mathrm{CC}(l=100 \mathrm{~m})$, and nonzero initial conditions $y_{i}(0)=0.0045 \mathrm{~m}$. Figures 11,12 and 13 are obtained at velocity $v=54 \mathrm{~m} / \mathrm{s}$, while Fig. 14 at varying velocity. It is value of the integration procedure relative error $E$ that is subject to variation in Fig. 11, where $R=600 \mathrm{~m}$. The following values were adopted in the studies: $E=0.01,0.1$ and 0.4 . Figures 12 and
13 represent two different variants of curve radius $R$ in CC, where $R=600 \mathrm{~m}$ in Fig. 12 and $R=2000 \mathrm{~m}$ in Fig. 13. Values of superelevations $h$ corresponding to these $R$ are 0.15 and $0.045 \mathrm{~m}$. Figure 14 is obtained for $R=2000 \mathrm{~m}$ and $h=0.045 \mathrm{~m}$ as well as reduced value of longitudinal stiffness making $40 \%$ of the nominal value $k_{z x}=1046 \mathrm{kN} / \mathrm{m}(0.4 \times)$. Velocity variants taken are $v=30,35,40$ and $42 \mathrm{~m} / \mathrm{s}$.

Similar co-ordinates are shown in Figs. 11, 12 and 13; however, their set is limited in Fig. 11 to make this figure legible. Selected sets of the co-ordinates are $y_{t}, y_{b}, \psi_{t}$, and $\psi_{b}$ and $y_{l}, y_{t}, y_{b}, \psi_{l}, \psi_{t}$, and $\psi_{b}$ for 
Fig. 23 Co-ordinates of wheelsets and bogie frame of bogie of MKIII passenger car; $R=900 \mathrm{~m} ; h=0.10$ $\mathrm{m} ; v=54 \mathrm{~m} / \mathrm{s}$; $y_{i}(0)=0.0045 \mathrm{~m}$
Fig. 24 Co-ordinates of wheelsets and bogie frame of bogie of MKIII passenger car; $R=900 \mathrm{~m} ; h=0.10$ $\mathrm{m} ; v=70 \mathrm{~m} / \mathrm{s}$; $y_{i}(0)=0.0045 \mathrm{~m}$
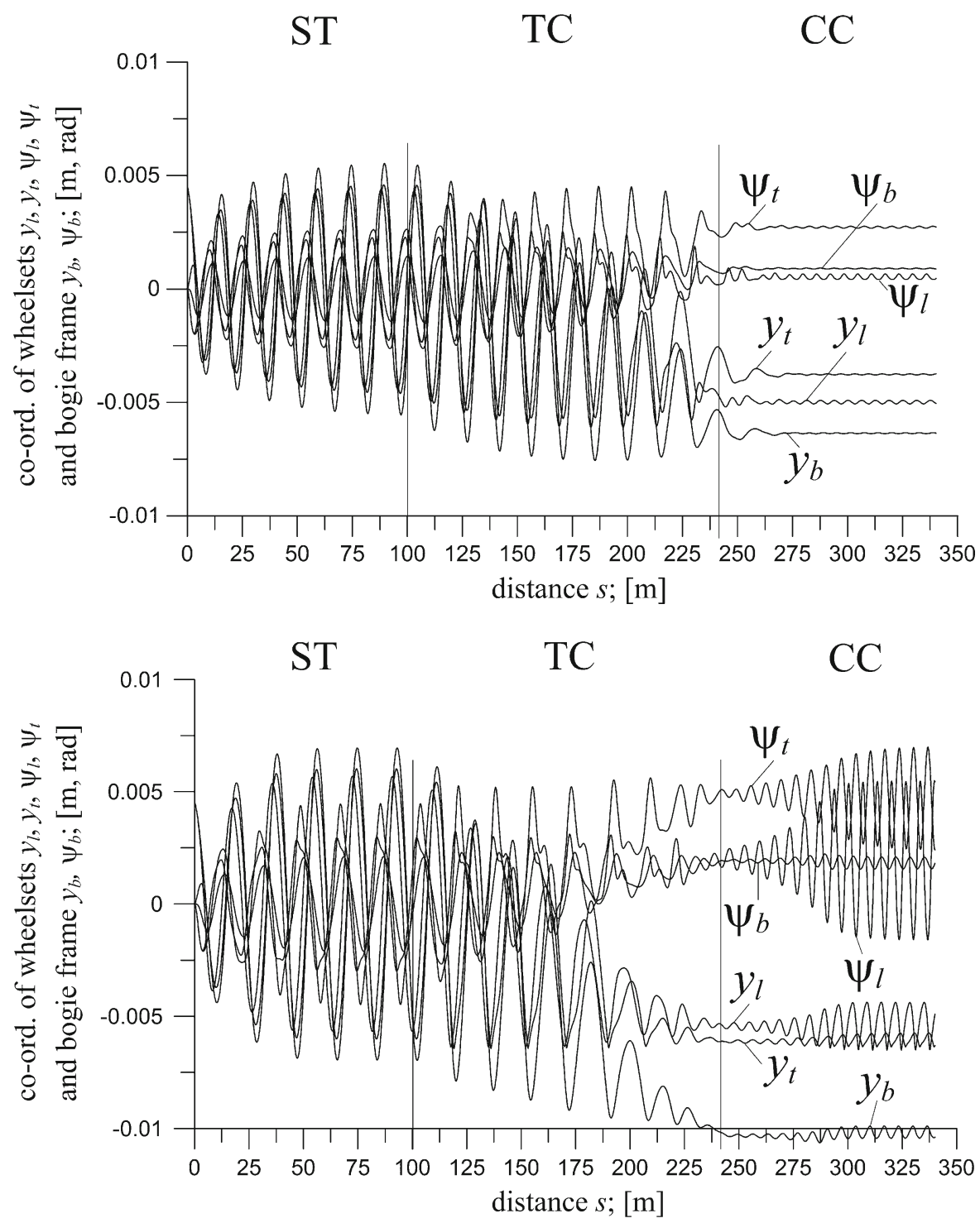

Figs. 11, 12 and 13, respectively. Representation of the co-ordinates in Fig. 14 is limited to $y_{l}$ only.

What makes Fig. 11 particularly interesting is change of the solution type from stationary to periodic (limit cycle) with drop of the admissible relative error $E$ of integration procedure. And so, for values $E=0.1$ and 0.4 there are no vibrations in the end part of TC, while in CC the solutions are stationary. On the other hand for $E=0.01$ vibrations are present within whole TC length, while in CC they take the form of limit cycle. This result reveals that unskilful adoption of $E$ value can lead not only to quantitative differences but also to serious qualitative errors in assessment of vehicle behaviour.

Quite intriguing result is that shown in Fig. 12 for $R=600 \mathrm{~m}$. Change of the solution character should be noted, which takes place in TC and then passes on to CC. One can observe that approximately in the middle of TC length the vibrations start to change not only the amplitude but also the frequency. It is untypical phenomenon because very often solutions in TC and $\mathrm{CC}$ are straight continuation of solution in ST for whole range of radii $R$ values. Here such continuation is result shown in Fig. 13 for $R=2000 \mathrm{~m}$. It can be explicitly 
Fig. 25 Co-ordinates of wheelsets and bogie frame of bogie of MKIII passenger car; $R=900 \mathrm{~m} ; h=0.10$ $\mathrm{m} ; v=83 \mathrm{~m} / \mathrm{s}$; $y_{i}(0)=0.0045 \mathrm{~m}$
Fig. 26 Co-ordinates of wheelset of bogie of MKIII passenger car; $R=600 \mathrm{~m}$; $h=0.15 \mathrm{~m} ; v=54 \mathrm{~m} / \mathrm{s}$; $y_{i}(0)=0.0045 \mathrm{~m} ; k_{z y}=$ $1308(1 \times), 5232(4 \times)$, $7848(6 \times) \mathrm{kN} / \mathrm{m}$
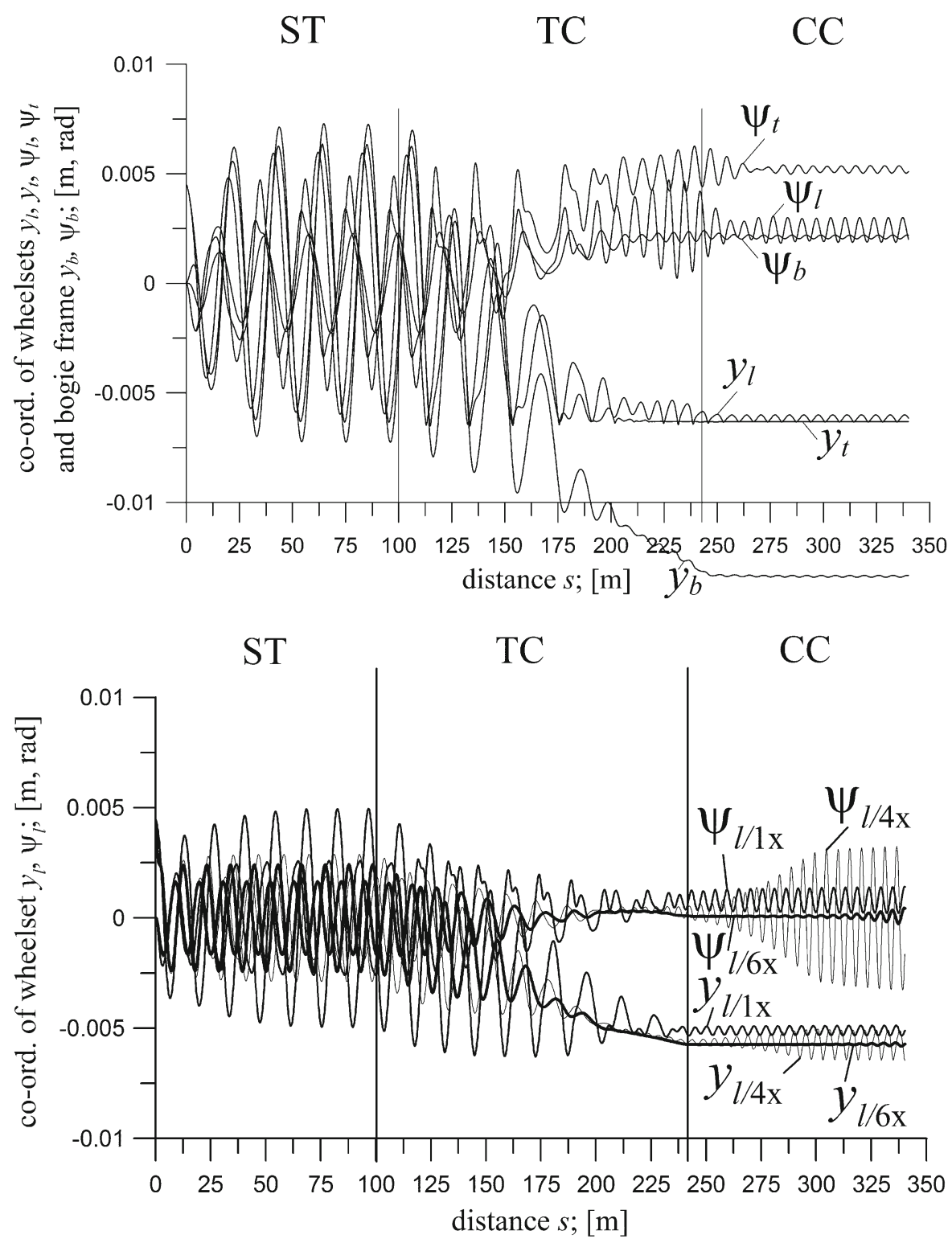

seen in this figure that change of the frequency in curve (TC and CC), if any, is difficult to notice.

In case of Fig. 14 two velocities, namely $v=30$ and $35 \mathrm{~m} / \mathrm{s}$ are smaller than critical velocity $v_{n}=39$ $\mathrm{m} / \mathrm{s}$, both in ST and CC of $R=1200 \mathrm{~m}$. Two remaining $v=40$ and $42 \mathrm{~m} / \mathrm{s}$ are bigger than $v_{n}$. The solutions for $v=30,35$ and $40 \mathrm{~m} / \mathrm{s}$ are typical. Thus the vibrations in case of solutions below critical velocity disappear or have tendency to disappear in ST and are absent (stationary solution) or of very small amplitude with tendency to disappear in CC. The solution for $v=40$ $\mathrm{m} / \mathrm{s}$ represents typical case of smooth passage through
TC from limit cycle in ST to limit cycle in CC. The vibration amplitudes for all three track sections ST, TC and CC are of similar magnitude. The case of $v=42$ $\mathrm{m} / \mathrm{s}$ focuses attention as it can be recognised as untypical. Untypical is fact that values of amplitudes in TC exceed amplitudes in ST and CC. Less untypical, however, still rare, is the fact that amplitudes in CC are significantly bigger than amplitudes in ST. One could suppose that the reason for both these untypical facts is reduced longitudinal stiffness $k_{z x}$ of bogie suspension. 
Fig. 27 Co-ordinates of wheelset of bogie of MKIII passenger car; $R=600 \mathrm{~m}$; $h=0.15 \mathrm{~m} ; v=54 \mathrm{~m} / \mathrm{s}$; $y_{i}(0)=0.0045 \mathrm{~m}$; $k_{z y}=784.8(0.6 \times)$; $1046.4(0.8 \times) \mathrm{kN} / \mathrm{m}$

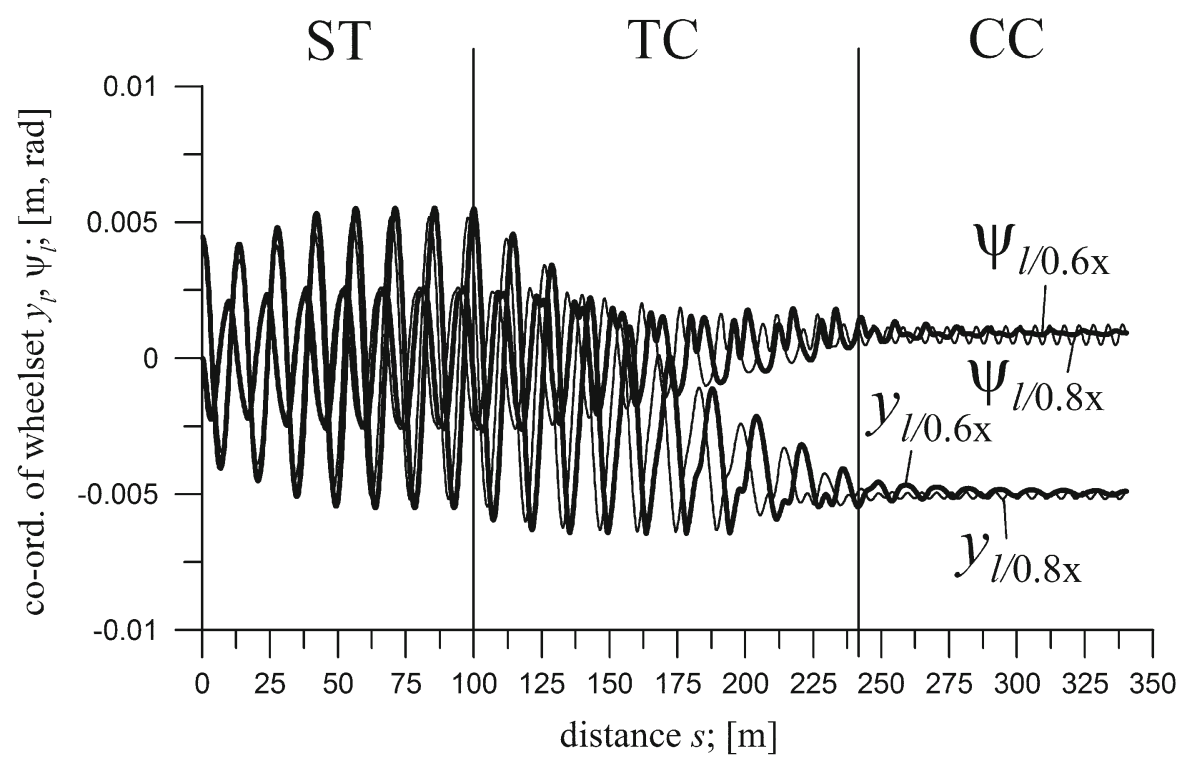

Fig. 28 Co-ordinates of wheelset of bogie of MKIII passenger car; $R=600 \mathrm{~m}$; $h=0.15 \mathrm{~m} ; v=54 \mathrm{~m} / \mathrm{s}$; $y_{i}(0)=0.0045 \mathrm{~m}$; $k_{z y}=261.6(0.2 \times)$; $523.2(0.4 \times) \mathrm{kN} / \mathrm{m}$

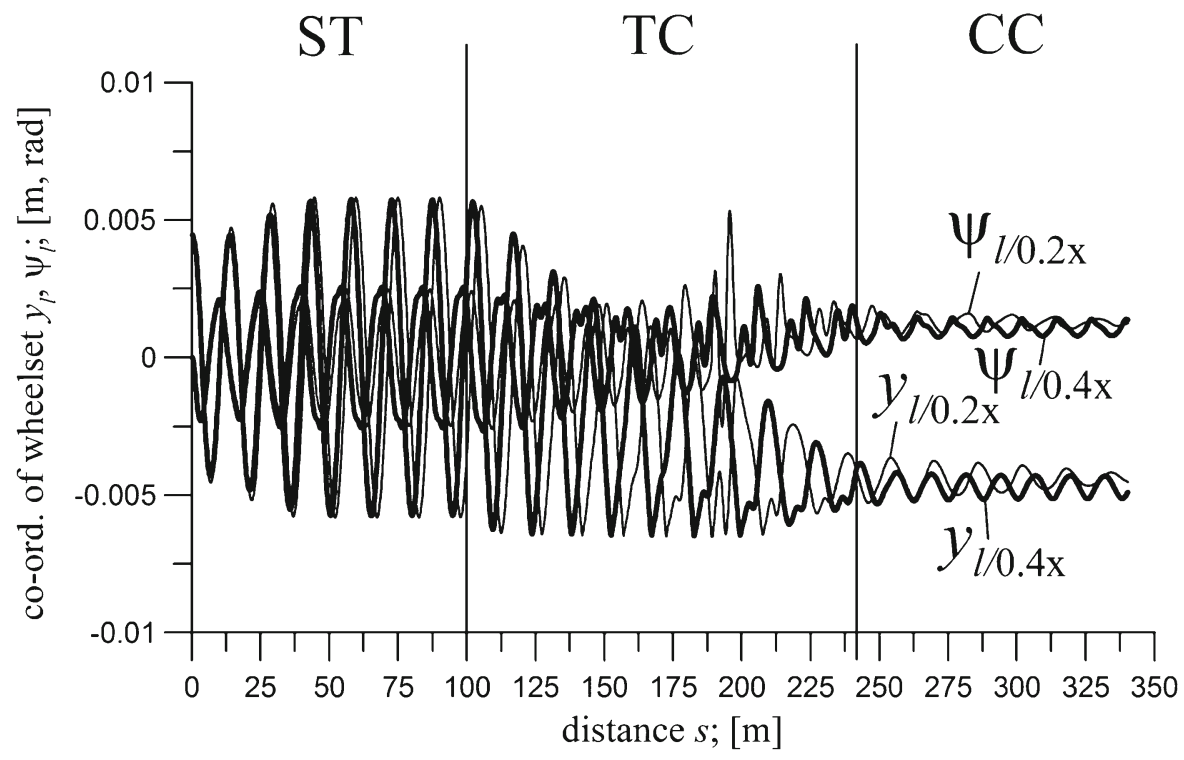

\subsection{Results for bogie of MKIII passenger car}

Results obtained for bogie of passenger car MKIII are presented in Figs. 15, 16, 17, 18, 19, 20, 21, 22, 23, 24 , $25,26,27$, and 28 . The routes in these figures have got the following common parameters, namely lengths of $\operatorname{ST}(l=100 \mathrm{~m}), \mathrm{TC}(l=140 \mathrm{~m})$ and CC $(l=100 \mathrm{~m})$, nonzero initial conditions $y_{i}(0)=0.0045 \mathrm{~m}$, increased lateral stiffness $k_{t y}=2,500,000 \mathrm{kN} / \mathrm{m}(100 \times)$ and lateral damping $c_{t y}=5000 \mathrm{kN} \mathrm{s} / \mathrm{m}(10 \times)$ of track. Besides, lateral damping of suspension was introduced $c_{z y}=56 \mathrm{kN} \cdot \mathrm{s} / \mathrm{m}$ and three times smaller value of sus- pension lateral stiffness $k_{z y}=1308 \mathrm{kN} / \mathrm{m}$ was adopted. This value was consequently used in the studies of bogie of MKIII car, that is why it was denoted as the nominal $(1 \times)$ one. Just described changes in track and suspension parameters were adopted from [29], results of which made the motivation to undertake the studies. It should be also stated that Figs. 15, 16, 17, 18, 19, $20,21,22,23,24$ and 25 were obtained for formally different contact parameters table than Figs. 26, 27 and 28. First of the tables is original one, while the second one was obtained with the newer software [50]. It was done in the same way and for the same reasons as in 
Fig. 29 Co-ordinates of wheelsets and car body of freight car of average parameters; $R=600 \mathrm{~m}$; $h=0.15 \mathrm{~m} ; v=41 \mathrm{~m} / \mathrm{s}$; $y_{i}(0)=0.0045 \mathrm{~m} ; E=0.4$
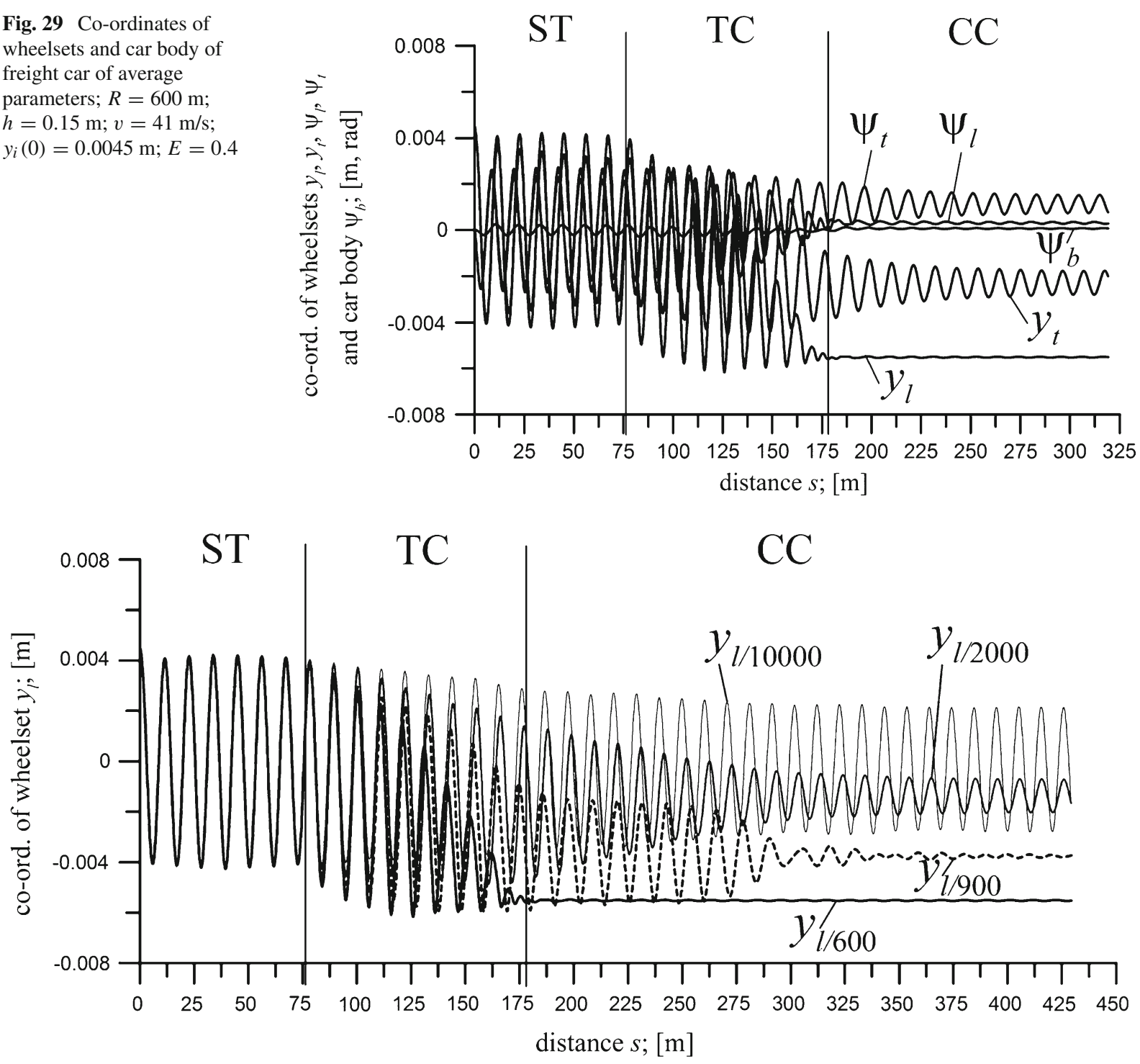

Fig. 30 Co-ordinate of wheelset of freight car of average parameters; $v=41 \mathrm{~m} / \mathrm{s} ; y_{i}(0)=0.0045 \mathrm{~m} ; R=600 \mathrm{~m}$ and $h=0.15 \mathrm{~m}$; $R=900 \mathrm{~m}$ and $h=0.10 \mathrm{~m} ; R=2000 \mathrm{~m}$ and $h=0.045 \mathrm{~m} ; R=1000 \mathrm{~m}$ and $h=0.009 \mathrm{~m} ; E=0.4$

Sect. 5.1 for $25 \mathrm{TN}$ bogie. Generally, results of bogie of MKIII car for both tables are very similar qualitatively; however, in CC some quantitative differences can be seen [2].

Figures 15 and 16 are obtained for radius $R=300$ $\mathrm{m}$ and $h=0.15 \mathrm{~m}$ and velocities $v=38$ and 52 $\mathrm{m} / \mathrm{s}$, respectively. On the other hand, Figs. 17 and 18 are obtained for $R=600 \mathrm{~m}$ and $h=0.15 \mathrm{~m}$ and, respectively, the same velocities. Figure 19 concerns the route where $R=600 \mathrm{~m}, h=0.15 \mathrm{~m}$ and $v=$ $54 \mathrm{~m} / \mathrm{s}$ and is of individual character. Figures 20, 21,
22, 23, 24 and 25 for $R=900 \mathrm{~m}$ and $h=0.10 \mathrm{~m}$ concern velocity $v$ variation, where $v=30 \mathrm{~m} / \mathrm{s}$ in Fig. 20, $v=46 \mathrm{~m} / \mathrm{s}$ in Fig. 21, $v=52 \mathrm{~m} / \mathrm{s}$ in Fig. 22 , $v=54 \mathrm{~m} / \mathrm{s}$ in Fig. 23, $v=70 \mathrm{~m} / \mathrm{s}$ in Fig. 24 and $v=83 \mathrm{~m} / \mathrm{s}$ in Fig. 25. Figures 26, 27 and 28 concern the route again, where $R=600 \mathrm{~m}, h=0.15 \mathrm{~m}$ and $v=54 \mathrm{~m} / \mathrm{s}$. This time suspension lateral stiffness $k_{z y}$ is subject to variation. Variants adopted in the studies are as follows: nominal $(1308 \mathrm{kN} / \mathrm{m}-1 \times)$ value, four times $(5232 \mathrm{kN} / \mathrm{m}-4 \times)$ and six times $(7848 \mathrm{kN} / \mathrm{m}-$ $6 \times)$ bigger than nominal value, represented in Fig. 26; 
Fig. 31 Co-ordinates of wheelsets of freight car of average parameters;

$R=600 \mathrm{~m} ; h=0.15 \mathrm{~m}$;

$v=44 \mathrm{~m} / \mathrm{s} ; y_{i}(0)=0.0045$

$\mathrm{m} ; c_{z x}=63 \mathrm{kN}$

$\mathrm{s} / \mathrm{m}(1.5 \times) ; c_{z y}=79.9 \mathrm{kN}$

$\mathrm{s} / \mathrm{m}(1.7 \times)$

$k_{z x}=800 \mathrm{kN} / \mathrm{m}(1 \times)$;

$k_{z y}=800 \mathrm{kN} / \mathrm{m}(1 \times)$;

$E=0.1$
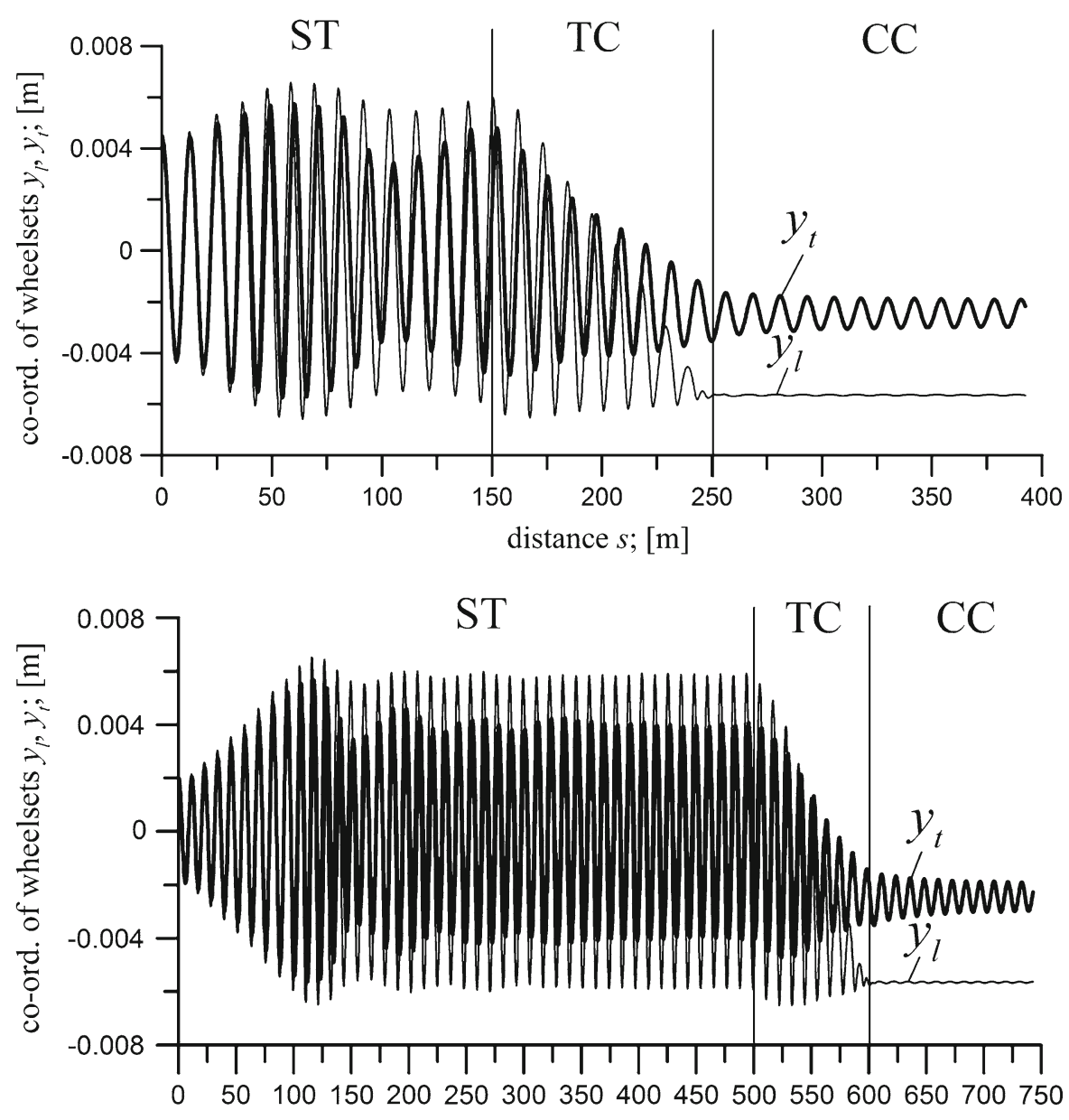

distance $s ;[\mathrm{m}]$
Fig. 32 Co-ordinates of wheelsets of freight car of average parameters;

$R=600 \mathrm{~m} ; h=0.15 \mathrm{~m}$; $v=44 \mathrm{~m} / \mathrm{s}$;

$y_{i}(0)=0.002 \mathrm{~m} ; c_{z x}=63$

$\mathrm{kN} \mathrm{s} / \mathrm{m}(1.5 \times) ; c_{z y}=79.9$

$\mathrm{kN} \mathrm{s} / \mathrm{m}(1.7 \times) ; k_{z x}=800$

$\mathrm{kN} / \mathrm{m}(1 \times) ; k_{z y}=800$

$\mathrm{kN} / \mathrm{m}(1 \times) ; E=0.1$ values making up $80 \%(1046.4 \mathrm{kN} / \mathrm{m}-0.8 \times)$ and $60 \%$ $(784.8 \mathrm{kN} / \mathrm{m}-0.6 \times)$ of the nominal value, represented in Fig. 27; and making up 40\% (523.2 kN/m - 0.4×) and $20 \%(261.6 \mathrm{kN} / \mathrm{m}-0.2 \times)$ of the nominal value, represented in Fig. 28.

Figures 15 and 16 include the case so intriguing that to some people it could seem unlikely. The most interesting elements occur in TC, where one deals with single (Fig. 15) and double (Fig. 16) changes of the solution character. Besides, in Fig. 15 second change of the solution character happens just after the entrance into CC. First of the changes consists in change of frequencies and amplitudes for higher and smaller than in ST and at TC beginning, respectively. Second of the changes consists in vibrations disappearance and switch to stationary solutions in CC. Despite the untypical nature of solutions in Figs. 15 and 16 their explanation turned out to be rather easy. It can be seen that scope of the vibrations of higher frequency is located more or less in surroundings of TC half length. So one can conclude, that vibrations appear for curve curvature $k$ and radius $R$ corresponding to half of TC length. Their values in that point for $3 \mathrm{rd}$ degree parabolic TC are $k=0.5 \cdot(1 / R)=0.5 / 300=0.0016(6) 1 / \mathrm{m}$ and $R=1 / k=1 / 0.0016(6)=600 \mathrm{~m}$, respectively. Based on that, one can suppose that higher frequency vibrations in TC could be related to solutions in $\mathrm{CC}$ for $R=600 \mathrm{~m}$ and its vicinity. Indeed, Figs. 17 and 18 for $R=600 \mathrm{~m}$ reveal existence of vibrations in CC of frequency higher and amplitudes smaller than it is in ST. Additional feature of them is fact that they exist in both TC and CC at velocities below (Figs. 15, 17) and above (Figs. 16, 18) critical velocity in ST $v_{n}=45.9 \mathrm{~m} / \mathrm{s}$. The confirmation is tendency of vibrations to decay in ST in Figs. 15 and 17 and slight increase in vibration amplitudes in ST in Figs. 16 and 18. Concluding result in 


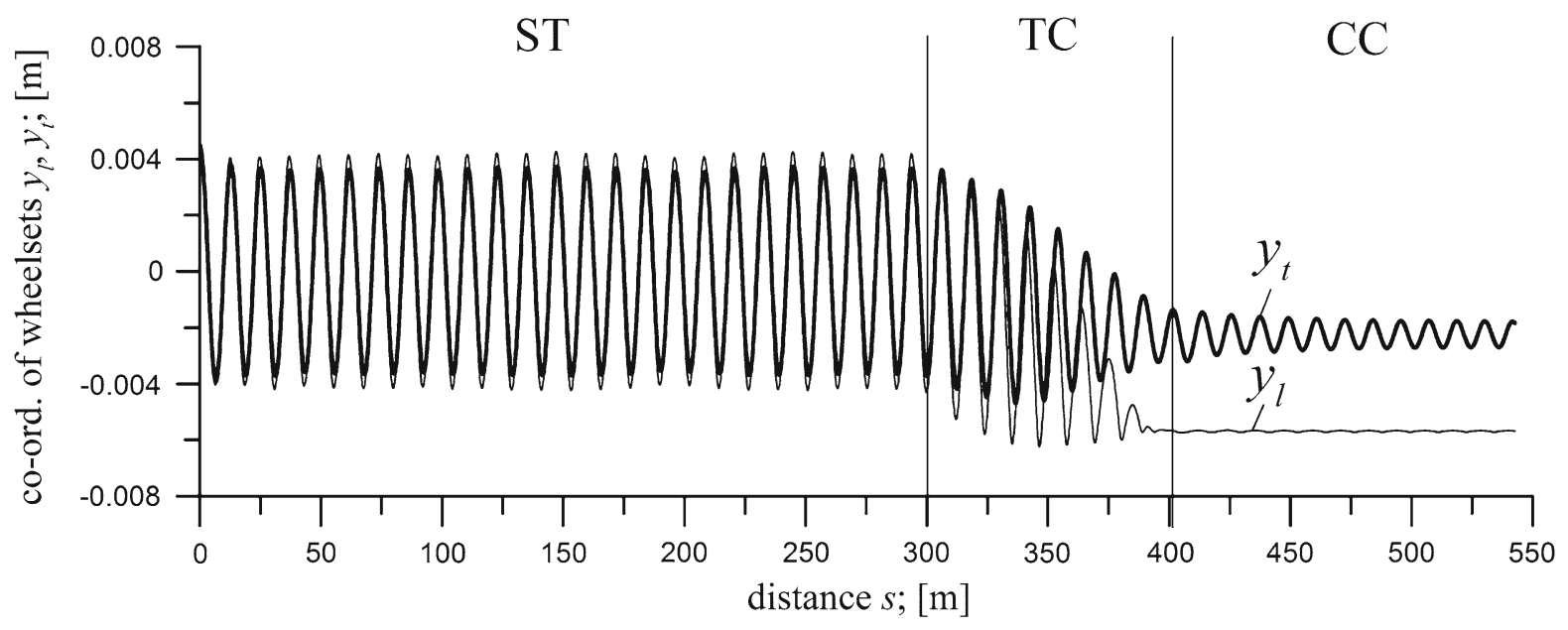

Fig. 33 Co-ordinates of wheelsets of freight car of average parameters; $R=600 \mathrm{~m} ; h=0.15 \mathrm{~m} ; v=44 \mathrm{~m} / \mathrm{s} ; y_{i}(0)=0.0045 \mathrm{~m}$; $c_{z x}=71.4 \mathrm{kN} \mathrm{s} / \mathrm{m}(1.7 \times) ; c_{z y}=70.5 \mathrm{kN} \mathrm{s} / \mathrm{m}(1.5 \times) ; k_{z x}=960 \mathrm{kN} / \mathrm{m}(1.2 \times) ; k_{z y}=800 \mathrm{kN} / \mathrm{m}(1 \times) ; E=0.1$

Fig. 34 Co-ordinates of wheelsets of hsfv1 freight car; $R=600 \mathrm{~m} ; h=0.15$ $\mathrm{m} ; v=45.3 \mathrm{~m} / \mathrm{s}$ $y_{i}(0)=0.0045 \mathrm{~m}$; $k_{z x}=20.67 \mathrm{kN} / \mathrm{m}(0.01 \times)$; $E=0.01$

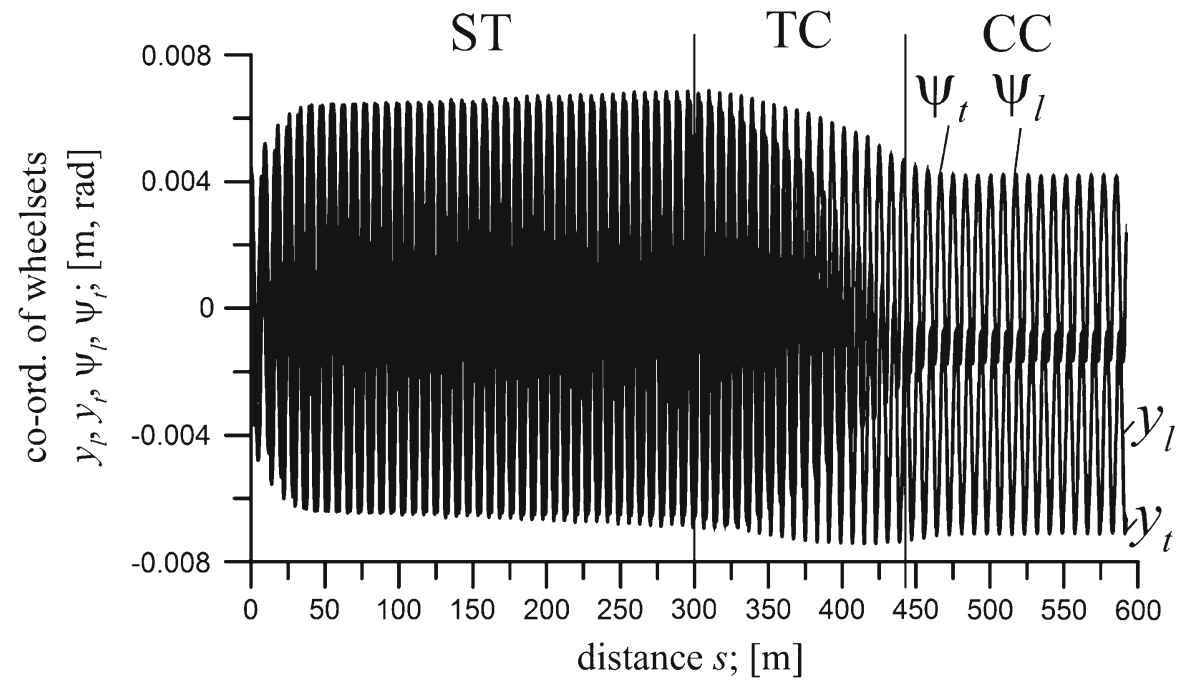

bigger by $2 \mathrm{~m} / \mathrm{s}$. Remaining parameters of the route are identical for both figures.

Figures 20, 21, 22, 23, 24 and 25 representing variation of velocity $v$ in the range from 30 to $83 \mathrm{~m} / \mathrm{s}$ for $R=900$ m reveal next untypical behaviour cases of MKIII car bogie in curved track. Behaviours in ST can be counted to typical, i.e. vibrations decay below critical velocity in ST $v_{n}=45.3 \mathrm{~m} / \mathrm{s}$ (Fig. 20), whereas above $v_{n}$ the amplitudes grow with increase in velocity $v$ (Figs. 21, 22, 23, 24 and 25). In TC and $v$ below $v_{n}$ in ST (Fig. 20), there are no vibrations and solutions make smooth passage between solutions for ST and CC. For $v$ above $v_{n}$ solutions in TC have got twofold character. First type of solutions (Figs. 21, 22 and 23) consists 
Fig. 35 Co-ordinates of wheelsets of hsfv1 freight car; $R=600 \mathrm{~m} ; h=0.15$ $\mathrm{m} ; v=45.3 \mathrm{~m} / \mathrm{s}$; $y_{i}(0)=0.0045 \mathrm{~m}$; $k_{z x}=206.7 \mathrm{kN} / \mathrm{m}(0.1 \times)$; $E=0.01$
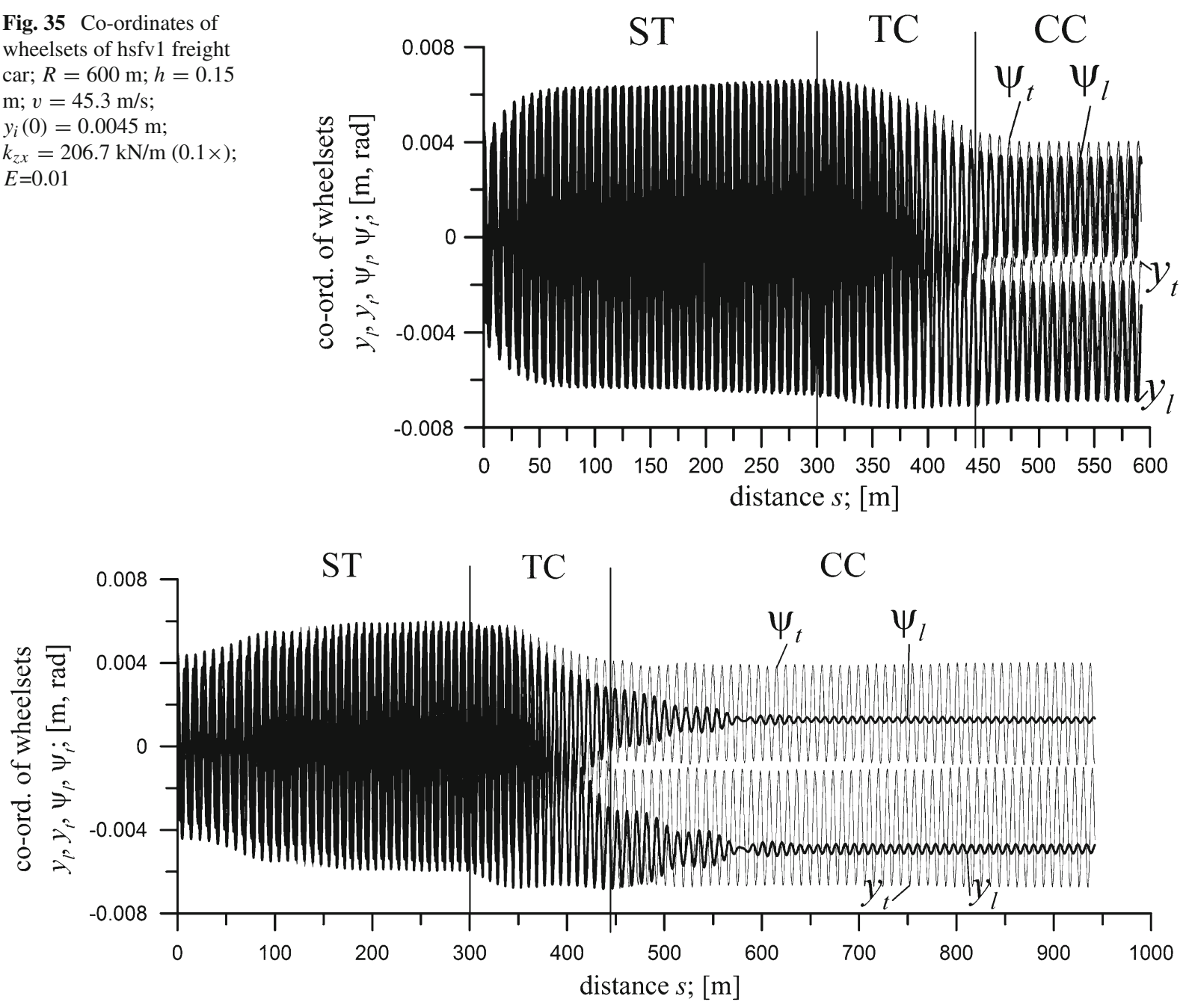

Fig. 36 Co-ordinates of wheelsets of hsfv1 freight car; $R=600 \mathrm{~m} ; h=0.15 \mathrm{~m} ; v=45.3 \mathrm{~m} / \mathrm{s} ; y_{i}(0)=0.0045 \mathrm{~m} ; k_{z x}=$ $413.4 \mathrm{kN} / \mathrm{m}(0.2 \times) ; E=0.01$

in fluent continuation of vibrations in ST within whole length of TC. Second type of solutions (Figs. 24, 25) consists in change of solution character in the middle part of TC. The initial vibrations being continuation of solutions in ST have got tendency to decay first and then to revive, however, with higher frequency and smaller amplitudes. Solutions for CC can be recognised as quite untypical. The influence of velocity $v$ increase on the solutions remains entirely ambiguous and impossible to predict. Solutions in Fig. 20 for $v=30 \mathrm{~m} / \mathrm{s}$ are stationary in CC. In Fig. 21 for $v=46 \mathrm{~m} / \mathrm{s}$ vibrations of moderate amplitudes appear in CC. Solutions in Fig. 22 for $v=52 \mathrm{~m} / \mathrm{s}$ are again stationary in CC. In Fig. 23 for $v=54 \mathrm{~m} / \mathrm{s}$ solutions in CC are stationary for trailing wheelset and bogie frame, whereas for the leading wheelset they exhibit tendency to vibrations; however, amplitude values are negligibly small. The evident vibrations appear in Fig. 24 for $v=70 \mathrm{~m} / \mathrm{s}$ in $\mathrm{CC}$, with amplitude values for the trailing wheelset being significant. In Fig. 25 for $v=83 \mathrm{~m} / \mathrm{s}$, vibrations in CC still exist; however, amplitudes are very small and this time bigger for the leading wheelset but not the trailing one. Lack of any systematic influence of velocity $v$ increase on the behaviour in $\mathrm{CC}$ is here evident.

Figures 26, 27 and 28 concern variation of bogie suspension lateral stiffness $k_{z y}$. In Fig. 26, results are presented for nominal value $(1 \times)$ as well as values 
Fig. 37 Co-ordinates of wheelsets of hsfv1 freight car; $R=600 \mathrm{~m} ; h=0.15$ $\mathrm{m} ; v=45.3 \mathrm{~m} / \mathrm{s}$; $y_{i}(0)=0.0045 \mathrm{~m}$; $k_{z x}=2067 \mathrm{kN} / \mathrm{m}(1 \times)$; $E=0.01$
Fig. 38 Co-ordinates of wheelsets of hsfv1 freight car; $R=600 \mathrm{~m} ; h=0.15$ $\mathrm{m} ; v=45.3 \mathrm{~m} / \mathrm{s}$ $y_{i}(0)=0.0045 \mathrm{~m}$; $k_{z x}=41,340 \mathrm{kN} / \mathrm{m}(20 \times)$; $E=0.01$
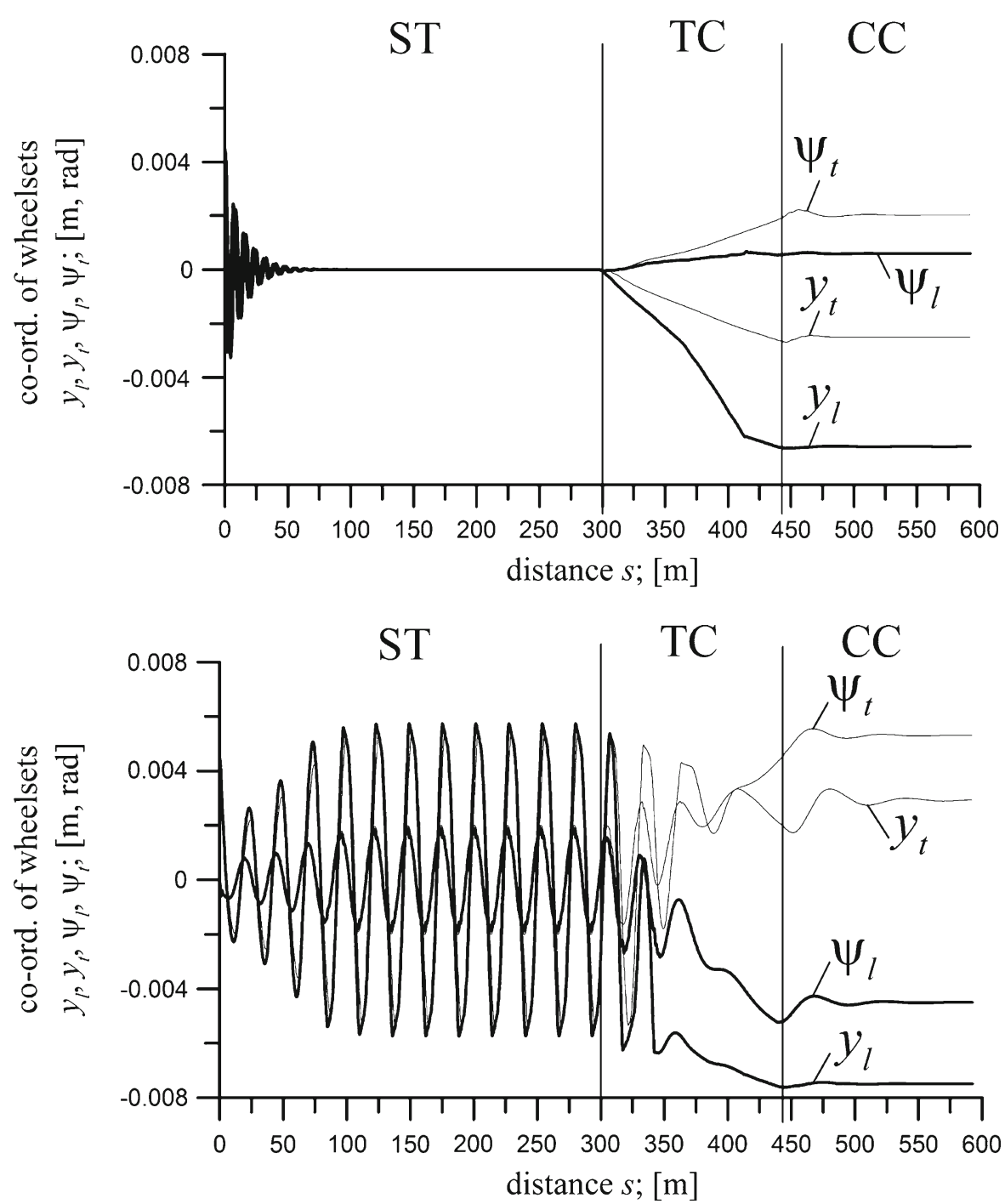

four times $(4 \times)$ and six times $(6 \times)$ bigger than nominal value. In Fig. 27, results are presented for stiffness values $k_{z y}$ making $80 \%(0.8 \times)$ and $60 \%(0.6 \times)$ of the nominal value, while in Fig. 28 making $40 \%$ $(0.4 \times)$ and $20 \%(0.2 \times)$ of the nominal value. Comparing results for ST in all three figures, where results for the leading wheelset are represented, one can observe that the smaller value of stiffness $k_{z y}$ the bigger amplitudes of lateral displacements $y_{l}$ in ST. This means that the amplitudes of $y_{l}$ are smallest for the case of stiffness making $20 \%(0.2 \times)$ (Fig. 28) of nominal value and the highest for the case of stiffness six times $(6 \times)$ (Fig. 26) bigger than the nominal value. This feature is not observed for the yaw angle $\psi_{l}$ of leading wheelset. Similar properties can be observed for the correspond- ing co-ordinates $y_{t}$ and $\psi_{t}$ (not shown here) of the trailing wheelset. As concerns behaviours in TC, all the courses in discussed Figs. 26, 27 and 28 can be characterised jointly as those representing fluent passage between solutions in ST and CC. The solutions in CC are not so uniform as those in TC. It is necessary to differentiate lower values of stiffness, i.e. $(0.2 \times) ;(0.4 \times)$ and $(0.6 \times)$ from higher ones, i.e. $(0.8 \times) ;(1 \times) ;(4 \times)$ and $(6 \times)$. For the lower stiffness values solutions in $\mathrm{CC}$ look like direct continuation of solutions in ST and TC. So, vibration frequencies are close to each other and are not subject to sudden changes. The amplitudes in CC are small comparing to those in ST and TC; however, the smaller $k_{z y}$ the bigger amplitude. For the higher stiffness values solutions in CC represent frequencies 
Fig. 39 Co-ordinates of wheelsets of hsfv1 freight car; $R=600 \mathrm{~m} ; h=0.15$ $\mathrm{m} ; v=45.3 \mathrm{~m} / \mathrm{s}$;

$y_{i}(0)=0.0045 \mathrm{~m} ; k_{z x}=$ $2,067,000 \mathrm{kN} / \mathrm{m}(1000 \times)$; $E=0.01$

Fig. 40 Co-ordinate of car body of hsfv1 freight car; $R=600 \mathrm{~m} ; h=0.15 \mathrm{~m}$; $v=20 ; 24 ; 25 ; 28 ; 45.3$ and $49 \mathrm{~m} / \mathrm{s} ; y_{i}(0)=0.0045$ $\mathrm{m} ; k_{z x}=206.7 \mathrm{kN} / \mathrm{m}$ $(0.1 \times) ; k_{z y}=3448 \mathrm{kN} / \mathrm{m}$ $(8 \times) ; E=0.01$
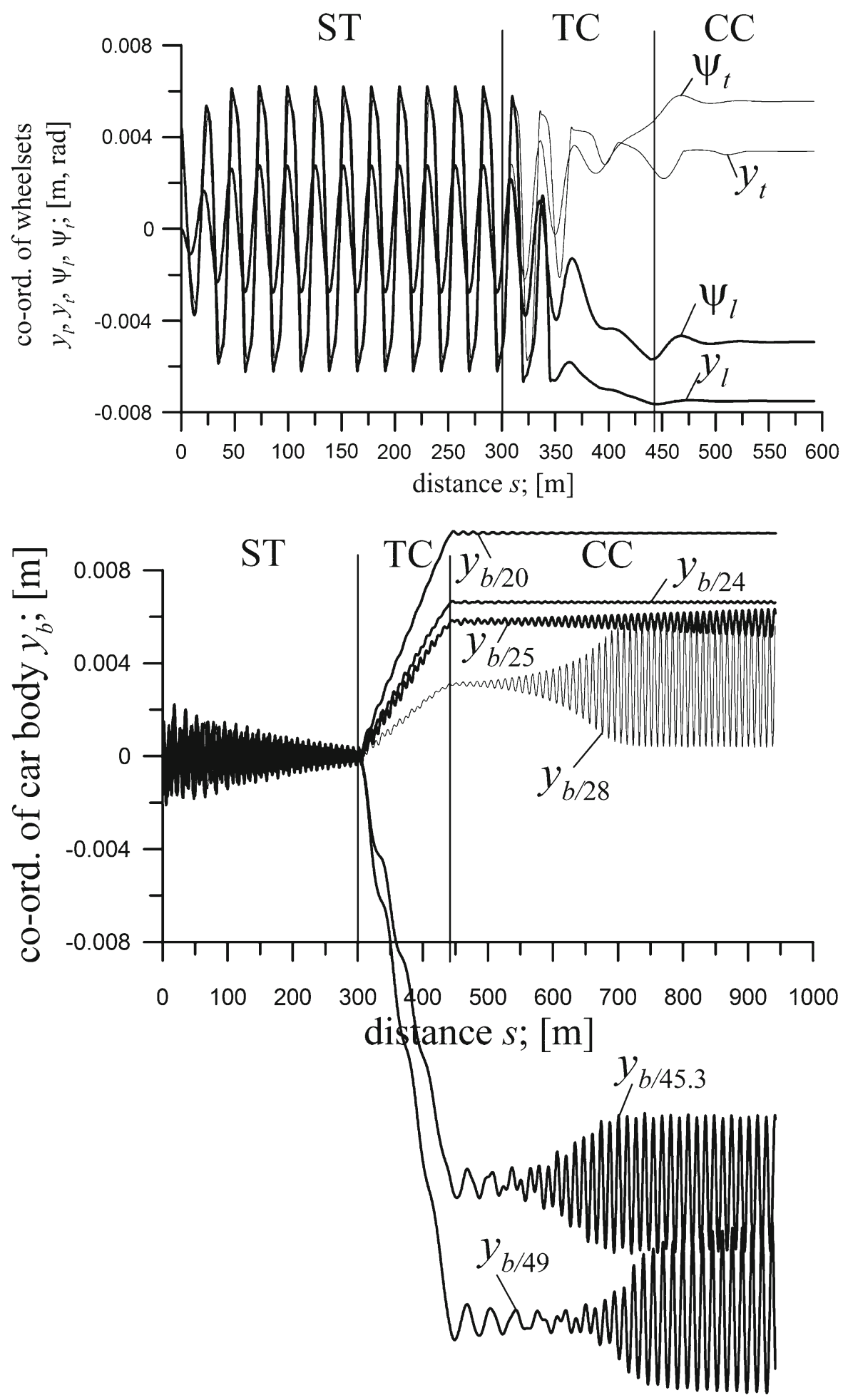
distinctly higher than in ST and TC. Vibration amplitudes grow with growth of the stiffness, from very small for $k_{z y}$ making $80 \%$ of the nominal value $(0.8 \times)$ to comparable with those in ST and TC for $k_{z y}$ four- $(4 \times)$ and six $(6 \times)$ times bigger than nominal value. This last case requires individual comment. Namely, at the end of the course of co-ordinate $\psi_{p}$, and less clearly of coordinate $y_{p}$, vibrations revive can be seen (Fig. 26). The results for longer CC section, not shown here, reveal that these vibrations expand to limit cycles of the amplitude even bigger than in case denoted $4 \times$. Concluding, one can see that both decrease and increase in suspension lateral stiffness $k_{z y}$ relative to values making $60 \%$ $(0.6 \times)$ and $80 \%(0.8 \times)$, respectively, lead to bigger vibration amplitudes in $\mathrm{CC}$, what could be counted as surprising to some extent.

\section{Results of simulations for 2-axle freight cars}

\subsection{Results for unloaded freight car of average parameters}

Results obtained for the freight car of average parameters are shown in Figs. 29, 30, 31, 32 and 33. The routes in Figs. 29 and 30 have got the following common parameters ST $(l=76.6 \mathrm{~m})$, TC $(l=102.4$ $\mathrm{m})$, velocity $v=41 \mathrm{~m} / \mathrm{s}$, nonzero initial conditions $y_{i}(0)=0.0045 \mathrm{~m}$, and maximum admissible relative error of integration procedure $E=0.4$. The difference between both figures (routes) concerns $\mathrm{CC}$ length ( $l=140$ and $250 \mathrm{~m}$, respectively). In addition, majority of the car co-ordinates is presented in Fig. 29 that concerns $R=600 \mathrm{~m}$ and $h=0.15 \mathrm{~m}$, while in Fig. 30 radii $R$ were subject to variation and just the leading wheelset lateral displacements were presented. The radii variants adopted in Fig. 30 were as follows: $R=600,900,2000$ and $10,000 \mathrm{~m}$, while corresponding superelevations were: $h=0.15,0.10,0.045$ and $0.009 \mathrm{~m}$. The routes in Figs. 31, 32 and 33 have got the following common parameters, namely TC $(l=102.4$ $\mathrm{m}), \mathrm{CC}(l=140 \mathrm{~m}), R=600 \mathrm{~m}, h=0.15 \mathrm{~m}, v=44$ $\mathrm{m} / \mathrm{s}$ and $E=0.1$. In addition, the same quantities are presented in Figs. 31, 32 and 33, namely the leading wheelset lateral displacements. Difference between these figures concerns ST length $(l=150,500$ and 300 $\mathrm{m}$, respectively). Besides, nonzero initial conditions in Figs. 31 and 33 are $y_{i}(0)=0.0045 \mathrm{~m}$, while in Fig. 32 are $y_{i}(0)=0.002 \mathrm{~m}$. Parameters of the suspension are changed in Figs. 31, 32 and 33, comparing to the nominal values. The changed values are longitudinal damping $c_{z x}=63 \mathrm{kN} \mathrm{s} / \mathrm{m}(1.5 \times)$ and lateral damping $c_{z y}=79.9 \mathrm{kN} \cdot \mathrm{s} / \mathrm{m}(1.7 \times)$ in Figs. 31 and 32 . The changed values are longitudinal stiffness $k_{z x}=960$ $\mathrm{kN} / \mathrm{m}(1.2 \times)$ as well as longitudinal $c_{z x}=71.4 \mathrm{kN} \mathrm{s} / \mathrm{m}$ $(1.7 \times)$ and lateral $c_{z y}=70.5 \mathrm{kN} \mathrm{s} / \mathrm{m}(1.5 \times)$ damping in Fig. 33.

Motivation to study these results dipper is Fig. 29, where lateral displacements $y_{l}$ and $y_{t}$, yaw rotations of wheelsets $\psi_{p}$ and $\psi_{k}$, and car body yaw rotation $\psi_{b}$ are represented. This result was published in [29] for the first time. It shows interesting case where limit cycle for the trailing wheelset exists only, while solution for the leading wheelset is quasi-stationary one. The term quasi is used due to existence of regular perturbation of the leading wheelset stationary solution of very small amplitude. This perturbation almost for sure arises from the coupling between both wheelsets through the car body but not from self-exciting vibrations of the leading wheelset. This phenomenon is particularly interesting as the leading wheelset is subject to vibrations of self-exciting nature in ST and TC, i.e. limit cycle and decreasing vibrations exist in those sections, similarly to the trailing wheelset.

Leading wheelset lateral displacements $y_{p}$ are shown in Fig. 30, where curve radii $R$ were subject to variation. This figure shows that phenomenon of disappearance of leading wheelset vibrations in CC, shown in Fig. 29, has got wider range and is not limited to $R=600 \mathrm{~m}$ only. Result shown in Fig. 30 for $R=900 \mathrm{~m}$ and not shown result for $R=1200 \mathrm{~m}$ reveal that also for these radii self-exciting vibrations of the leading wheelset disappear. Solutions of the leading wheelset in CC start to have limit cycle character from $R=2000 \mathrm{~m}$. It is confirmed with the shown results for $R=2000$ and 10,000 as well as not shown results for $R=3000$, 4000 and $6000 \mathrm{~m}$.

Lateral displacements $y_{l}$ and $y_{t}$ of both wheelsets shown in Fig. 31 (as well as not shown linear $y_{b}$ as well as angular $\psi_{p}, \psi_{k}$ and $\psi_{b}$ co-ordinates) reveal that above some velocity ( $v=42 \mathrm{~m} / \mathrm{s}$, here) car studied here possesses behaviour in ST that seemingly remains beat like course. It concerns both wheelsets and to a lesser extent not shown car body result. Similar behaviours were also obtained for many configurations of suspension stiffness and dumping values other than in Fig. 31, including nominal values of $k_{z x}, k_{z y}, c_{z x}$ and $c_{z y}$, i.e. the same as in Figs. 29 and 30. 
Fig. 41 Co-ordinate of wheelset of hsfv1 freight car on ST section;

$v=20 ; 24 ; 25 ; 28$ and $45.3 \mathrm{~m} / \mathrm{s} ; y_{i}(0)=0.0045$; $k_{z x}=206.7 \mathrm{kN} / \mathrm{m}(0.1 \times)$; $k_{z y}=3448 \mathrm{kN} / \mathrm{m}(8 \times)$; $E=0.01$

Fig. 42 Co-ordinates of wheelset of hsfv1 freight car; $R=300,600,750,2000$ and $6000 \mathrm{~m}$;

$h=0.15 ; 0.15 ; 0.12 ; 0.045$ and $0.015 \mathrm{~m} ; v=45.3 \mathrm{~m} / \mathrm{s}$; $y_{i}(0)=0.0045$;

$k_{z x}=206.7 \mathrm{kN} / \mathrm{m}(0.1 \times)$; $k_{z y}=3448 \mathrm{kN} / \mathrm{m}(8 \times)$; $E=0.01$

Fig. 43 Co-ordinates of wheelsets and bogie frames of passenger car MKIII; $R=4000 \mathrm{~m} ; h=0.03 \mathrm{~m}$; $v=20 \mathrm{~m} / \mathrm{s} ; y_{j}(0)=0 \mathrm{~m}$
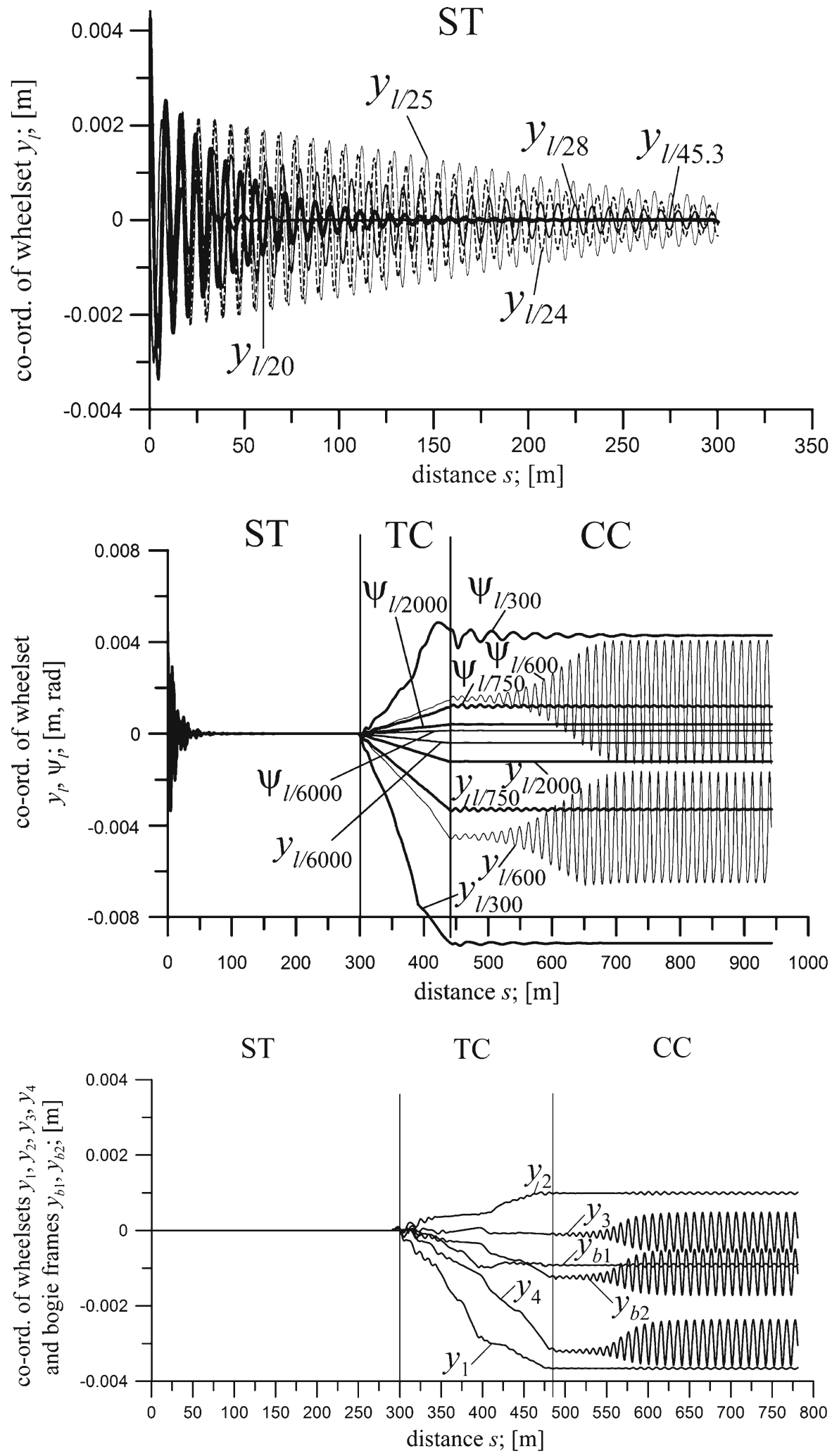


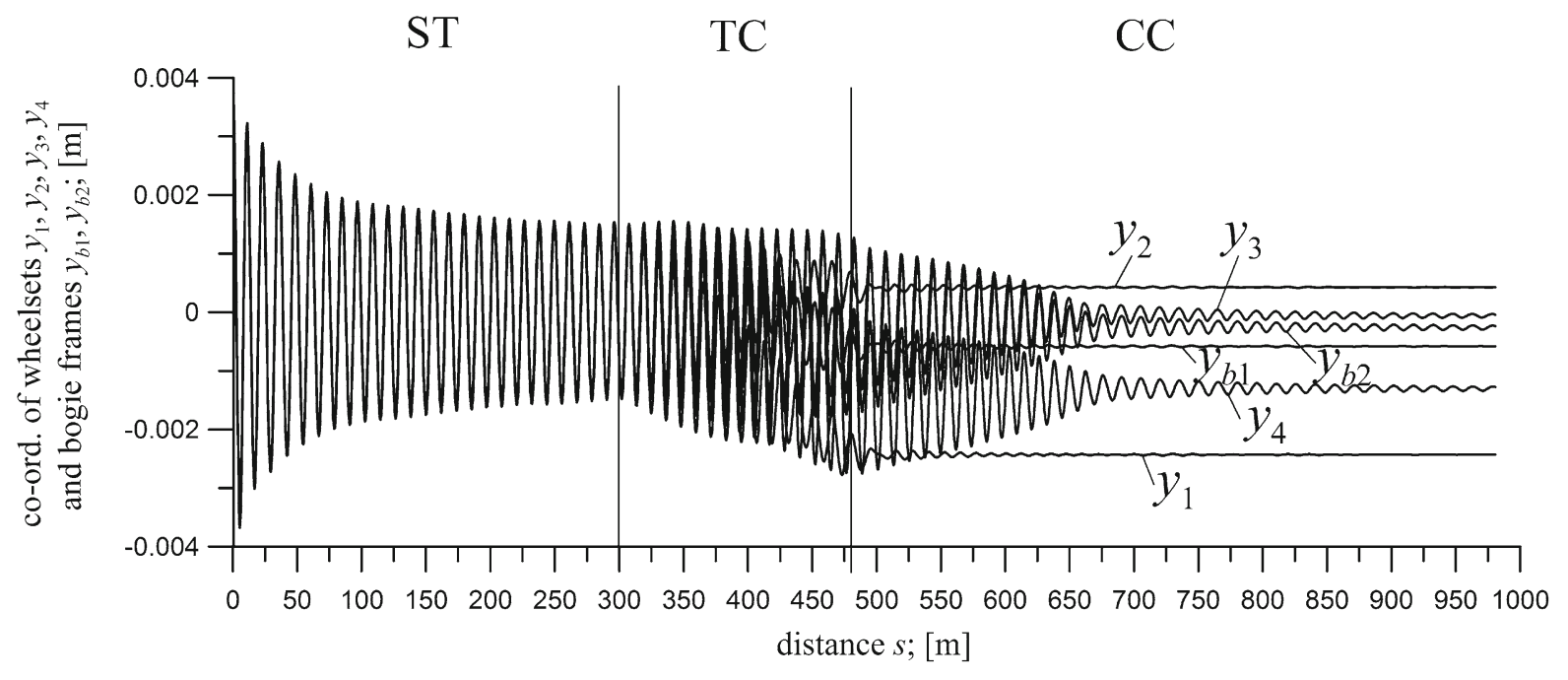

Fig. 44 Co-ordinates of wheelsets and bogie frames of passenger car MKIII; $R=4000 \mathrm{~m} ; h=0.03 \mathrm{~m} ; v=20 \mathrm{~m} / \mathrm{s} ; y_{j}(0)=0.004 \mathrm{~m}$

Fig. 45 Co-ordinates of wheelsets and bogie frame of passenger car MKIII; $R=6000 \mathrm{~m} ; h=0.015 \mathrm{~m}$; $v=20 \mathrm{~m} / \mathrm{s}$; $y_{j}(0)=0.006 \mathrm{~m}$

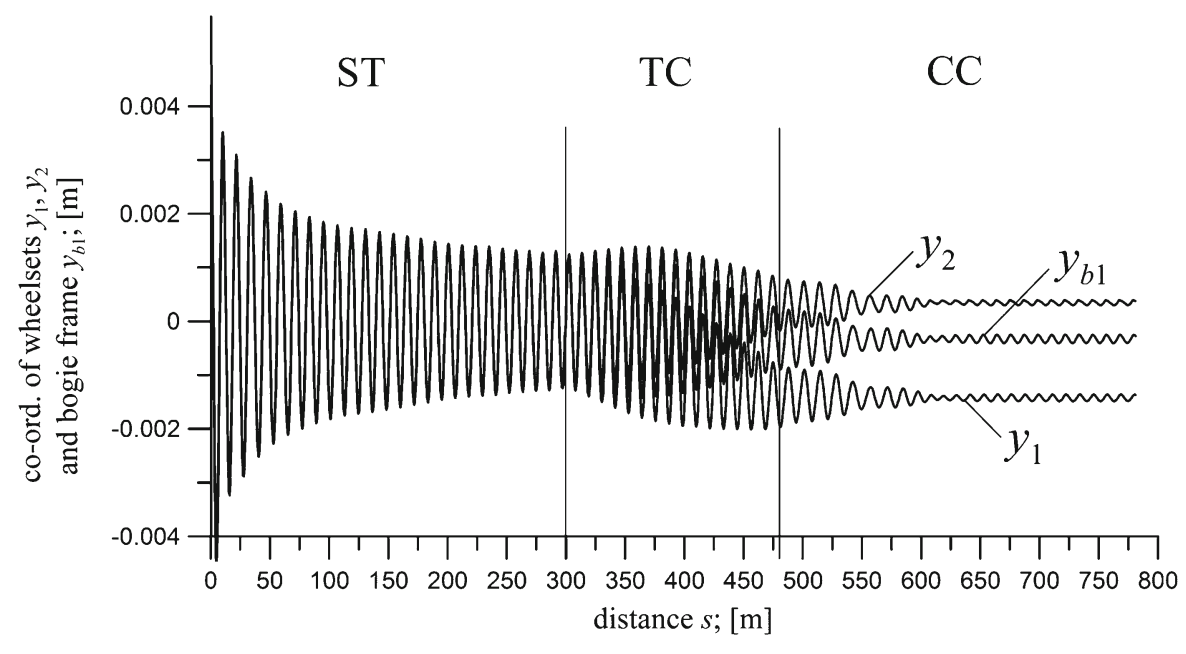

Fig. 46 Co-ordinate of wheelset of passenger car MKIII; $R=6000 \mathrm{~m}$; $h=0.015 \mathrm{~m} ; v=20 \mathrm{~m} / \mathrm{s}$; $y_{j}(0)=0.006 \mathrm{~m}$

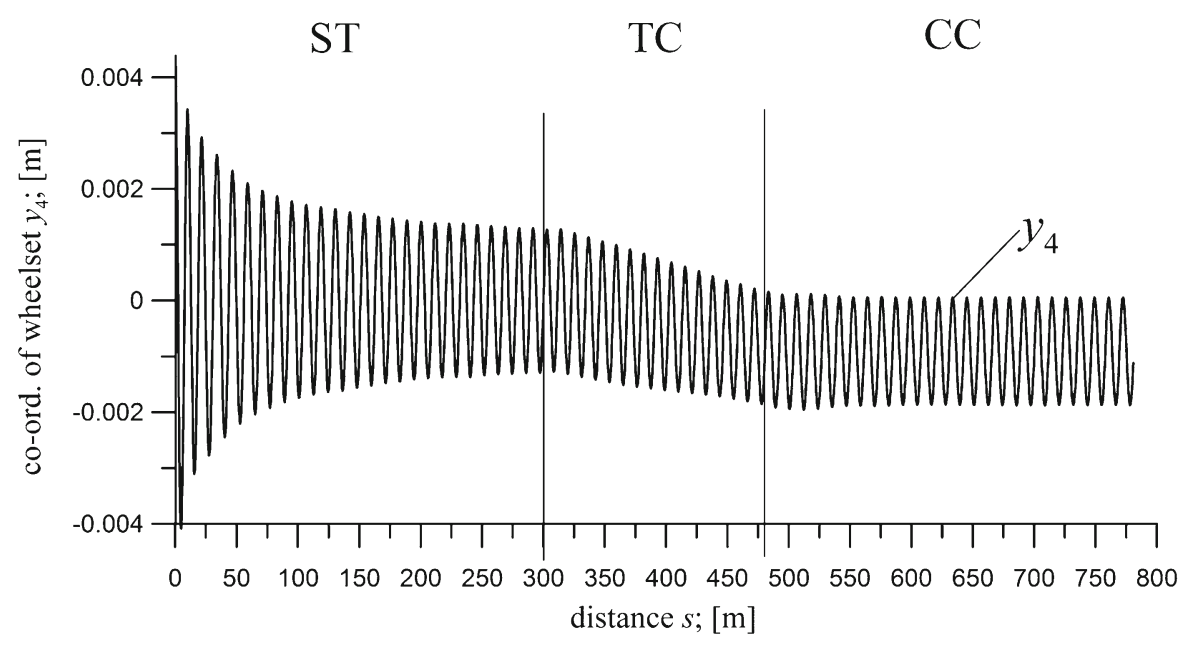




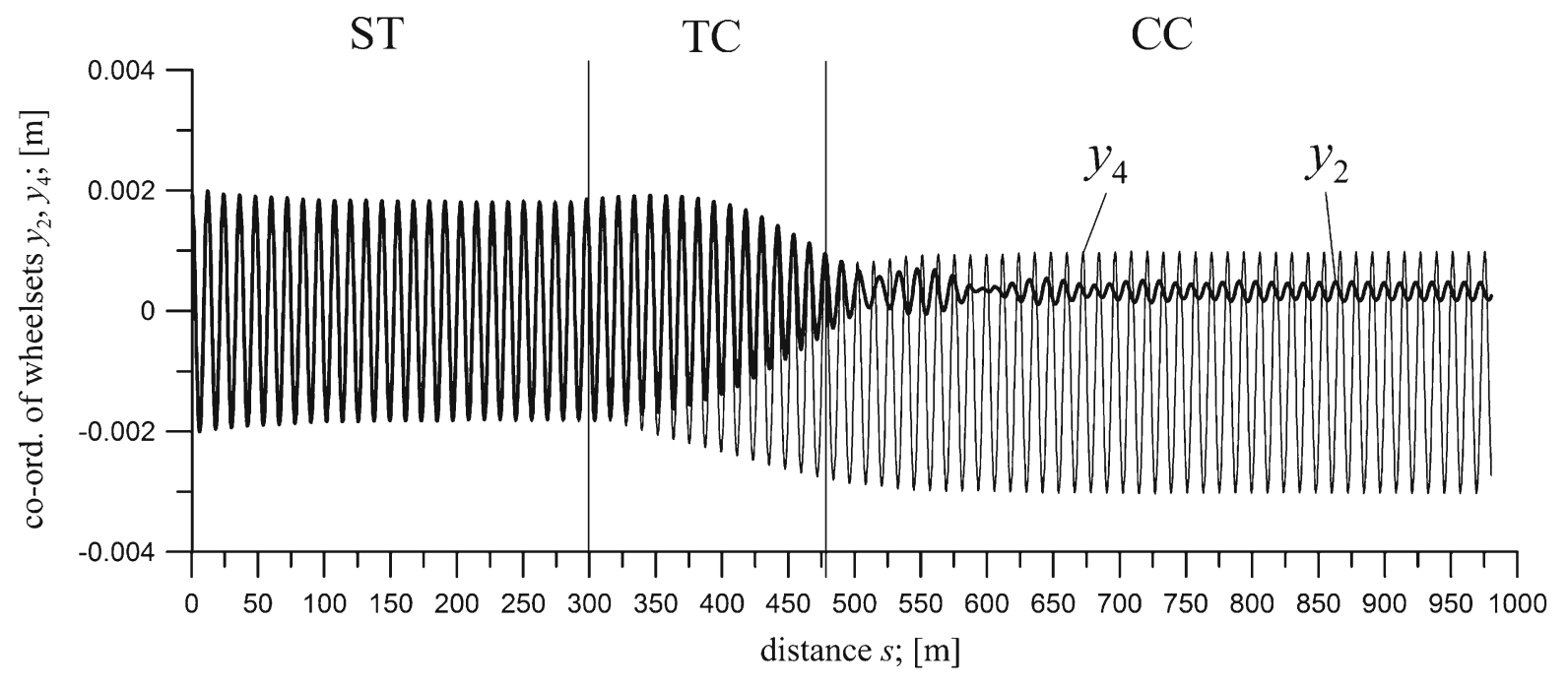

Fig. 47 Co-ordinates of wheelsets of passenger car MKIII; $R=6000 \mathrm{~m} ; h=0.015 \mathrm{~m} ; v=20 \mathrm{~m} / \mathrm{s} ; y_{j}(0)=0.002 \mathrm{~m}$

Figure 32 representing lateral displacements $y_{l}$ and $y_{t}$ of both wheelsets shows that described above phenomenon of worse dumping properties at higher velocities $v$ has got transient character and after enough long time it transforms into limit cycle. Such conclusion also concerns not shown here results for linear $y_{b}$ as well as angular $\psi_{p}, \psi_{k}$ and $\psi_{b}$ co-ordinates. Results similar to Fig. 32, where initial conditions are $y_{i}(0)=0.002 \mathrm{~m}$, were also obtained for other initial conditions, namely $y_{i}(0)=0.001,0.003,0.004$ and $0.0045 \mathrm{~m}$.

The authors counted phenomenon as shown in Fig. 31 to unfavourable and undertook the effort to answer if its elimination is possible. At first, the objective was pointed out to check if it is not result of improper value of the admissible maximum relative error $E$ of integration procedure. Consequently, the following variants were adopted $E=$ $0.4,0.3,0.2,0.1,0.01,0.001$ and 0.0001 for stiffness and dumping parameters as in Figs. 29 and 30. Besides, the variants $E=0.8,0.5,0.4,0.3,0.2$, $0.15,0.1,0.08,0.05$ and 0.01 for the parameters as in Fig. 31 were tested. The tries to vary value of the admissible relative error $E$ did not bring about consequent betterment of the results with drop of the $E$ value. Finally, the decision was taken to use $E=0.1$ in the studies of 2-axle freight car of average parameters.

The second try to eliminate phenomenon from Fig. 31 was through proper choice of car suspension parameters of stiffness $k_{z x}$ and $k_{z y}$ and dumping $c_{z x}$ and $c_{z y}$. Figure 33 that exhibits lateral displacements $y_{l}$ and $y_{t}$ of both wheelsets represents example of such results. As a result of the numerical experiments performed the authors managed to find single set of the parameters for which discussed phenomenon disappeared almost entirely (for all co-ordinates, also not shown linear $y_{b}$ as well as angular $\psi_{p}, \psi_{k}$ and $\psi_{b}$ coordinates) during velocity $v$ variation, until numerical derailment, i.e. $v \cong 48 \mathrm{~m} / \mathrm{s}$. Precisely speaking, the solutions had got character of those shown in Fig. 33 or 32. It is also worth saying that finding proper set of the suspension parameters was very difficult and required to perform many time-consuming simulations. It were largely the actions made through trails and errors. One should also realise that in real railway conditions nonfavourable values of stiffness and dumping parameters can result from both the design mistakes and the failures of suspension elements.

\subsection{Results for laden hsfv1 freight car}

Results obtained for the 2-axle laden freight car hsfv1 are shown in Figs. 34, 35, 36, 37, 38, 39, 40, 41 and 42. The routes in Figs. 34, 35, 37, 38 and 39 have got the following common parameters, namely lengths of ST $(l=300 \mathrm{~m})$, TC $(l=142 \mathrm{~m})$ and CC $(l=150$ $\mathrm{m})$, curve radius $R=600 \mathrm{~m}$, superelevation $h=0.15$ $\mathrm{m}$, velocity $v=45.3 \mathrm{~m} / \mathrm{s}$, nonzero initial conditions $y_{i}(0)=0.0045 \mathrm{~m}$, and maximum admissible relative error of integration procedure $E=0.01$. The route 
Fig. 48 Co-ordinates of of passenger car MKIII; $R=10,000 \mathrm{~m} ; h=0.009$ $\mathrm{m} ; v=20 \mathrm{~m} / \mathrm{s}$; $y_{j}(0)=0 \mathrm{~m}$ wheelsets and bogie frames

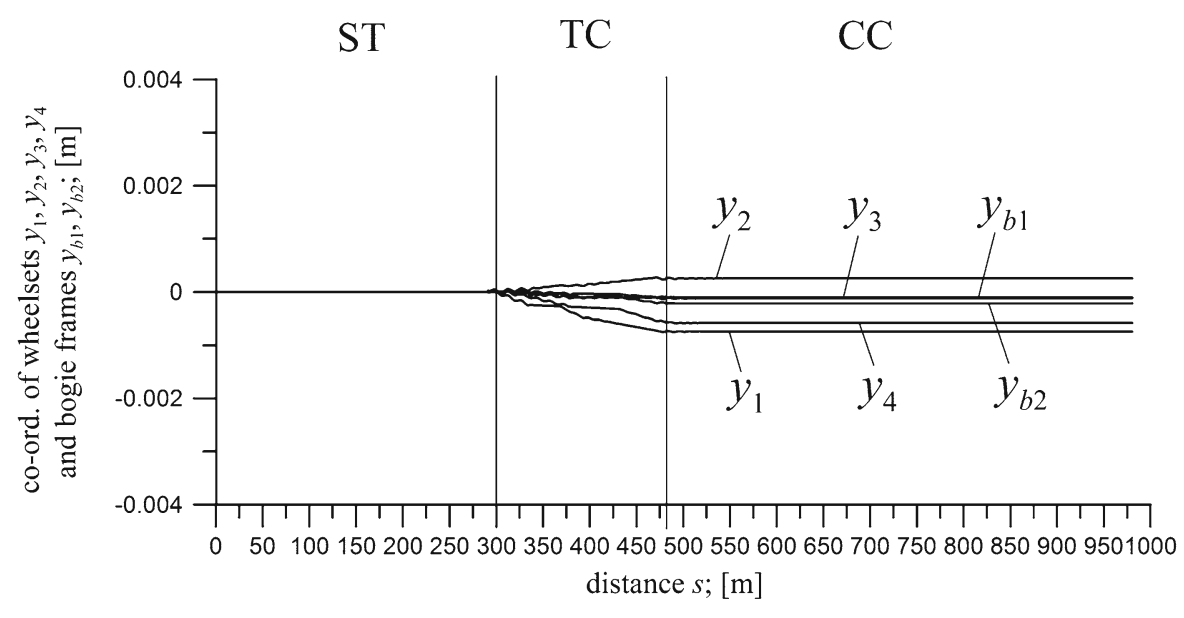

Fig. 49 Co-ordinates of wheelsets and bogie frames of passenger car MKIII; $R=10,000 \mathrm{~m} ; h=0.009$ $\mathrm{m} ; v=20 \mathrm{~m} / \mathrm{s}$ $y_{j}(0)=0.004 \mathrm{~m}$

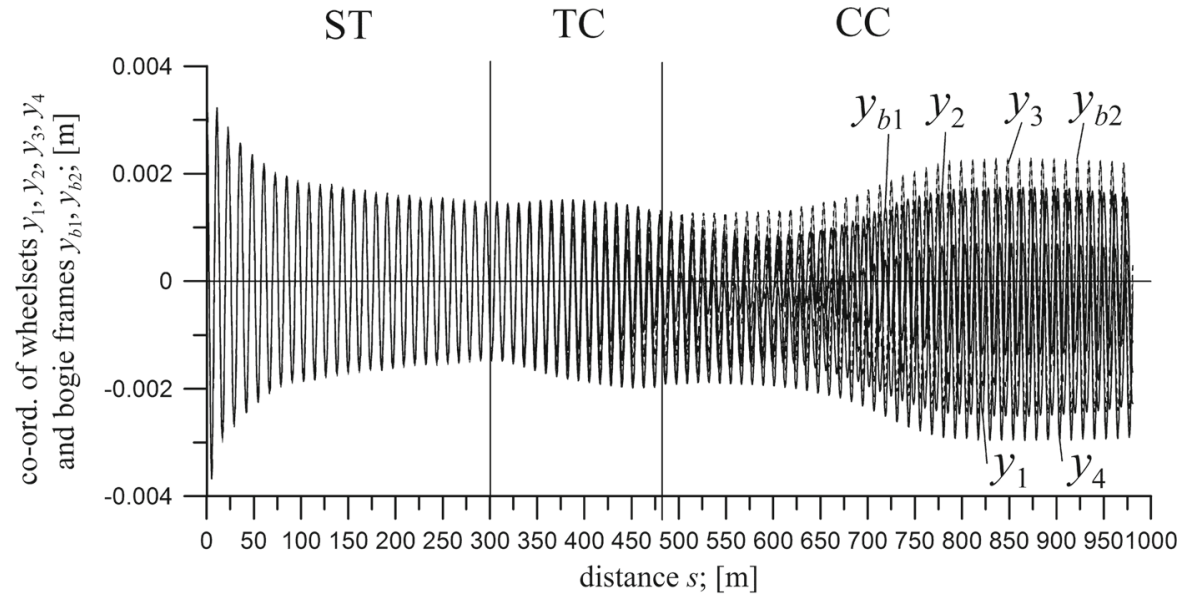

in Fig. 36 differs from the just described in length of CC $(l=500 \mathrm{~m})$. Suspension lateral stiffness $k_{z x}$ is subject to variation in Figs. 34, 35, 36, 37, 38 and 39. The variants adopted in Figs. 34, 35, 36, 37, 38 and 39 are values: one hundred times smaller than nominal $(20.67 \mathrm{kN} / \mathrm{m}-0.01 \times)$, ten times smaller than nominal $(206.7 \mathrm{kN} / \mathrm{m}-0.1 \times)$, making $20 \%$ of the nominal $(413.4 \mathrm{kN} / \mathrm{m}-0.2 \times)$, nominal $(2067 \mathrm{kN} / \mathrm{m}-$ $1 \times)$, twenty times bigger than nominal $(41,340 \mathrm{kN} / \mathrm{m}$ $-20 \times)$, and one thousand times bigger than nominal $(2,067,000 \mathrm{kN} / \mathrm{m}-1000 \times)$. The variants calculated but not shown due to limited paper space and to some extent obvious courses because of their intermediate character are values: one thousand times smaller than nominal $(2.067 \mathrm{kN} / \mathrm{m}-0.001 \times)$, making $40 \%$ of the nominal $(826.8 \mathrm{kN} / \mathrm{m}-0.4 \times)$, four times bigger than nominal $(8268 \mathrm{kN} / \mathrm{m}-4 \times)$, ten times bigger than nominal $(20,670 \mathrm{kN} / \mathrm{m}-10 \times)$, fourteen times bigger than nominal $(28,938 \mathrm{kN} / \mathrm{m}-14 \times)$, eighteen times bigger than nominal $(37,206 \mathrm{kN} / \mathrm{m}-18 \times)$, one hundred times bigger than nominal $(206,700 \mathrm{kN} / \mathrm{m}-100 \times)$, and five thousand times bigger than nominal $(10,335,000 \mathrm{kN} / \mathrm{m}$ $-5000 \times)$.

The route in Fig. 40 has got the following parameters: lengths of ST $(l=300 \mathrm{~m}), \mathrm{TC}(l=142 \mathrm{~m})$ and CC $(l=500 \mathrm{~m})$, curve radius $R=600 \mathrm{~m}$, superelevation $h=0.15 \mathrm{~m}$, nonzero initial conditions $y_{i}(0)=0.0045$ $\mathrm{m}$. The maximum admissible relative error of integration procedure $E=0.01$. Results in Fig. 40 were obtained for decreased value of the longitudinal stiffness $k_{z x}(206.7 \mathrm{kN} / \mathrm{m}-0.1 \times)$ and increased value of the lateral stiffness $k_{z y}(3448 \mathrm{kN} / \mathrm{m}-8 \times)$. The quantity being varied in Fig. 40 is velocity $v$. The variants adopted are: $v=20,24,25,28,45.3$ and $49 \mathrm{~m} / \mathrm{s}$. The route in Fig. 41 comparing to Fig. 40 is limited to ST. Rest of the parameters and varied quantity are the same as in Fig. 40. 
Fig. 50 Co-ordinates of wheelsets and bogie frames of passenger car MKIII on ST section; $v=20 \mathrm{~m} / \mathrm{s}$; $y_{j}(0)=0.001 \mathrm{~m}$
Fig. 51 Co-ordinates of wheelsets and bogie frames of passenger car MKIII on ST section; $v=20 \mathrm{~m} / \mathrm{s}$; $y_{j}(0)=0.002 \mathrm{~m}$
Fig. 52 Co-ordinates of wheelsets and bogie frames of passenger car MKIII on ST section; $v=20 \mathrm{~m} / \mathrm{s}$; $y_{j}(0)=0.004 \mathrm{~m}$
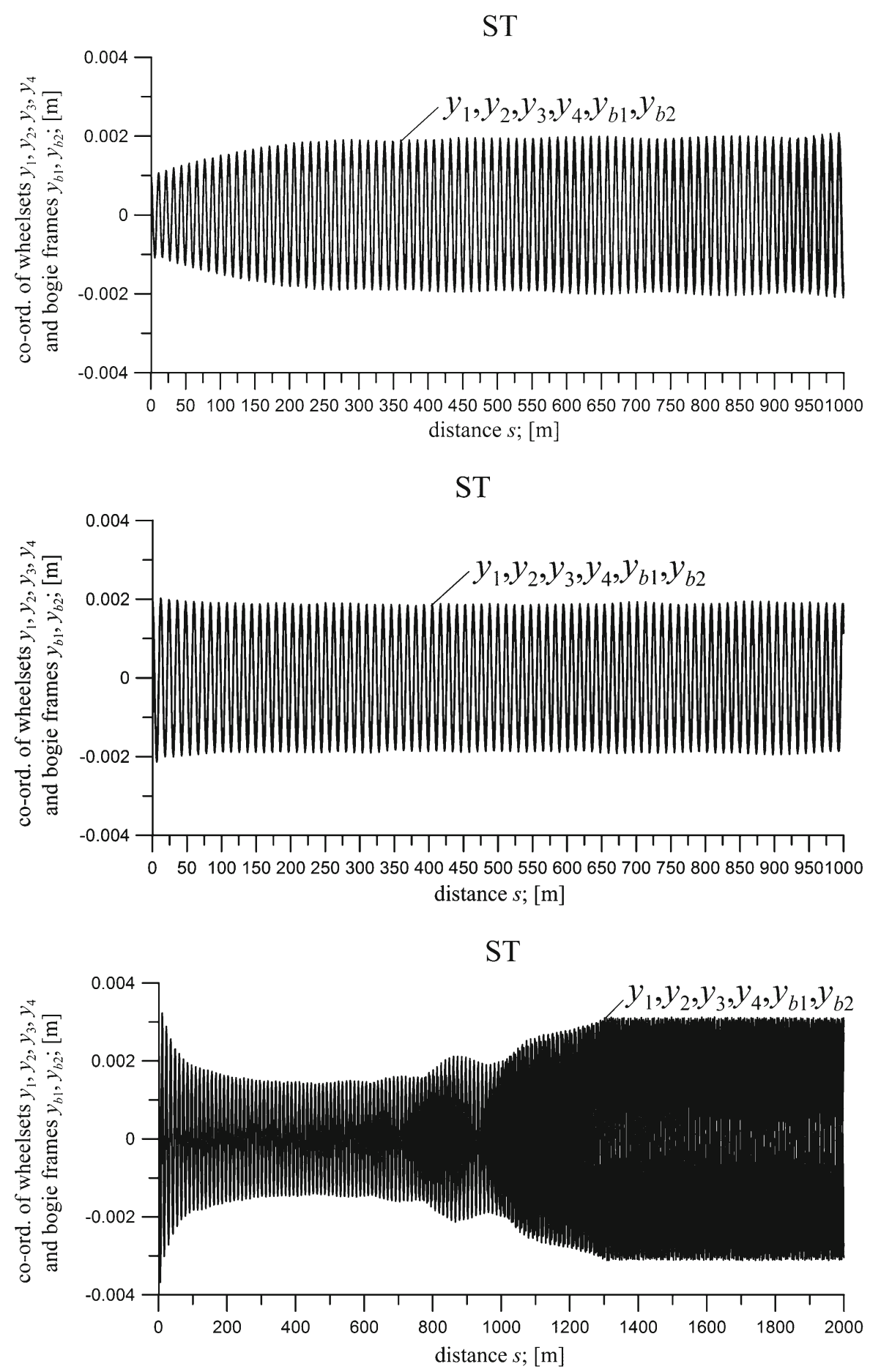

Except the curve radius $R$, the route in Fig. 42 has got the same basic parameters as in Fig. 40. Namely, these are: lengths ST $(l=300 \mathrm{~m})$, TC $(l=142$ $\mathrm{m})$ and $\mathrm{CC}(l=500 \mathrm{~m})$, and nonzero initial condi- tions $y_{i}(0)=0,0045 \mathrm{~m}$. The maximum admissible relative error of integration procedure $E=0.01$. Also the stiffness values $k_{z x}(206.7 \mathrm{kN} / \mathrm{m}-0.1 \times)$ and $k_{z y}$ $(3448 \mathrm{kN} / \mathrm{m}-8 \times)$ are the same as for Fig. 40 . The 
main difference is constant velocity $v=45,3 \mathrm{~m} / \mathrm{s}$ and curve radii $R$ being varied. The variants adopted in Fig. 42 are $R=300,600,750,2000$ and $6000 \mathrm{~m}$, while superelevations are $0.15,0.15 ; 0.12,0.0045$ and $0.015 \mathrm{~m}$, respectively. The variants calculated but not shown here are $R=450,650,700,900,1200 \mathrm{~m}$.

Longitudinal stiffness $k_{z x}$ is smaller than nominal one in Figs. 34, 35 and 36. Comparing these figures with Fig. 37 for the nominal value of stiffness $k_{z x}$, it can be generally seen that decrease in this stiffness value leads to vibrations of limit cycle character in ST and CC. The lower stiffness $k_{z x}$ the bigger amplitudes at the same time. And indeed, in Figs. 36, 35 and 34 obtained for decreasing stiffness $0.2 \times, 0.1 \times$ and $0.01 \times$ vibrations in $\mathrm{ST}$ possess the bigger and bigger amplitudes. Vibrations in ST in Fig. 37 decay quickly. The behaviours in TC in Figs. 34, 35 and 37 make fluent passage from solutions in ST to solutions in CC. On the other hand vibrations in TC exist in Figs. 34, 35 and 36 only. As concerns solutions in CC, in Figs. 36, 35 and 34 obtained for decreasing stiffness $0.2 \times, 0.1 \times$ and $0.01 \times$ vibrations in $\mathrm{CC}$ have got limit cycle character and their amplitudes increase, correspondingly (i.e. with $k_{z x}$ decrease). One can see in Fig. 36 that limit cycle amplitudes for the leading wheelset $y_{l}$ and $\psi_{l}$ are significantly smaller that for the trailing one $y_{t}$ and $\psi_{t}$. In Fig. 35, amplitudes for the leading wheelset are still smaller but this time comparable to those for the trailing wheelset. In Fig. 34, the corresponding amplitudes of both wheelsets coincide in terms of practice $\left(y_{l} \approx y_{t}\right.$ and $\psi_{l} \approx \psi_{t}$ ). The same feature concerns not shown result for the stiffness $0.001 \times$.

Longitudinal stiffness $k_{z x}$ is bigger than nominal one in Figs. 38 and 39. Comparing these figures with Fig. 37 for the nominal value of stiffness $k_{z x}(1 \times)$, it can be generally seen that increase in this stiffness value leads to vibrations of limit cycle character in ST. The higher stiffness $k_{z x}$ the bigger amplitudes at the same time. The behaviour in ST in Fig. 37 is a case of decaying vibrations (motion below critical velocity in ST $v_{n}=64.5 \mathrm{~m} / \mathrm{s}$ ). The character of behaviours similar to shown in Fig. 37 was also obtained for the stiffness $4 \times$ and $10 \times$, not show in the paper. Some difference in ST are frequencies lower for the stiffness $10 \times$ than it is for stiffness $1 \times$. In Figs. 38 and 39 obtained for increasing stiffness $20 \times$ and $1000 \times$ vibrations in ST are first increasing and then achieve form of the limit cycle what means that motion above critical velocity $v_{n}$ exists $\left(v_{n}=57\right.$ and $52 \mathrm{~m} / \mathrm{s}$, respectively). The limit cycle is achieved faster and amplitudes are bigger for the higher values of longitudinal stiffness $k_{z x}$. Frequencies of vibrations in ST are close to those mentioned for not shown case of stiffness $10 \times$. Both just mentioned facts concern also not shown results for stiffness $14 \times, 18 \times, 100 \times$, and $5000 \times$. Comparing results for stiffness $k_{z x}$ lower and equal to nominal one (Figs. 34, 35,36 and 37) with stiffness higher than nominal one (Figs. 38 and 39 as well as the results not shown) change of the solution character, in terms of frequency, in ST can be stated. The frequencies in ST are clearly lower for higher stiffness. As concerns behaviour in TC, no vibrations exist in Fig. 37. In case of Figs. 38 and 39, vibrations disappear in TC. As concern behaviours in CC for stiffness $20 \times$ and $1000 \times$ in Figs. 38 and 39 and for not shown results of stiffness $14 \times, 18 \times, 100 \times$, and $5000 \times$ they are quite uniform, i.e. take form of stationary (quasi-static) solutions. It is worth mentioning that solutions in ST for stiffness $100 \times, 1000 \times$ (Fig. 39) and $5000 \times$ are almost identical. In case of TC and CC similar identity is even wider, i.e. spreads out over stiffness range $20 \times$ (Fig. 38), 100× 1000× (Fig. 39) and $5000 \times$.

Concluding jointly the cases of longitudinal stiffness $k_{z x}$ increase and decrease it is proper to note that both these changes with respect to nominal value lead in ST to vibration appearance and finally to limit cycles. The noticeable difference for both cases are lower frequencies for higher stiffness, at the same time. Appearance of periodic vibrations in ST for continuously decreasing longitudinal stiffness $k_{z x}$ and correspondingly increasing amplitudes mean continuous drop of critical velocity $v_{n}$ in ST. Indeed, in ST $v_{n}=$ 37, 42.8, 55 and $64.5 \mathrm{~m} / \mathrm{s}$ in Figs. 34, 35, 36 and 37, respectively. Appearance of vibrations in ST for continuously increasing stiffness $k_{z x}$ and correspondingly increasing amplitudes mean also continuous drop of $v_{n}$ in ST. In ST $v_{n}=64.5,57$ and $52 \mathrm{~m} / \mathrm{s}$ in Figs. 37, 38 and 39, respectively. In CC decrease in longitudinal stiffness $k_{z x}$ leads to vibration appearance and finally to limit cycles. Appearance of periodic vibrations in $\mathrm{CC}$ for continuously decreasing longitudinal stiffness $k_{z x}$ and correspondingly increasing amplitudes mean continuous drop of critical velocity $v_{n}$ in CC. Increase in the stiffness $k_{z x}$ in CC leads to preserving stationary solutions appearing already for nominal value of stiffness $k_{z x}$. The conclusions for ST can be counted as not necessarily expected. On the other hand they 
Fig. 53 Co-ordinates of wheelsets and bogie frames of passenger car MKIII; $R=600 \mathrm{~m} ; h=0.15 \mathrm{~m}$; $v=35 \mathrm{~m} / \mathrm{s} ; y_{j}(0)=0 \mathrm{~m}$; $k_{z x}=266,700 \mathrm{kN} / \mathrm{m}$ $(100 \times)$

Fig. 54 Co-ordinates of wheelsets and bogie frames of passenger car MKIII; $R=600 \mathrm{~m} ; h=0.15 \mathrm{~m}$; $v=40 \mathrm{~m} / \mathrm{s} ; y_{j}(0)=0 \mathrm{~m}$ $k_{z x}=266,700 \mathrm{kN} / \mathrm{m}$ $(100 \times)$

Fig. 55 Co-ordinates of wheelsets and bogie frames of passenger car MKIII; $R=600 \mathrm{~m} ; h=0.15 \mathrm{~m}$; $v=45 \mathrm{~m} / \mathrm{s} ; y_{j}(0)=0 \mathrm{~m}$; $k_{z x}=266,700 \mathrm{kN} / \mathrm{m}$ $(100 \times)$

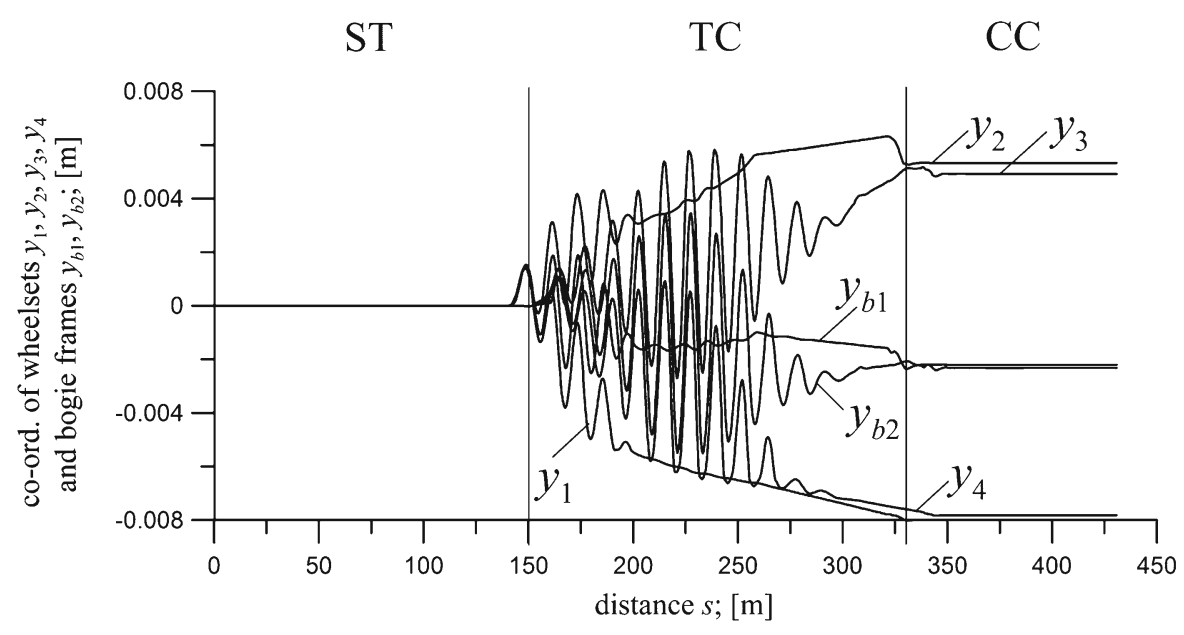

ST

TC

$\mathrm{CC}$

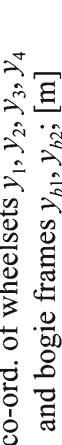

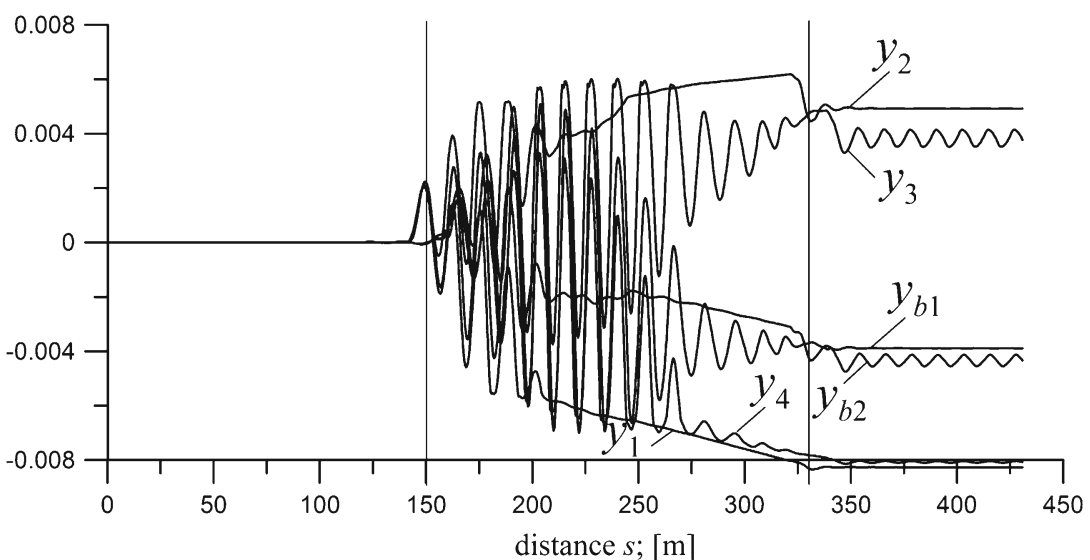

TC

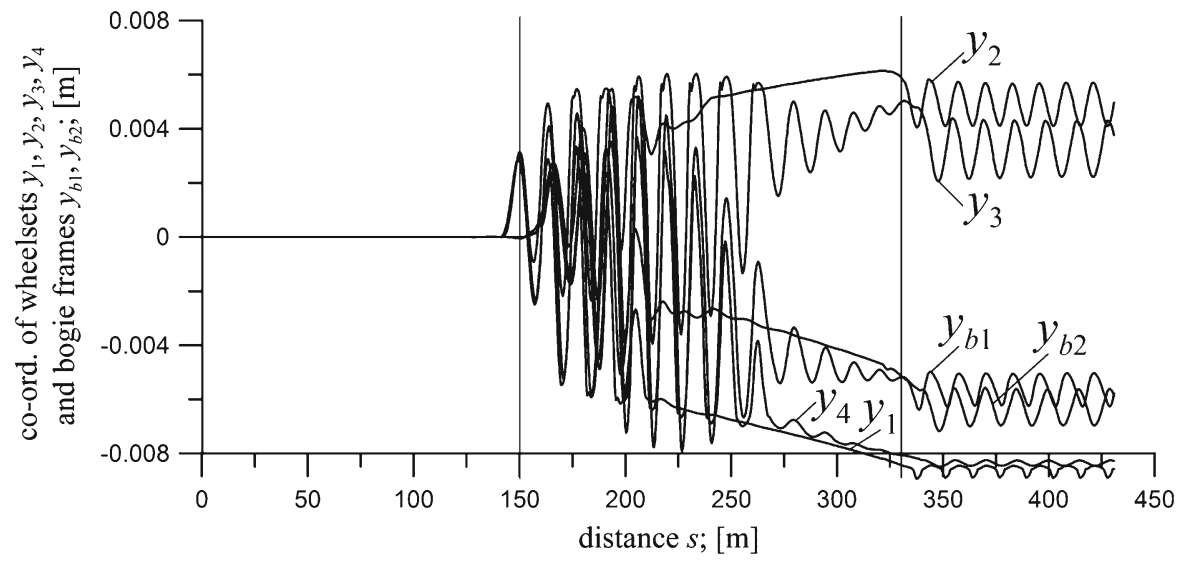

and the conclusions for $\mathrm{CC}$ have important practical dimension.
Figure 40 represents co-ordinate $y_{b}$ of lateral displacement of car body for velocities $v=20,24 ; 25,28$, 45.3 and $49 \mathrm{~m} / \mathrm{s}$. It can be seen that increase in veloc- 
Fig. 56 Co-ordinates of wheelsets and bogie frames of passenger car MKIII; $R=600 \mathrm{~m} ; h=0.15 \mathrm{~m}$; $v=47 \mathrm{~m} / \mathrm{s} ; y_{j}(0)=0 \mathrm{~m}$; $k_{z x}=266,700 \mathrm{kN} / \mathrm{m}$ $(100 \times)$
Fig. 57 Co-ordinates of wheelsets and bogie frames of passenger car MKIII; $R=600 \mathrm{~m} ; h=0.15 \mathrm{~m}$; $v=55 \mathrm{~m} / \mathrm{s} ; y_{j}(0)=0 \mathrm{~m}$; $k_{p z x}=200 \mathrm{kN} / \mathrm{m}(10 \times)$
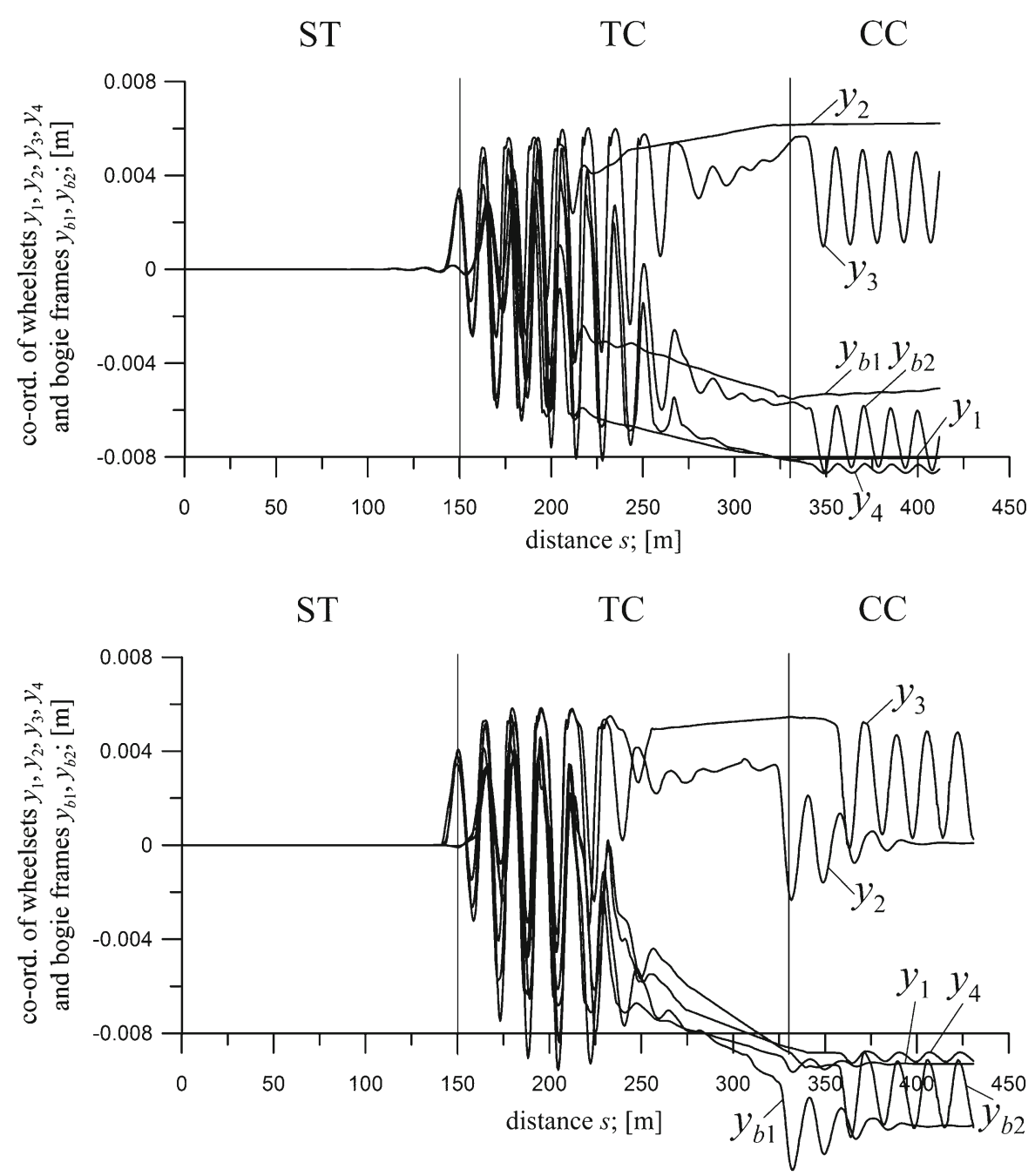

ity $v$ results in appearance of limit cycles in CC despite vibrations decaying in ST (motion below critical velocity in ST $v_{n}=67 \mathrm{~m} / \mathrm{s}$ ). And so, solutions in CC for velocities $v=20$ and $24 \mathrm{~m} / \mathrm{s}$ are stationary ones. For velocity $v=25 \mathrm{~m} / \mathrm{s}$ vibrations of increasing amplitudes appear in $\mathrm{CC}$, which can expand to limit cycles. In case of velocities $v=28,45.3$ and $49 \mathrm{~m} / \mathrm{s}$ solutions in CC have got expanded limit cycle form. Location of the courses in $\mathrm{CC}$ on both sides of horizontal zero line indicates superelevation excess for $v$ from 20 to $28 \mathrm{~m} / \mathrm{s}$ and superelevation deficiency for $v=45.3$ and $49 \mathrm{~m} / \mathrm{s}$. Behaviours in ST shown in Fig. 40 (for co-ordinate $y_{b}$ ) and more legibly in Fig. 41 (for co-ordinate $y_{l}$ ) should be counted to untypical ones. As mentioned above the motion is below critical velocity for all velocities $v$ represented in both figures. The way vibrations decay is, however, unexpected. Usually, the higher velocity the time of complete vibrations disappearance longer and therefore higher values of amplitude last longer, too. It is different in Fig. 41, however. It can be seen that vibrations disappear fastest for the terminal values of velocity, i.e. $v=45.3$ and $20 \mathrm{~m} / \mathrm{s}$. As compared to $v=20 \mathrm{~m} / \mathrm{s}$, the time of vibrations disappearance for $v=24$ and $25 \mathrm{~m} / \mathrm{s}$ is typical, i.e. it elongates with velocity increase and amplitudes of higher values last longer. The behaviour for velocity $v=28 \mathrm{~m} / \mathrm{s}$ is untypical, i.e. the disappearance time does not elongate but shortens. Such opposite behaviour lasts longer and the time of disappearance for $v=45.3 \mathrm{~m} / \mathrm{s}$ is even shorter.

Figure 42 represents curve radius $R$ variation in the rage from 300 to $6000 \mathrm{~m}$ for velocity $v=45.3 \mathrm{~m} / \mathrm{s}$. Co-ordinates of leading wheelset lateral displacement 
Fig. 58 Co-ordinates of wheelsets and bogie frames of passenger car MKIII;

$R=600 \mathrm{~m} ; h=0.15 \mathrm{~m}$;

$v=55 \mathrm{~m} / \mathrm{s}$;

$y_{j}(0)=0.004 \mathrm{~m}$;

$k_{p z x}=200 \mathrm{kN} / \mathrm{m}(10 \times)$
Fig. 59 Co-ordinate of bogie frame of passenger car MKIII; $R=600 \mathrm{~m}$; $h=0.15 \mathrm{~m} ; v=35 \mathrm{~m} / \mathrm{s}$; $y_{j}(0)=0.004 \mathrm{~m}$; $k_{p z y}=476 \mathrm{kN} / \mathrm{m}(1 \times)$ and $4760 \mathrm{kN} / \mathrm{m}(10 \times)$
ST

TC

$\mathrm{CC}$

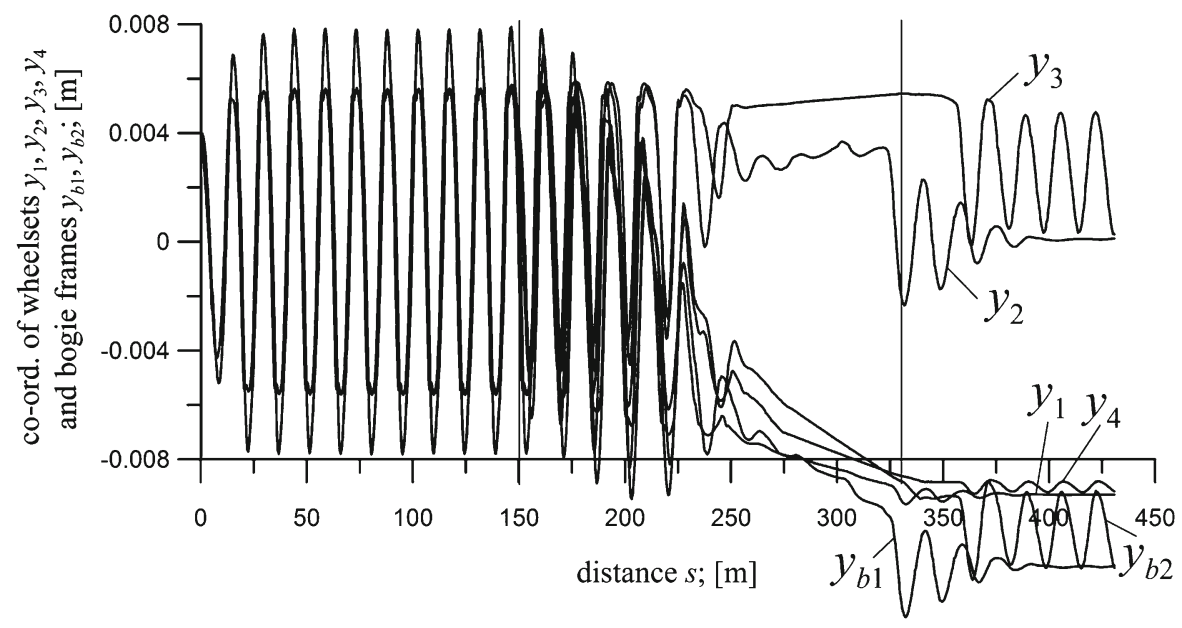

$y_{l}$ and yaw angle $\psi_{l}$ are represented in Fig. 42. The figure reveals next untypical behaviours of the laden 2axle freight car hsfv1. In case of ST some reference to these results is result shown in Fig. 35. Current results differ from those in Fig. 35 in eight times bigger lateral stiffness $k_{z y}(3448 \mathrm{kN} / \mathrm{m}-8 \times)$. Rise of this stiffness results in increase in the critical velocity $v_{n}$ in ST, therefore motion in ST is now realised below critical velocity in ST $v_{n}=67 \mathrm{~m} / \mathrm{s}$. Behaviours in ST can be recognised as typical, i.e. vibrations are decaying, while big amplitude limit cycle existed in Fig. 35. The behaviours in TC can be counted as typical and qualitatively similar for different radii $R$. The behaviours in CC should be recognised as untypical ones. Solutions for $R=300$ $\mathrm{m}$ are stationary. In case of $R=600 \mathrm{~m}$ vibrations take limit cycle form. The amplitudes are significant. Result for $R=600 \mathrm{~m}$ can be referred to Fig. 35, for which lateral stiffness $k_{z y}$ has got nominal value. Despite serious difference in stiffness $k_{z y}$ value and obvious differences in ST, the solutions in CC in Figs. 42 and 35 should be agreed as close qualitatively and close quantitatively. It is worth mentioning that car body lateral displacement $y_{b}$ for $v=45.3 \mathrm{~m} / \mathrm{s}$ shown in Fig. 40 is supplement to the result in Fig. 42 for $R=600$ m. It 
could also be stated that in case of not shown results for $R=450$ and $650 \mathrm{~m}$ limit cycle type solutions in $\mathrm{CC}$ also exist. Solutions in CC for $R=750,2000$ and $6000 \mathrm{~m}$ are stationary, again. It is so also in case of not shown results for radii $R=700,900$ and $1200 \mathrm{~m}$. As a typical configuration of the solutions in $\mathrm{CC}$ during increase in curve radius $R$ the stationary solutions for small $R$, appearance of periodic vibrations for higher $R$ values, and consequent existence of vibrations till the biggest $R=\infty$ (TP) is acknowledged. It is also worth confronting results described in this paragraph (Fig. 42) with results for 25TN bogie in Figs. 4, 5, 6 and 7 in Sect. 5.1. The limit cycle type solutions in CC for small radii exist there, next they disappear, and then they revive and exist till $R=\infty$.

\section{Simulation results for 4-axle MKIII passenger car}

Results obtained for 4-axle passenger car MKIII are shown in Figs. 43, 44, 45, 46, 47, 48, 49, 50, 51, 52, 53, 54, 55, 56, 57, 58, 59 and 60. The routes in Figs. 43, 45 and 46 have got the following common parameters, namely lengths of ST $(l=300 \mathrm{~m})$, TC $(l=180.46$ $\mathrm{m})$ and CC $(l=300 \mathrm{~m})$, while velocity $v=20 \mathrm{~m} / \mathrm{s}$. The routes in Figs. 44, 47, 48 and 49 differ from just discussed in length of CC $(l=500 \mathrm{~m})$. Besides, curve radius $R=4000 \mathrm{~m}$ and superelevation $h=0.03 \mathrm{~m}$ in Figs. 43 and 44 , radius $R=6000 \mathrm{~m}$ and $h=0.015 \mathrm{~m}$ in Figs. 45, 46 and 47, and radius $R=10,000 \mathrm{~m}$ and $h=0.009 \mathrm{~m}$ in Figs. 48 and 49. Figures 43, 44, 45, $46,47,48$ and 49 represent results of initial conditions $y_{j}(0)$ variation. The variants adopted are: $y_{j}(0)=0 \mathrm{~m}$ and $y_{j}(0)=0.004 \mathrm{~m}$ in Figs. 43 and 44, respectively; $y_{j}(0)=0.006 \mathrm{~m}, y_{j}(0)=0.006 \mathrm{~m}$ and $y_{j}(0)=0.002$ $\mathrm{m}$ in Figs. 45, 46 and 47, respectively; and $y_{j}(0)=0 \mathrm{~m}$ and $y_{j}(0)=0.004 \mathrm{~m}$ in Figs. 48 and 49, respectively.

The routes in Figs. 50, 51 and 52 represent results for ST. The common parameter of the routes in Figs. 50 and 51 is length of ST $(l=1000 \mathrm{~m})$, and besides velocity $v=20 \mathrm{~m} / \mathrm{s}$. The route in Fig. 52 differs from just discussed in length of ST $(l=2000 \mathrm{~m})$. Value of the initial conditions $y_{j}(0)$ is varied in Figs. 50, 51 and 52. The values adopted are: $y_{j}(0)=0 \mathrm{~m}, y_{j}(0)=0.002$ $\mathrm{m}$ and $y_{j}(0)=0.004 \mathrm{~m}$, respectively.

The routes in Figs. 53, 54, 55 and 56 have got the following common parameters, namely lengths of ST $(l=150 \mathrm{~m}), \mathrm{TC}(l=180.46 \mathrm{~m})$ and $\mathrm{CC}(l=100 \mathrm{~m})$, curve radius $R=600 \mathrm{~m}$ and superelevation $h=0.15$ $\mathrm{m}$. Besides, zero initial conditions $y_{i}(0)=0 \mathrm{~m}$ are the same. All results were obtained for primary suspension longitudinal stiffness $k_{z x}(266,700 \mathrm{kN} / \mathrm{m}-100 \times)$ one hundred times bigger than nominal. Vehicle velocity $v$ is varied in Figs. 53, 54, 55 and 56. The variants adopted are: $v=35,40,45$ i $47 \mathrm{~m} / \mathrm{s}$, respectively.

The routes in Figs. 57 and 58 have got the following common parameters, namely lengths of ST $(l=150$ $\mathrm{m})$, TC $(l=180.46 \mathrm{~m})$ and CC $(l=100 \mathrm{~m})$, curve radius $R=600 \mathrm{~m}$ and superelevation $h=0.15 \mathrm{~m}$. Velocity amounts $v=55 \mathrm{~m} / \mathrm{s}$. All results were obtained for ten times bigger than nominal longitudinal stiffness of secondary suspension $k_{p z x}(200 \mathrm{kN} / \mathrm{m}-10 \times)$. Value of the initial conditions $y_{j}(0)$ is varied in Figs. 57 and 58. The values adopted are: $y_{j}(0)=0 \mathrm{~m}$ and $y_{j}(0)=0.004 \mathrm{~m}$.

The route in Fig. 59 has got the following parameters: lengths of ST $(l=150 \mathrm{~m}), \mathrm{TC}(l=180.46 \mathrm{~m})$ and CC $(l=100 \mathrm{~m})$, curve radius $R=600 \mathrm{~m}$ and superelevation $h=0.15 \mathrm{~m}$. Velocity and nonzero initial conditions amount $v=35 \mathrm{~m} / \mathrm{s}$ and $y_{j}(0)=0.004$ $\mathrm{m}$, respectively. Results were obtained for two different values of lateral stiffness in secondary suspension $k_{p z y}$. These were nominal value $k_{p z y}=476 \mathrm{kN} / \mathrm{m}(1 \times)$ and value ten times bigger than nominal one $k_{p z y}=4760$ $\mathrm{kN} / \mathrm{m}(10 \times)$.

The route in Fig. 60 have got the following parameters, namely lengths of ST $(l=150 \mathrm{~m}), \mathrm{TC}(l=180.46$ $\mathrm{m})$ and $\mathrm{CC}(l=100 \mathrm{~m})$, curve radius $R=600 \mathrm{~m}$ and superelevation $h=0.15 \mathrm{~m}$. Additionally, zero initial conditions $y_{i}(0)=0 \mathrm{~m}$ are the same. All results were obtained for primary suspension longitudinal stiffness $k_{z x}(266.7 \mathrm{kN} / \mathrm{m}-0.1 \times)$ ten times smaller than nominal. Vehicle velocity adopted was $v=59 \mathrm{~m} / \mathrm{s}$.

Passing to analysis of results in Figs. 43, 44, 45, $46,47,48$ and 49 it is worth saying that they make a fragment of the wider studies connected with variation of the initial conditions $y_{j}(0)$ for the routes of different curve radii $R$. In case of radii $R$ within the range between 600 and $2000 \mathrm{~m}$ no unexpected behaviours of the studied 4-axle car were found and thus results for this range were omitted here.

Figures 43 and 44 for $R=4000 \mathrm{~m}$ show intriguing result of influence of two different values of initial conditions imposed in ST on the results obtained in TC and CC. Stationary solutions (no vibrations) occur in ST in Fig. 43 for zero initial conditions $y_{j}(0)=0$ $\mathrm{m}$, what is obvious due to excitation lack. Less obvi- 
Fig. 60 Co-ordinates of wheelsets and bogie frames of passenger car MKIII; $R=600 \mathrm{~m} ; h=0.15 \mathrm{~m}$; $v=59 \mathrm{~m} / \mathrm{s} ; y_{j}(0)=0 \mathrm{~m}$; $k_{z x}=266.7 \mathrm{kN} / \mathrm{m}(0.1 \times)$

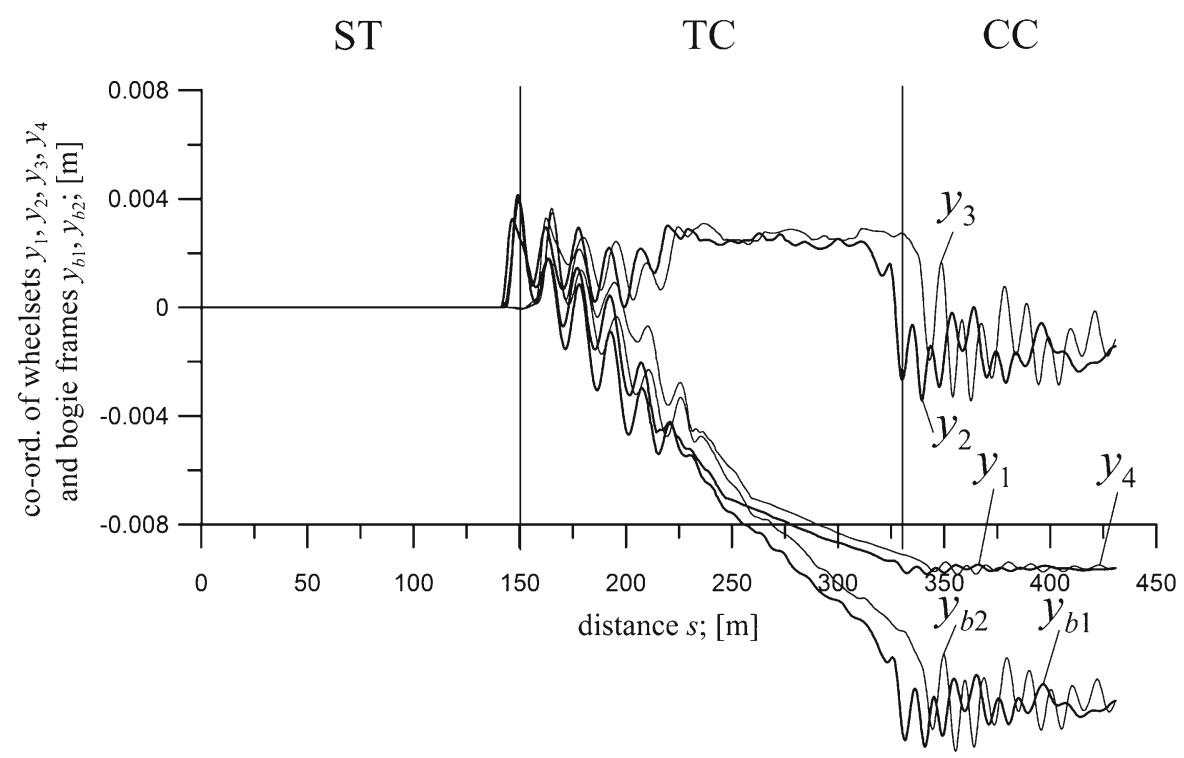

ous are solutions with no vibrations in TC, especially because of periodic solutions existing in CC. In this context the result discussed is worthy of confrontation with the result of current section shown in Fig. 55, where despite zero initial conditions in ST intensive vibrations are excited in TC. Solution in CC is untypical to some extent in Fig. 43. Vibrations in type of limit cycle appear not before CC is entered despite values of radius $R$ at the end part of TC are practically the same as in CC. It should be noticed that limit cycle concerns rear bogie only, i.e. its wheelsets and the frame represented with co-ordinates $y_{3}, y_{4}$ and $y_{b 2}$. Such type of behaviour should be recognised as rare and thus untypical. Negligibly small vibrations of the leading bogie seem not to result from its self-exciting vibrations but from the coupling between both bogies through the car body. In Fig. 44 for nonzero initial conditions $y_{j}(0)=0.004 \mathrm{~m}$ self-exciting vibrations exist in ST, what is obvious because motion above critical velocity $v_{n}$ takes place $\left(v_{n}=19.1 \mathrm{~m} / \mathrm{s}\right)$. Vibrations still last in TC. Vibrations for wheelsets and boogie frame of leading bogie (displacements $y_{1}, y_{2}$ and $y_{b 1}$ ) have got decaying character at the end part of TC at the same time. On the other hand, vibrations for wheelsets and boogie frame of trailing bogie (displacements $y_{3}, y_{4}$ and $y_{b 2}$ ) have got almost the same amplitudes along whole TC. The solutions in CC are untypical for several reasons. Firstly, similarly to Fig. 43, only trailing bogie represented with co-ordinates $y_{3}, y_{4}$ and $y_{b 2}$ is subject to periodic vibrations (limit cycle). Secondly, periodic vibrations in CC possess amplitudes significantly smaller in Fig. 44 than in Fig. 43. Thirdly, averaged balance position for trailing bogie co-ordinates $y_{3}$, $y_{4}$ and $y_{b 2}$ does not match analogical balance position in Fig. 43. Fourthly, the balance positions for leading co-ordinates $y_{1}, y_{2}$ and $y_{b 1}$ in Figs. 43 and 44 are not the same, too. Concluding results in CC in Figs. 43 and 44 existence of multiple periodic solutions for the trailing bogie and multiple quasi-stationary solutions for the leading bogie is evident. It is worthy of notice that bigger values of amplitudes and balance positions in Fig. 43 were obtained for smaller initial conditions $y_{j}(0)=0 \mathrm{~m}$, while the smaller values of amplitudes and balance positions in Fig. 44 were obtained for bigger initial conditions $y_{j}(0)=0.004 \mathrm{~m}$. Such opposition can be recognised as untypical. In case of TC different solutions are possible for different initial conditions. Because of the transient character of TC calling such solutions multiple ones can be contested, however.

Results equally interesting as discussed above are these obtained for $R=6000 \mathrm{~m}$ and shown in Figs. 45, 46 and 47. It is another one example of influence of different values of initial conditions imposed in ST on the results obtained for TC and CC. In case of Figs. 45 and 46 obtained for nonzero initial conditions $y_{j}(0)=0.006 \mathrm{~m}$ self-exciting vibrations exist in ST. Vibrations still last in TC. The amplitudes of vibrations for wheelsets and boogie frame of leading bogie (displacements $y_{1}, y_{2}$ and $\left.y_{b 1}\right)$ are smaller at the end part of TC than at the beginning part at the same time. On 
the other hand, for trailing wheelset displacement $y_{4}$ of trailing bogie (and not shown displacements $y_{3}$ and $y_{b 2}$ of this bogie) the amplitudes have got almost the same values along whole TC. In case of CC solutions for the leading bogie (Fig. 45) represent vibrations of small amplitude. One can recognise bigger amplitudes and self-exciting nature of vibrations for the trailing bogie (e.g. $y_{4}$ in Fig. 46) to be untypical, whereas leading bogie co-ordinates $\left(y_{1}, y_{2}\right.$ and $\left.y_{b 1}\right)$ possess very small amplitudes and origin of vibrations comes out from the coupling between both bogies though car body probably. In case of Fig. 47 self-exciting vibrations of similar amplitudes for leading and trailing boogie occur in ST for nonzero initial conditions $y_{j}(0)=0.002 \mathrm{~m}$. Vibrations for wheelsets and frame of the leading bogie (e.g. displacement $y_{2}$ shown in Fig. 47) have got decaying character at the end part of TC at the same time. On the other hand, vibration amplitudes for wheelsets and frame of the trailing bogie (e.g. displacement $y_{4}$ shown in Fig. 47) remain almost the same within whole TC. Solutions in CC are of limit cycle type. The amplitudes of co-ordinate $y_{4}$ of trailing wheelset in trailing bogie are significant in CC and close to those in ST and TC. On the other hand, the amplitude of co-ordinate $y_{2}$ of trailing wheelset in leading bogie is very small. Comparing it with amplitudes in Fig. 44, however, where origin of vibrations is self-exciting, one can suppose that also here vibrations of the leading wheelset possess self-exciting nature. Similarly to Figs. 45 and 46 also for Fig. 47 one can recognise amplitudes for the trailing bogie significantly bigger than for the leading one to be untypical. Concluding results in $\mathrm{CC}$ for the pair of Figs. 45 and 46 as well as for Fig. 47, existence of periodic multiple solutions of self-exciting origin for the trailing bogie is evident.

However, in case of multiple solutions of the leading bogie one of the solutions is quasi-stationary (results from coupling between the bogies through car bodyFig. 45) and the second one is periodic of self-exciting nature (Fig. 47). It is worthy of note that bigger values of vibration amplitudes in CC in Fig. 47 were obtained for smaller initial conditions $y_{j}(0)=0.002 \mathrm{~m}$, whereas the smaller values of the amplitudes in Fig. 45 were obtained for the bigger initial conditions $y_{j}(0)=0.006$ $\mathrm{m}$. Similarly as earlier, such opposition can be recognised as untypical.

Very interesting results are shown also in Figs. 48 and 49 for $R=10,000 \mathrm{~m}$. They make next example of influence of different initial conditions values imposed in ST on the results in TC and CC. There are no vibrations along the whole length of route, i.e. in ST, TC and CC, for zero initial conditions $y_{i}(0)=0 \mathrm{~m}$ in Fig. 48. Co-ordinates of lateral displacements of the leading and trailing bogie $\left(y_{1}, y_{2}, y_{b 1}\right.$ and $y_{3}, y_{4}, y_{b 2}$, respectively) are small in TC and CC, i.e. their values are of $0.001 \mathrm{~m}$ order. Solutions in $\mathrm{CC}$ are stationary ones. In case of Fig. 49 obtained for nonzero initial conditions $y_{j}(0)=0.004 \mathrm{~m}$, vibrations of significant amplitudes last along the whole route length. Values of their amplitudes are of the similar order in ST, TC and CC. In spite of large value of curve radius $R$ (close to the conditions in ST) small deflection of lateral displacements $y_{1}, y_{b 1}$ and $y_{3}, y_{4}, y_{b 2}$ towards inner curve side takes place, caused by the superelevation excess. Concluding results in Figs. 48 and 49, existence of multiple solutions of the same type for both bogies is evident in CC. One of the multiple solutions is of stationary character (Fig. 48), while second of the solutions is of periodic character (Fig. 49). It is worthy of note that periodic solutions and accompanying them bigger lateral displacements (Fig. 49) were obtained for bigger initial conditions $y_{j}(0)=0.004 \mathrm{~m}$, while smaller values of the displacements (Fig. 48) were obtained for the smaller initial conditions $y_{j}(0)=0 \mathrm{~m}$. Such type of the assignment can be counted as typical. Different solutions in TC are possible for different initial conditions.

Results shown in Figs. 50, 51 and 52 concern motion in ST. Three different values of the initial conditions were adopted here, namely $y_{j}(0)=0.001,0.002$ and $0.004 \mathrm{~m}$. Results in Figs. 50 and 51 and not shown figure for $y_{j}(0)=0.003 \mathrm{~m}$ show that despite different initial conditions the same limit cycle solution is obtained after initial transient phenomena finished. It is worth mentioning that such a feature is fundamental for the limit cycles. Figure 52 reveals that one can deal with multiple solutions also in ST. The limit cycle shown in Fig. 52 has got much bigger amplitude value than those in Figs. 50 and 51.

Results in Figs. 53, 54, 55 and 56 were obtained for radius $R=600 \mathrm{~m}$, suspension longitudinal stiffness $k_{z x}$ one hundred times increased relative to nominal value $(266,700 \mathrm{kN} / \mathrm{m}-100 \times)$, and zero initial conditions $y_{j}(0)=0 \mathrm{~m}$. Velocity $v$ was varied within the range from 35 to $47 \mathrm{~m} / \mathrm{s}$ at the same time. Vibrations in ST do not occur in such conditions as there is no any factor that excites them. Solutions are quantitatively similar in TC no matter which velocity is considered. 
Intensive vibrations are excited from the very beginning of TC for all co-ordinates shown, i.e. lateral displacements $y_{1}, y_{2}, y_{b 1}, y_{3}, y_{4}$ and $y_{b 2}$. In case of the leading bogie $\left(y_{1}, y_{2}\right.$ and $\left.y_{b 1}\right)$ vibrations reach maximum amplitudes in the initial part of TC, while in case of the trailing bogie $\left(y_{3}, y_{4}\right.$ and $\left.y_{b 2}\right)$ slightly further, closer to the TC middle part. Vibrations of the leading bogie decay quite fast so that they do not occur for $2 / 3$ of TC length from its end side. In case of the trailing bogie the process of vibrations decay is weaker and except the smallest velocity $v=35 \mathrm{~m} / \mathrm{s}$ (Fig. 53) it stops at the end of TC. Much bigger qualitative variety of solutions can be observed in CC. In Fig. 53 for $v=35 \mathrm{~m} / \mathrm{s}$, all lateral displacements are represented by stationary solutions. In Fig. 54 for $v=40 \mathrm{~m} / \mathrm{s}$, stationary solutions concern the leading boogie. In case of the trailing bogie periodic solutions of small amplitudes occur. In Fig. 55 for $v=45 \mathrm{~m} / \mathrm{s}$, one can observe periodic solutions for both bogies in CC. Vibration amplitudes are bigger than for $v=40 \mathrm{~m} / \mathrm{s}$ (Fig. 54) at the same time. Besides, amplitudes of solutions for the trailing bogie are distinctly bigger than those for the leading one. Finally, solutions in Fig. 56 for $v=47 \mathrm{~m} / \mathrm{s}$ are qualitatively similar to those in Fig. 54, i.e. for velocity $v=40 \mathrm{~m} / \mathrm{s}$. Solutions of the leading bogie are stationary, while of the trailing one are periodic. Amplitudes of the periodic solutions are considerably larger than those in Fig. 54 and also in Fig. 55. Concluding, results represented in Figs. 53, 54, 55 , and56 are characterised by lack of systematic nature in terms of prediction possibility of solution type for subsequently increased velocity. Qualitatively different results, but still similar with respect to the impossibility of solution type prediction, are shown in Figs. 4, 5 and 6 for 25TN bogie and in Figs. 20, 21, 22, 23, 24 and 25 for individually tested bogie of MKIII car.

The interesting result concerning initial conditions variation makes comparison of Figs. 57 and 58. These figures were obtained for radius $R=600 \mathrm{~m}$, velocity $v=55 \mathrm{~m} / \mathrm{s}$ (bigger than critical velocity in ST $v_{n}=23.2 \mathrm{~m} / \mathrm{s}$ ), and longitudinal stiffness of secondary suspension $k_{p z x}$ ten times bigger $(200 \mathrm{kN} / \mathrm{m}-10 \times)$ than nominal value. Zero initial condition $y_{j}(0)=0 \mathrm{~m}$ is applied in Fig. 57 and nonzero $y_{j}(0)=0.004 \mathrm{~m}$ in Fig. 58. Solutions in ST are typical, namely there are stationary solutions (no vibrations) in Fig. 57 and periodic vibrations (limit cycles) of big amplitudes appear in Fig. 58. The solutions in first part of TC are in Figs. 57 and 58 to some extent similar qualitatively but at the very beginning the influence of solution type in ST (no vibrations in Fig. 57 and periodic vibrations in Fig. 58) is clearly visible. In the second part of TC solutions in both figures are in practice identical qualitatively and quantitatively. They have got character of some perturbations more than regular oscillations. Identity of solutions in the second part of TC passes of course onto solutions in $\mathrm{CC}$, where after some time for becoming set solutions for the leading bogie are stationary and for the trailing one are periodic of quite significant amplitudes. Just discussed results are example of solutions that reveal the possibility of no influence of initial conditions imposed in ST on results in TC and CC.

Figure 59 exhibits interesting case when vibration amplitudes in TC are bigger than in ST and CC. The figure shows just one co-ordinate, namely lateral displacement $y_{b 2}$ of trailing bogie frame. This result obtained for lateral stiffness of secondary suspension $k_{p z y}$ ten times bigger $(4760 \mathrm{kN} / \mathrm{m}-10 \times)$ than nominal value is distinctively intriguing as second result in Fig. 59 for the nominal value of the stiffness $k_{p z y}(476 \mathrm{kN} / \mathrm{m}$ $-1 \times)$ can be counted as typical and thus not being particularly interesting. For the nominal value of $k_{p z y}$ limit cycle occurs in ST (velocity higher than critical velocity in ST $v_{n}=19.1 \mathrm{~m} / \mathrm{s}$ ), vibrations gradually decay in $\mathrm{TC}$, and solutions are stationary in $\mathrm{CC}$ (velocity lower than critical velocity $v_{n}$ in CC of $R=600 \mathrm{~m}, v_{n}$ not determined due to numerical derailments for high $v$ values). Another intriguing circumstance is that intensified vibrations in TC appear at raised lateral stiffness $k_{p z y}$. It could seem that any increase in stiffness in suspension should result in reduction of vibration amplitudes but not in their increase. The next surprising fact is that values of the amplitudes in ST for both stiffness values are quite similar and vibrations univocally intensify in TC section. It is also worth noticing that maximum values of the amplitude appear at half length of TC approximately, what here means curve radius $R=1200 \mathrm{~m}$ $(R=1 / k=1 / 0.0008(3)=1200 \mathrm{~m}$, where curvature $k=0.5 \cdot(1 / R)=0.5 / 600=0.0008(3) 1 / \mathrm{m})$. The amplitudes drop down for radii smaller than $1200 \mathrm{~m}$, so that solution in CC $(R=600 \mathrm{~m})$ finally becomes stationary. When looking at lateral displacements of wheelsets and bogie frame jointly one can see they are in the same phase and they have visibly smaller vibration amplitudes of wheelsets comparing to the frame. These two facts concern both stiffness values but only for the raised stiffness the amplitudes of lateral vibrations of wheelsets are bigger in TC than in ST and CC. Above mentioned facts can indicate that discussed 
intensified vibrations of bogie frame in TC result from conformity of wheelsets vibration frequency in track (excitation) with natural frequency of bogie frame (at the raised stiffness $k_{p z y}$ ). Finally, it should be also mentioned that analogical behaviours are also observed for the leading bogie.

Figure 60 for velocity $v=59 \mathrm{~m} / \mathrm{s}$ is included for the primary suspicion on appearance of chaotic solutions in the end part of TC and in CC. Analogical results were also obtained for velocities $v=50$ and $57 \mathrm{~m} / \mathrm{s}$, which results are not shown here. The suspicion came out from considerable similarity of the courses in CC to the result in [13]. Extended study of the case in Fig. 60 and those not shown here consisted in elongation of CC section demonstrated that observed phenomenon of the irregular vibrations is of transient nature and vibrations gradually pass into stationary solutions. Differently than it was in case of the result in [13].

\section{Conclusion}

Results of research discussed in this paper collect quite considerable number of railway vehicle behaviours being not necessarily expected and thus untypical. Diversity of obtained behaviours and studied generic models of railway vehicles demonstrate high complexity of railway vehicle-track systems and that nonlinear behaviours concern whole class of such systems rather than limited number of their individual examples.

The results counted as most untypical in studies of $25 \mathrm{TN}$ bogie of freight cars were:

- disappearance of vibrations in TC despite their occurrence in ST and CC;

- existence of vibrations in CC for small curve radius, their disappearance for the bigger radius, and their revival for even greater radii;

- and periodic solutions in CC generated by the most flexible track laterally and stationary solutions generated by the stiffer tracks.

Results of analogous nature for bogie of average parameters were:

- change of periodic solution type in ST for different in CC, consisting in significantly different frequency and amplitudes and taking place in TC;

- vibration amplitudes in TC that exceed amplitudes in ST and CC;
- and periodic vibrations amplitudes in $\mathrm{CC}$ that significantly exceed those in ST.

The most intriguing results for individually tested bogie of MKIII passenger car were:

- double change of solution type within TC, firstly, of frequencies and amplitudes for higher and lower than in ST and secondly, of vibrations for their decay and switch to stationary solutions in CC;

- double change of solution type in TC and at CC very beginning, firstly of frequencies and amplitudes for higher and lower than in ST and secondly, of vibrations for their decay and switch to stationary solutions in $\mathrm{CC}$;

- change of solution within TC from being direct continuation of periodic vibrations in ST into making beginning of periodic vibrations in $\mathrm{CC}$, accompanied, however, with significant change of frequency and amplitudes for higher and lower, respectively;

- multiple, entirely random and impossible to predict solutions in $\mathrm{CC}$ with increase in velocity, what includes alternate stationary and periodic solutions, alternate periodic solutions of different frequencies and amplitudes, and different solution types for leading and trailing wheelsets;

- and increase in periodic vibration amplitudes in CC for both the increase and decrease in suspension lateral stiffness.

The most untypical behaviours of 2-axle unloaded freight car of average parameters were as follows:

- disappearance of vibrations (stationary solutions) in $\mathrm{CC}$ for the leading wheelset with simultaneous periodic solutions of considerable amplitudes for the trailing wheelset, existing for some range of small and moderate curve radii;

- and generally long duration of transient phenomena in ST due to nonzero initial conditions.

The 2-axle hsfv1 freight car in loaded state gathered the following untypical nonlinear results:

- the same effect of critical velocity decrease in ST for decrease and increase in suspension longitudinal stiffness;

- the illogical way vibrations decay in ST for increasing velocity (being still below critical velocity in ST), because of decay irregularity in terms of decay time and amplitudes;

- and existence of stationary solution in CC for small curve radius, appearance of periodic solutions for 
some range of the bigger radii, and return to the stationary solutions for even greater radii, up to infinite one (ST).

In case of 4-axle passenger car MKIII the following untypical features were disclosed:

- mutually larger periodic vibration amplitudes and averaged balance positions in CC for smaller initial conditions imposed in ST and the smaller amplitudes and balance positions for the bigger initial conditions for some range of large curve radii;

- existence of periodic solutions for the trailing bogie only, with stationary solutions for the leading bogie at the same time;

- smaller amplitudes of periodic solutions for the leading bogie than it is for the trailing bogie;

- multiple periodic solutions in CC for some range of curve radii;

- multiple stationary and periodic solutions in CC for the largest curve radii;

- multiple periodic solutions in ST;

- multiple, random and impossible to predict solutions in $\mathrm{CC}$ with increase in velocity, what includes alternate stationary and periodic solutions and different solution types for leading and trailing bogie;

- possibility of no influence of the initial conditions imposed in ST on the behaviour in final part of TC and in $\mathrm{CC}$, where periodic solution occurred;

- and maximum vibration amplitudes in TC much higher than in ST and CC at some configuration of the suspension parameters.

Considering differences between studied objects and objects groups it seems that studied individually bogies undergo the biggest variety of untypical features. The reason for this might be their smallest mass, shortest length and simplified secondary suspension. Namely, the bogies are only loaded with the vehicle body mass. On the other hand, studied model of 4-axle passenger car MKIII is equipped with the same bogie as tested individually and not simplified suspension based on the real vehicle. In case of this vehicle and its bogies variety of different unexpected behaviours is approximately the same in number as for the bogies in total. Despite similar number, complexity of such behaviours and their scope seem to be higher than in case of the bogies in total. The lowest number and variety of unexpected results was obtained for 2-axle freight cars. Here, results for unloaded car seem to be more diversified and difficult to study due to long-lasting transient phenomena in ST caused by nonzero initial conditions. It seems that smaller mass of this vehicle as compared to the loaded car might be responsible for these features.

The authors gathered more simulation results than those shown in this paper. They concern systematic variation of the models' parameters and provide conclusions that give more orderly view of the studied vehicles. Thanks to it some generalisations and recommendations for these parameters can be formulated. These results are a matter of next paper by the authors. Current paper supplemented with the next one will give even more complete insight into nonlinear dynamical properties of mechanical systems of railway vehicle type.

Acknowledgements Scientific work financed as research Project No. 2014/15/N/ST8/02668 from funds of National Science Centre, Poland.

\section{Compliance with ethical standards}

Conflict of interest The authors declare that they have no conflict of interest concerning the publication of this manuscript.

Open Access This article is distributed under the terms of the Creative Commons Attribution 4.0 International License (http:// creativecommons.org/licenses/by/4.0/), which permits unrestricted use, distribution, and reproduction in any medium, provided you give appropriate credit to the original author(s) and the source, provide a link to the Creative Commons license, and indicate if changes were made.

\section{References}

1. Zboinski, K., Golofit-Stawinska, M.: Simulation study into non-linear properties of railway vehicles in transition curve at velocities around the critical one. In: 23rd International Symposium on Dynamics of Vehicles on Roads and Tracks, Qingdao. Electronic Conference Materials, Paper IAVSD2013-20.3-ID452 (2013)

2. Zboinski, K., Golofit-Stawinska, M.: Advances in studying non-linear phenomena in railway transition curve at velocities around the critical one. In: Rosenberger, $M$. et al. (eds.) The Dynamics of Vehicles on Roads and TracksProceedings of 25th IAVSD Symposium, Graz, Austria, pp. 947-956. CRC Press, Boca Raton (2017). ISBN: 978-1-13802885-2

3. Zboinski, K., Golofit-Stawinska, M.: Non-linear dynamics of railway vehicles in transition curves around critical velocity with focus on 2-axle cars. In: Spiryagin, M., et al. (eds.)The Dynamics of Vehicles on Roads and TracksProceedings of the 24th IAVSD Symposium, Rockhampton, Queensland, Australia, pp. 599-604. CRC Press, Boca Raton (2018). ISBN: 978-1-138-48263-0 
4. Zboinski, K., Golofit-Stawinska, M.: The issue of classification of railway vehicles behaviour in transition curves above critical velocity. In: Zobory, I. (ed.) Proceedings of the 14th VSDIA Conference, pp. 153-162. Budapest University of Technology and Economics, Budapest (2014). ISBN 978963-313-186-2

5. Zboinski, K., Golofit-Stawinska, M.: Dynamics properties of railway bogie of average parameters in transition curve at velocities around critical one. In: Robertas, K. (ed.) Proceedings of the 20th International Conference Transport Means 2016. Publishing House "Technologija", pp. 10641070 (2016)

6. Zboinski, K., Golofit-Stawinska, M.: Vehicle-track system parameters influencing dynamics in transition curves. In: Pombo, J. (ed.) Proceedings of the Third International Conference on Railway Technology: Research, Development and Maintenance, Paper 89. Civil-Comp Press, Stirlingshire, UK (2016). https://doi.org/10.4203/ccp.110.089

7. Zboinski, K., Golofit-Stawinska, M.: The impact of primary suspension stiffness of 2-axle bogie of MKIII passenger car on its dynamical behaviour. Transp. Probl. 13(1), 135-146 (2018). https://doi.org/10.21307/tp.2018.13.1.12

8. Zboinski, K., Golofit-Stawinska, M.: Dynamics of 2 and 4Axle Railway Vehicles in Transition Curves above Critical Velocity, in J. Pombo (ed.), Proc. of the Second Intl. Conf. on Railway Technology: Research, Development and Maintenance. Stirlingshire, UK. Civil-Comp Press, Paper 265, (2014), https://doi.org/10.4203/ccp.104.265

9. Schupp, G.: Computational bifurcation analysis of mechanical systems with applications to railway vehicles. In: Abe, M. (ed.) Proceedings of the 18th IAVSD Symposium on the Dynamics of Vehicles on Roads and on Tracks. Vehicle Systems Dynamics, vol. 41(suppl.), pp. 458-467 (2004)

10. Polach, O.: On non-linear methods of bogie stability assessment using computer simulations. Proc. Inst. Mech. Eng. F J. Rail Rapid Transit 220(1), 13-27 (2006)

11. Zboinski, K., Dusza, M.: Self-exciting vibrations and Hopf's bifurcation in non-linear stability analysis of rail vehicles in curved track. Eur. J. Mech. Part A/Solids 29(2), 190-203 (2010)

12. Xu, G., Steindl, A., Troger, H.: Nonlinear stability analysis of a bogie of a low-platform wagon. In: Proceedings of the 12th IAVSD Symposium on the Dynamics of Vehicles on Roads and on Tracks, Vehicle System Dynamics, vol. 20(suppl.), pp. 653-665 (1992)

13. Zboinski, K., Dusza, M.: Extended study of rail vehicle lateral stability in a curved track. Veh. Syst. Dyn. 49(5), 789810 (2011)

14. Zboinski, K., Dusza, M.: Bifurcation analysis of 4-axle rail vehicle models in a curved track. Nonlinear Dyn. 89(2), 863885 (2017). https://doi.org/10.1007/s11071-017-3489-y

15. Zboinski, K.: Nieliniowa dynamika pojazdow szynowych w łuku (Non-linear dynamics of rail vehicles in a curve). Wydawnictwo Naukowe ITE PIB. Scientific Publishers ITE PIB, Warsaw-Radom. Polish (2012). ISBN 987-83-7789$129-2$

16. True, H.: Multiple attractors and critical parameters and how to find them numerically: the right, the wrong and the gambling way. Veh. Syst. Dyn. 51(3), 443-459 (2013). https:// doi.org/10.1080/00423114.2012.738919
17. Goodall, R.M., Iwnicki, S.D.: Non-linear dynamic techniques v. equivalent conicity methods for rail vehicle stability assessment. In: Abe, M. (ed.) Proceedings of the 18th IAVSD Symposium on the Dynamics of Vehicles on Roads and on Tracks. Vehicle System Dynamics, vol. 41(suppl.), pp. 791-799 (2004)

18. Huilgol, R.R.: Hopf-Friedrichs bifurcation and the hunting of a railway axle. Q. J. Appl. Math. 36, 85-94 (1978)

19. Gasch, R., Moelle, D., Knothe, K.: The effect of nonlinearities on the limit-cycles of railway vehicles. In: Hedrick, K. (ed.) Proceedings of the 8th IAVSD Symposium, Cambridge, USA, pp. 207-224. Swets \& Zeitlinger, Lisse (1984)

20. True, H., Birkedal Nielsen, J.: On the dynamics of steady curving of railway vehicles. In: Zobory, I. (ed.) Proceedings of the 6th Mini Conference on Vehicles System Dynamics, Identification and Anomalies, pp. 73-81. Technical University of Budapest, Budapest (1998)

21. True, H., Hansen, T.G., Lundell, H.: On the quasi-stationary curving dynamics of a railroad truck. In: Proceedings of the ASME/IEEE/AREA Joint Railroad Conference, ASMERTD, vol. 29, pp. 131-138 (2005)

22. True, H.: Recent advances in the fundamental understanding of railway vehicle dynamics. Int. J. Veh. Des. 40(1/2/3), 251264 (2006)

23. Polach, O.: Characteristic parameters of nonlinear wheel/rail contact geometry. Veh. Syst. Dyn. 48(suppl.), 19-36 (2010)

24. Di Gialleonardo, E., Bruni, S., True, H.: Analysis of the non-linear dynamics of a 2-axle freight wagon in curves. Veh. Syst. Dyn. 52(1), 125-141 (2014). https://doi.org/10. 1080/00423114.2013.863363

25. Hoffmann, M.: Dynamics of European two-axle freight wagons. Ph.D. thesis, Technical University of Denmark, Informatics and Mathematical Modelling, Lyngby (2006)

26. Hoffmann, M., True H.: The dynamics of two-axle freight wagons with UIC standard suspension. In: Proceedings of the 10th VSDIA Conference, pp. 183-190. Budapest University of Technology and Economics, Budapest (2006). ISBN 978-963-420-968-3

27. Wang, K., Liu, P.: Lateral stability analysis of heavy-haul vehicle on curved track based on wheel/rail coupled dynamics. J. Transp. Technol. 2, 150-157 (2012)

28. Dusza, M.: The study of track gauge influence on lateral stability of 4-axle rail vehicle model. Arch. Transp. 30(2), 7-20 (2014)

29. Zboinski, K.: Dynamical investigation of railway vehicles on a curved track. Eur. J. Mech. A Solids 17(6), 1001-1020 (1998)

30. Zhai, W.M., Wang, K.Y.: Lateral interactions of trains and tracks on small radius curves: simulation and experiment. Veh. Syst. Dyn. 44(sup1), 520-530 (2006). https://doi.org/ $10.1080 / 00423110600875260$

31. Kurzeck, B., Hecht, M.: Dynamic simulation of frictioninduced vibrations in a light railway bogie while curving compared with measurement results. Veh. Syst. Dyn. 48(S1), 121-138 (2010). https://doi.org/10.1080/ 00423111003669045

32. Kondo, O., Yamazaki, Y.: Simulation technology for railway vehicle dynamics. Nippon Steel \& Sumitomo Metal technical report no. 105 (December), pp. 77-83 (2013) 
33. Prandi, D.: Railway bogie stability control from secondary yaw actuators. M.Sc. thesis, Politecnico di Milano, Scuola di Ingegneria Industriale e dell'Informazione (2014)

34. Matsumoto, A., Michitsuji, Y.: Analysis of flange-climb derailments of freight trains on curved tracks due to rolling. In: Proceedings of the 10th International Conference on Railway Bogies and Running Gears, pp. 91-100. Scientific Society of Mechanical Engineers, Budapest (2016). ISBN 978-963-9058-38-5

35. Shaltout, R., Baeza, L., Ulianov, C.: Development of a simulation tool for the dynamic analysis of railway vehicletrack interaction. Transp. Probl. 10(spec. edit.), 47-58 (2015). https://doi.org/10.21307/tp-2015-061

36. Lau, A., Kassa, E.: Simulation of vehicle-track interaction in small radius curves and switches and crossings. In: Pombo, J. (ed) Proceedings of the Third International Conference on Railway Technology: Research, Development and Maintenance, Paper 126. Civil-Comp Press, Stirlingshire, UK (2016). https://doi.org/10.4203/ccp.110.126

37. Kuba, T., Lugner, P.: Dynamic behaviour of tramways with different kinds of bogies. Veh. Syst. Dyn. 50(supp1), 277-289 (2012). https://doi.org/10.1080/00423114.2012. 666356

38. Carballeira, J., Baeza, L., Rovira, A., García, E.: Technical characteristics and dynamic modelling of Talgo trains. Veh. Syst. Dyn. 46(S1), 301-316(2008). https://doi.org/10.1080/ 00423110801939170

39. Kufver, B.: Optimisation of horizontal alignments for railway - procedure involving evaluation of dynamic vehicle response. Ph.D. thesis, Royal Institute of Technology, Stockholm (2000)

40. Long, X.Y., Wei, Q.C., Zheng, F.Y.: Dynamical analysis of railway transition curves. Proc. Inst. Mech. Eng. Part F J. Rail Rapid Transit 224(1), 1-14 (2010)

41. Zboinski, K., Woznica, P.: Combined use of dynamical simulation and optimisation to form railway transition curves. Veh. Syst. Dyn. 56(9), 1394-1450 (2018). https://doi.org/ 10.1080/00423114.2017.1421315

42. Zboinski, K.: Numerical studies on railway vehicle response to transition curves with regard to their different shape. Arch. Civ. Eng. 44(2), 151-181 (1998)

43. Sun, K., Mou, S., Qiu, J., Wang, T., Gao, H.: Adaptive fuzzy control for non-triangular structural stochastic switched nonlinear systems with full state constraints. IEEE Trans. Fuzzy Syst. (2018). https://doi.org/10.1109/TFUZZ.2018. 2883374
44. Qiu, J., Sun, K., Wang, T., Gao, H.: Observer-based fuzzy adaptive event-triggered control for pure-feedback nonlinear systems with prescribed performance. IEEE Trans. Fuzzy Syst. (2019). https://doi.org/10.1109/TFUZZ.2019. 2895560

45. Zboinski, K.: Modelling dynamics of certain class of discrete multi-body systems based on direct method of the dynamics of relative motion. Meccanica 47(6), 1527-1551 (2012). https://doi.org/10.1007/s11012-011-9530-1

46. Lurie, A.I.: Analytical Mechanics, 1st edn. Springer, Berlin (2002). (originally: Lurie A.I., Analiticeskaja mechanika, FizMatGIZ, Moscow 1961. Russian)

47. Choromanski, W., Zboinski, K.: The software package ULYSSES for automatic generation of equation and simulation of railway vehicle motion. In: Proceddings of the of Scientific Conference on Transport Systems Engineering, sec. 4, pp. 47-52. PW i KT PAN (Warsaw University of Technology and Transport Committee of Polish Academy of Science), Warsaw (1995)

48. Zboinski, K.: Relative kinematics exploited in Kane's approach to describe multibody systems in relative motion. Acta Mech. 147(1-4), 19-34 (2001)

49. Kalker, J.J.: A fast algorithm for the simplified theory of rolling contact. Veh. Syst. Dyn. 11, 1-13 (1982)

50. Kik, W.: Comparison of the behaviour of different wheelsettrack models. In: Sauvage, G. (ed.) Proceedings of the 12th IAVSD Symposium on the Dynamics of Vehicles on Roads and on Tracks. Vehicle System Dynamins, vol. 20(suppl.), pp. 325-339 (1992)

51. Gear, C.W.: Numerical Initial Value Problems in Ordinary Differential Equations. Prentice Hall, New York (1971)

52. Hairer, E., Wanner, G.: Solving Ordinary Differential Equations, Part II: Stiff and Differential-Algebraic Problems. Springer, Berlin (1991)

53. Dusza, M., Zboiński, K.: Comparison of two different methods for identification of railway vehicle critical velocity. In: Proceedings of the 12th Mini Conference on Vehicle System Dynnamics, Identification and Anomalies VSDIA 2010, pp. 161-170. Budapest University of Technology and Economics, Hungary (2010)

Publisher's Note Springer Nature remains neutral with regard to jurisdictional claims in published maps and institutional affiliations. 